\title{
DIOGO GORAYEB DE CASTRO
}

Efeitos do midazolam, associado ao propofol, na indução da anestesia em gatas submetidas a ovariossalpingo-histerectomia 


\section{DIOGO GORAYEB DE CASTRO}

Efeitos do midazolam, associado ao propofol, na indução da anestesia em gatas submetidas a ovariossalpingo-histerectomia

Dissertação apresentada ao Programa de Pós-Graduação em Clínica Cirúrgica Veterinária da Faculdade de Medicina Veterinária e Zootecnia da Universidade de São Paulo para obtenção do título de Mestre em Medicina Veterinária

Departamento:

Cirurgia

Área de concentração:

Clínica Cirúrgica Veterinária

Orientadora:

Prof $^{a}$. Dra. Sílvia Renata Gaido Cortopassi 
Autorizo a reprodução parcial ou total desta obra, para fins acadêmicos, desde que citada a fonte.

DADOS INTERNACIONAIS DE CATALOGAÇÃO-NA-PUBLICAÇÃO

(Biblioteca Virginie Buff D’Ápice da Faculdade de Medicina Veterinária e Zootecnia da Universidade de São Paulo)

Castro, Diogo Gorayeb de

Efeitos do midazolam, associado ao propofol, na indução da anestesia em gatas submetidas a ovariossalpingo-histerectomia / Diogo Gorayeb de Castro. -- 2010

$111 \mathrm{f}$ : : il.

Dissertação (Mestrado) - Universidade de São Paulo. Faculdade de Medicina Veterinária e Zootecnia. Departamento de Cirurgia, São Paulo, 2010.

Programa de Pós-Graduação: Clínica Cirúrgica Veterinária.

Área de concentração: Clínica Cirúrgica Veterinária.

Orientador: Profa. Dra. Silvia Renata Gaido Cortopassi.

1. Anestesia balanceada. 2. Gatos. 3. Midazolam. 4. Propofol. I. Título. 


\section{ERRATA}

CASTRO, D. G. de. Efeitos do midazolam, associado ao propofol, na indução da anestesia em gatas submetidas a ovariossalpingo-histerectomia. 2010. 111 f. Dissertação (Mestrado em Ciências) - Faculdade de Medicina Veterinária e Zootecnia, Universidade de São Paulo, São Paulo, 2010.

Folha

Folha de rosto

Folha de Avaliação

Abstract
Parágrafo

3으

3으

1 은
Onde se lê

Mestre em Medicina Veterinária

Mestre em Medicina Veterinária Dissertação (Mestrado em Medicina Veterinária) -
Leia-se

Mestre em Ciências

Mestre em Ciências Dissertação (Mestrado em Ciências) - 


\section{CERTIFICADO}

Certificamos que o Projeto intitulado: "Uso de benzodiazepinicos na anestesia balanceada de gatas submetidas a ovário-salpingo-histerectomia", protocolado sob o $n^{0} 1584 / 2008$, utilizando 30 (trinta) gatos, sob a responsabilidade da Profa. Dra. Silvia Renata Gaido Cortopassi, está de acordo com os princípios éticos de experimentação animal da Comissão de Bioética da Faculdade de Medicina Veterinária e Zootecnia da Universidade de São Paulo e foi aprovado em reunião de 11/02/09.

(We certify that the Research "Use of benzodiazepines in the balanced anesthesia of cats undergoing hysterectomy surgery", protocol number 1584/2008, utilizing 30 (thirty) cats, under the responsibility Profa. Dra. Silvia Renata Gaido Cortopassi, agree with Ethical Principles in Animal Research adopted by Bioethic Commission of the School of Veterinary Medicine and Zootechny of University of São Paulo and was approved in the meeting of day 02/11/09).

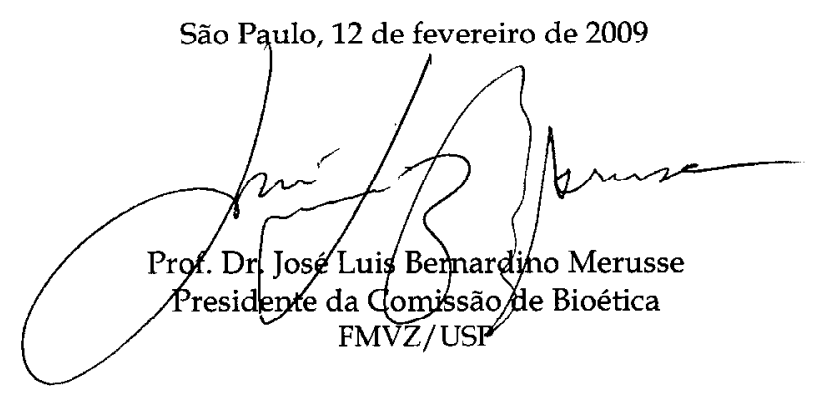




\section{FOLHA DE AVALIAÇÃO}

Nome: CASTRO, Diogo Gorayeb de

Título: Efeitos do midazolam, associado ao propofol, na indução da anestesia em gatas submetidas a ovariossalpingo-histerectomia

Dissertação apresentada ao Programa de Pós-Graduação em Clínica Cirúrgica Veterinária da Faculdade de Medicina Veterinária e Zootecnia da Universidade de São Paulo para obtenção do título de Mestre em Medicina Veterinária

Data:

1

\section{Banca Examinadora}

Prof. Dr. Instituição:

Assinatura: Julgamento:

Prof. Dr. Instituição:

Assinatura: Julgamento:

Prof. Dr. Instituição:

Assinatura: Julgamento: 


\section{Agradecimentos}

À minha família por toda a compreensão e apoio, suportando a distância e as ausências por estar mais uma vez longe de casa.

À Professora Silvia Renata Gaido Cortopassi, pela orientação, determinação e perseverança durante todos esses anos.

Aos meus grandes amigos de pós-graduação, Thaís Andrade Costa Casagrande, Juliana de Araújo Caldeira, Leda Marques de Oliveira Barros e Luiz Felipe de Moraes Barros, sem os quais este trabalho não poderia ter sido concluído.

Aos amigos Samanta Rios Melo e Bruno Gregnanin Pedron, pela imprescindível participação durante toda a parte prática deste trabalho.

A todos os professores residentes, médicos veterinários e funcionários do Hospital Veterinário da FMVZ-USP, por toda a dedicação. Em especial ao Jesus dos Anjos Vieira, José Miron Oliveira da Silva e Otávio Rodrigues dos Santos.

A todos meus amigos, sem os quais a minha vida não seria fantástica. Em especial a minha grande amiga Thaís Rodrigues Macedo; obrigado por partilhar mais essa etapa de formação profissional.

Ao Professor Antonio Felipe Paulino de Figueiredo Wouk por acreditar no meu potencial.

A Deus. 


\section{RESUMO}

CASTRO, D. G. de. Efeitos do midazolam, associado ao propofol, na indução da anestesia em gatas submetidas a ovariossalpingo-histerectomia. [Effects of midazolam associated to propofol on anesthetic induction of cats submitted to ovariohysterectomy]. 2010. 111 f. Dissertação (Mestrado em Ciências) - Faculdade de Medicina Veterinária e Zootecnia, Universidade de São Paulo, São Paulo, 2010.

O propofol é o fármaco mais freqüentemente empregado na indução da anestesia de pequenos animais apesar de seu efeito depressor cardiovascular e respiratório. Sabe-se que a associação com outros fármacos pode determinar a redução de suas doses e essa possibilidade é pouco conhecida nos felinos. No presente estudo, foram avaliados os efeitos do emprego do midazolam associado ao propofol na indução da anestesia em gatas submetidas a ovariossalpingo-histerectomia. Foram utilizadas 30 gatas, jovens adultas, submetidas a ovariossalpingo-histerectomia. Após serem pré-tratadas com acepromazina e morfina, foram distribuídas em três grupos: o grupo GP recebeu indução somente com propofol; o grupo GMP recebeu midazolam imediatamente antes da indução com propofol; e o grupo GPM recebeu uma subdose de propofol, seguido por midazolam e novamente propofol até ser possível a intubação. Foi avaliada a redução da dose do propofol quando em associação com midazolam; a qualidade de intubação endotraqueal e grau de relaxamento muscular; a qualidade de indução da anestesia após a administração de propofol ou propofol em associação com midazolam, analisando qual a melhor seqüência de administração e a qualidade e o tempo de recuperação nas gatas submetidas à indução da anestesia com propofol ou propofol-midazolam. Foram também observados as freqüências cardíaca e respiratória, pressão arterial, oximetria, capnometria e hemogasometria. A partir dos resultados obtidos verificouse que a dose de propofol para indução da anestesia em gatas é reduzida em 34\% e 23\% quando precedido ou antecedido pelo midazolam, respectivamente; a associação com midazolam não intensificou o relaxamento muscular promovido pelo propofol, não interferindo assim na qualidade de intubação endotraqueal das gatas; o uso prévio de midazolam em relação ao propofol na indução da anestesia não determinou agitação, tampouco excitação nas gatas; ambas as seqüências de administração da associação propofol-midazolam são factíveis, porém a seqüência 
propofol-midazolam se mostrou superior devido a menor dose empregada de propofol; do ponto de vista clínico, a associação com midazolam determinou prolongamento do tempo de recuperação das gatas, mas não determinou efeitos adversos no momento de despertar.

Palavras-chave: Anestesia balanceada. Gatos. Midazolam. Propofol. 


\section{ABSTRACT}

CASTRO, D. G. Effects of midazolam associated to propofol on anesthetic induction of cats submitted to ovariohysterectomy. [Efeitos do midazolam, associado ao propofol, na indução da anestesia em gatas submetidas a ovariossalpingo-histerectomia]. 2010. 111 f. Dissertação (Mestrado em Medicina Veterinária) - Faculdade de Medicina Veterinária e Zootecnia, Universidade de São Paulo, São Paulo, 2010.

Propofol is the most frequent drug used for induction of anesthesia in small animals. Its cardiovascular and respiratory depressor effects are well known. The association with other drugs may determine a reduction of its dose, and this possibility is not well known in cats. The present study evaluated the effects of midazolam associated to propofol during induction of anesthesia in cats submitted to ovariohysterectomy. Thirty cats were enrolled in this study. After premedicated with acepromazine and morphine, they were distributed in three groups: GP group that received only propofol for induction; GMP group that received midazolam immediately before propofol induction; and GPM group that received a sub dose of propofol, followed by midazolam and propofol until intubation was possible. The dose reduction of propofol when associated to midazolam; the quality of endotracheal intubation and the muscle relaxation degree were evaluated; the quality of anesthetic induction after administration of propofol or propofol associated with midazolam was compared, in order to identify the best administration sequence. The quality and time of recovery were evaluated as well. Heart and respiratory rates, arterial blood pressure, oximetry, capnometry and hemogasometry were also accessed. The results showed that propofol dose for anesthesia induction was reduced in 34\% and 23\% when preceded or succeeded by midazolam, respectively; The association with midazolam did not increase muscle relaxation promoted by propofol, therefore not interfering in the quality of endotracheal intubation in cats; the use of midazolam previously to propofol on anesthetic induction did not cause agitation or excitement; both sequence of administration of the association of propofol-midazolam were effective, although the sequence propofol-midazolam was been shown to be better, since the propofol dose was lower; from the clinic point of view, the association with midazolam determined a prolongation of the recovery, however no side effects were noted. 
Keywords: Balanced anesthesia. Cats. Midazolam. Propofol. 


\section{LISTA DE FIGURAS}

Figura 1 - Variação dos valores médios da freqüência cardíaca (batimentos por minuto) dos três grupos estudados, em diferentes momentos de avaliação 40

Figura 2 - Variação dos valores médios da pressão arterial sistólica $(\mathrm{mmHg})$ dos três grupos estudados, em diferentes momentos de avaliação. 42

Figura 3 - Variação dos valores médios da freqüência respiratória (movimentos respiratórios por minuto) dos três grupos estudados, em diferentes momentos de avaliação 43

Figura 4 - Variação dos valores médios da fração expirada de dióxido de carbono (mmHg)dos três grupos estudados, em diferentes momentos de avaliação. 45

Figura 5 - Variação dos valores médios da saturação da oxi-hemoglobina periférica (\%) dos três grupos estudados, em diferentes momentos de avaliação

Figura 6 - Variação dos valores médios da fração inspirada de isofluorano (\%) dos três grupos estudados, em diferentes momentos de avaliação. 47

Figura 7 - Variação dos valores médios da fração expirada de isofluorano (\%) dos três grupos estudados, em diferentes momentos de avaliação 


\section{LISTA DE TABELAS}

Tabela 1 - Valores médios e respectivos desvios-padrão dos pesos (kg), idades (meses) e raças dos animais dos grupos GP (propofol), GPM (propofol/midazolam) e GMP (midazolam/propofol).......................38

Tabela 2 - Valores médios e respectivos desvios-padrão da frequência cardíaca (batimentos por minuto), frequência respiratória (movimentos respiratórios por minuto) e pressão arterial sistólica $(\mathrm{mmHg})$ avaliados nos animais dos grupos GP (propofol), GPM (propofol/midazolam) e GMP (midazolam/propofol). 44

Tabela 3 - Valores médios e respectivos desvios-padrão da fração expirada de dióxido de carbono $\left(\mathrm{PETCO}_{2}\right)(\mathrm{mmHg})$, saturação da oxi-hemoglobina do sangue periférico $\left(\mathrm{SpO}_{2}\right)(\%)$, concentração de isofluorano inspirado (ISOi) (\%) e concentração de isofluorano expirado (ISOe) avaliados dos animais dos grupos GP (propofol), GPM (propofol/midazolam) e GMP (midazolam/propofol). 49

Tabela 4- Valores médios e respectivos desvios-padrão do potencial hidrogeniônico do sangue arterial $(\mathrm{pH})$, pressão parcial de dióxido de carbono no sangue arterial $\left(\mathrm{PaCO}_{2}\right)$, pressão parcial de oxigênio no sangue arterial $\left(\mathrm{PaO}_{2}\right)$, saturação de oxigênio na hemoglobina no sangue arterial $\left(\mathrm{SaO}_{2}\right)$, concentração plasmática de bicarbonato $\left(\mathrm{HCO}_{3}{ }^{-}\right)$e déficit de base (DB) avaliados dos animais dos grupos GP (propofol), GPM (propofol/midazolam) e GMP (midazolam/propofol). 52

Tabela 5 - Valores médios e respectivos desvios-padrão da temperatura retal dos animais dos grupos GP (propofol), GPM (propofol/midazolam) e GMP (midazolam/propofol), nos momentos basal e pós medicação préanestésica. .53

Tabela 6 - Escores e desvios-padrão do grau de relaxamento muscular dos grupos GP (propofol), GPM (propofol/midazolam) e GMP (midazolam/propofol), atribuídos pelos dois observadores (anestesista e cirurgião). 54

Tabela 7 - Valores médios e respectivos desvios-padrão dos tempos (minutos) de anestesia e de recuperação (extubação, manutenção de cabeça erguida, posição esternal e locomoção) dos grupos GP (propofol), GPM (propofol/midazolam) e GMP (midazolam/propofol). 55

Tabela 8 - Valores médios e respectivos desvios-padrão das doses de propofol (mg/kg) empregadas na indução dos animais dos grupos GP (propofol), GPM (propofol/midazolam) e GMP (midazolam/propofol). 
Tabela 9 - Escores de intubação e desvios-padrão dos grupos GP (propofol), GPM (propofol/midazolam) e GMP (midazolam/propofol), atribuídos pelos observadores (anestesista e cirurgião)......................................56 


\section{SUMÁRIO}

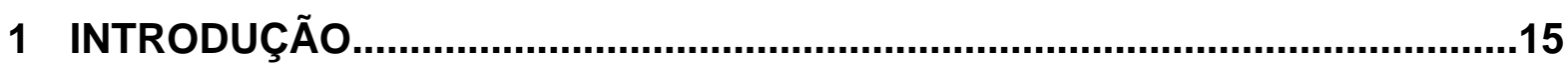

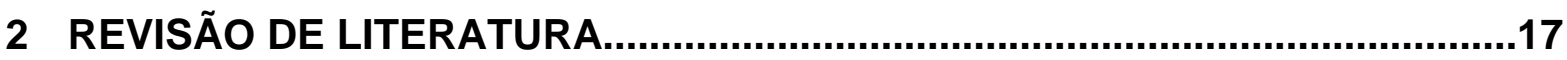

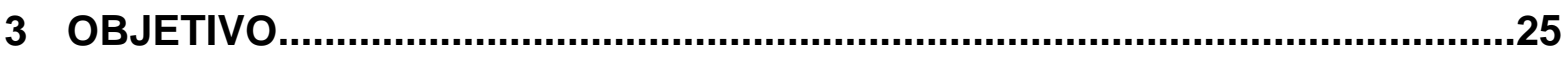

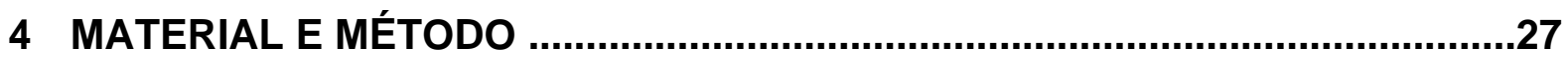

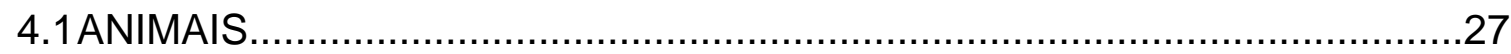

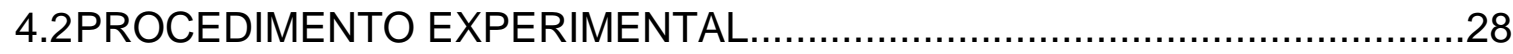

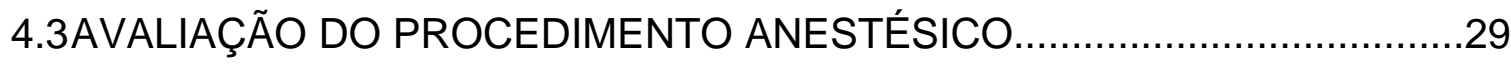

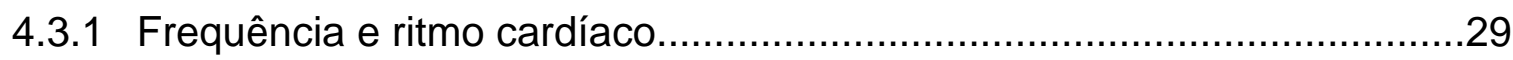

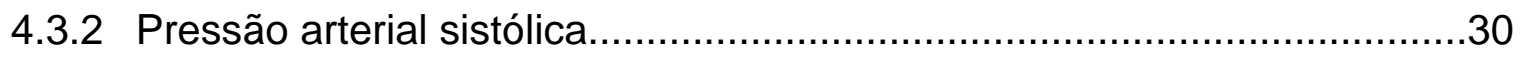

4.3.3 Frequência respiratória e fração expirada de dióxido de carbono.............30

4.3.4 Saturação da oxi-hemoglobina no sangue periférico................................31

4.3.5 Fração inspirada e expirada de isofluorano..............................................31

4.3.6 Potencial hidrogeniônico do sangue arterial $(\mathrm{pH})$, pressão parcial de dióxido de carbono no sangue arterial $\left(\mathrm{PaCO}_{2}\right)$, pressão parcial de oxigênio no sangue arterial $\left(\mathrm{PaO}_{2}\right)$, saturação de oxigênio na hemoglobina no sangue arterial $\left(\mathrm{SaO}_{2}\right)$, concentração plasmática de bicarbonato $\left(\mathrm{HCO}_{3}{ }^{-}\right)$e déficit de base (DB)

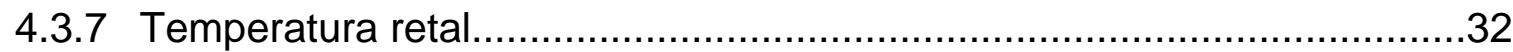

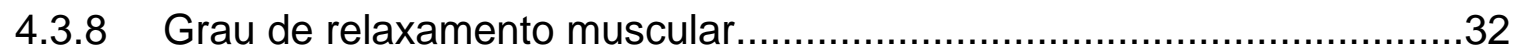

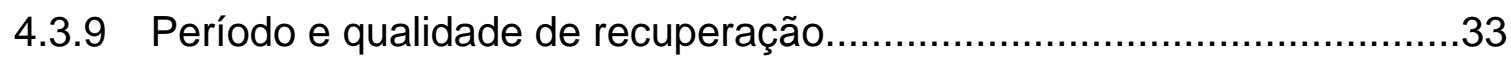

4.3.10 Dose de propofol necessária para intubação endotraqueal......................34

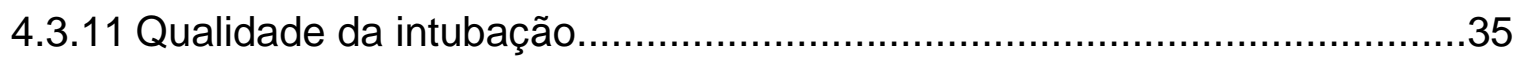

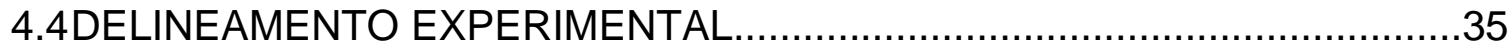

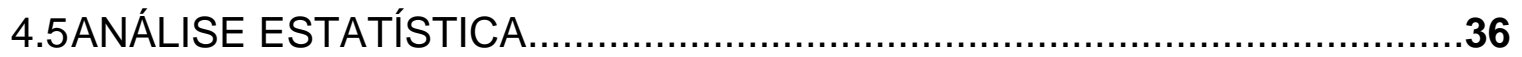

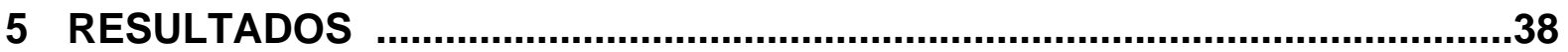

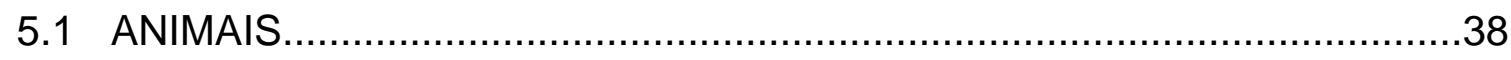

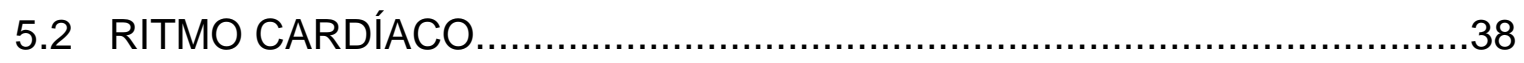

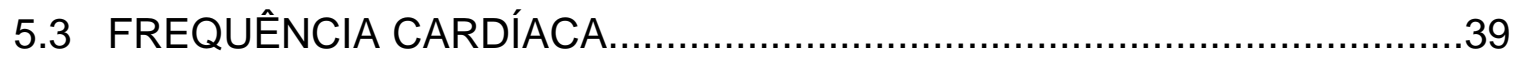

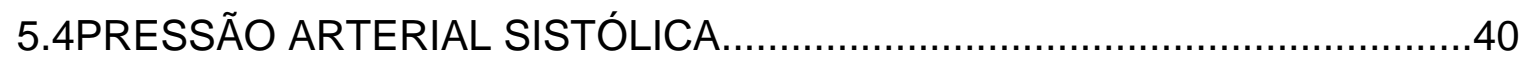


5.5FREQUÊNCIA RESPIRATÓRIA .................................................... 42

5.6 FRAÇÃO EXPIRADA DE DIÓXIDO DE CARBONO ................................45

5.7SATURAÇÃO DA OXI-HEMOGLOBINA NO SANGUE PERIFÉRICO..........46

5.8FRAÇÃO INSPIRADA DE ISOFLUORANO ......................................46

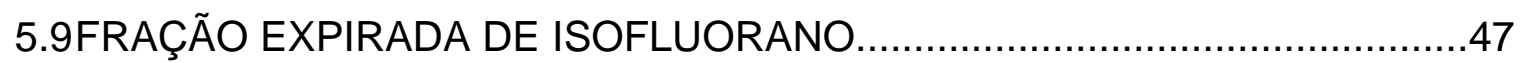

5.10 POTENCIAL HIDROGENIÔNICO DO SANGUE ARTERIAL (pH)......50

5.11 PRESSÃO PARCIAL DE DIÓXIDO DE CARBONO NO SANGUE

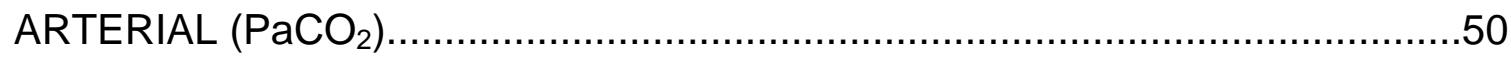

5.12 PRESSÃO PARCIAL DE OXIGÊNIO NO SANGUE ARTERIAL

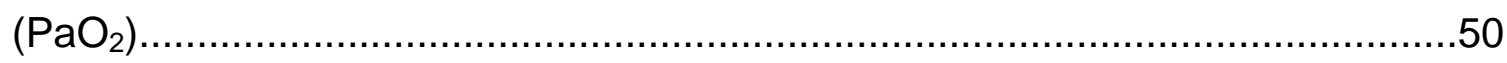

5.13 SATURAÇÃO DE OXIGÊNIO NA HEMOGLOBINA NO SANGUE

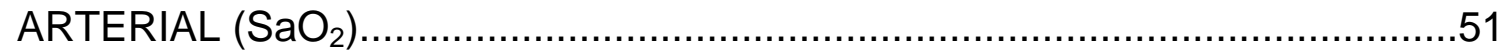

5.14 CONCENTRAÇÃO PLASMÁTICA DE BICARBONATO $\left(\mathrm{HCO}_{3}{ }^{-}\right) \ldots \ldots . . .51$

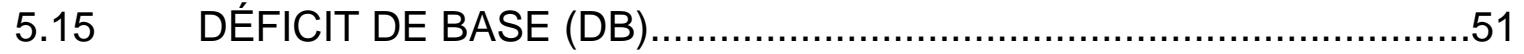

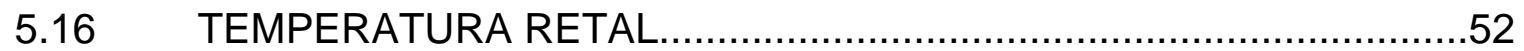

5.17 GRAU DE RELAXAMENTO MUSCULAR ..................................53

5.18 PERÍODO E QUALIDADE DE RECUPERAÇÃO..............................54

5.19 DOSE DE PROPOFOL NECESSÁRIA PARA INTUBAÇÃO

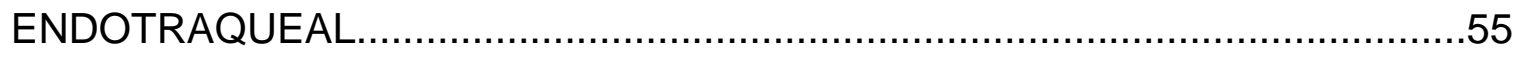

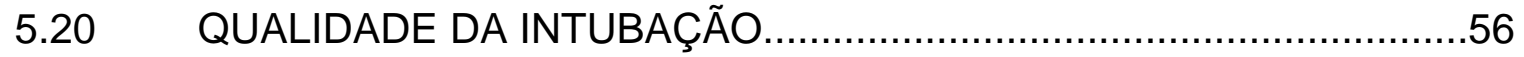

6 DISCUSSÃO

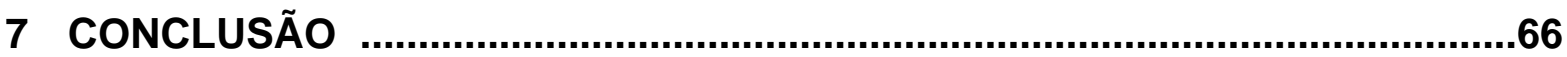

REFERÊNCIAS ..................................................................................67

APÊNDICES..................................................................................... 


\section{INTRODUÇÃO}

A anestesia em felinos merece especial atenção uma vez que esta espécie apresenta particularidades marcantes e nem sempre respeitadas. O uso isolado de agentes anestésicos em doses elevadas deve ser evitado, uma vez que o emprego de associações anestésicas pode ser uma alternativa com o principal objetivo de minimizar a ocorrência de efeitos adversos intrínsecos de cada fármaco.

Certamente o propofol é o fármaco mais empregado na indução da anestesia em pequenos animais. Seus efeitos cardiorrespiratórios são bem conhecidos e frequentemente observa-se depressão respiratória e hipotensão arterial após seu uso em bolus. A associação de propofol com outros agentes, tais como cetamina e midazolam, tem proporcionado a redução de suas doses, contribuindo assim, para a menor ocorrência de apnéia e hipotensão. Já foi demonstrado que o emprego prévio de midazolam reduz a dose deste agente, possibilitando uma anestesia com menos efeitos deletérios (STEGMANN; BESTER, 2001).

Neste contexto, sabe-se que uma das vantagens de se estabelecer associações anestésicas é a obtenção de um protocolo mais seguro, uma vez que a espécie felina apresenta maior mortalidade em procedimentos anestésicos do que a espécie canina (PASCOE; ILKIW; CRAIG, 2007).

Atualmente, o midazolam tem seu uso em gatos restrito à associação com a cetamina. Entretanto, o uso do midazolam na indução tem se mostrado uma opção eficiente em cães e humanos. Em procedimentos ambulatoriais, observou-se que o uso de midazolam, em felinos, foi capaz de reduzir em $26 \%$ a dose de propofol utilizado (BLEY; ROSS; PRICE, 2007). 
Uma vez que há pouca informação acerca do uso deste fármaco em gatos, principalmente quando empregado na anestesia geral para procedimentos cirúrgicos, é de suma importância o desenvolvimento de estudos que possam avaliálo, principalmente na indução da anestesia geral.

Portanto, o objetivo desde estudo foi avaliar a associação do midazolam ao propofol na indução da anestesia em gatas, verificando a possibilidade de redução de dose de propofol, os efeitos cardiovasculares e respiratórios desencadeados, assim como o período de recuperação. 


\section{REVISÃO DE LITERATURA}

A espécie felina apresenta notórias particularidades, e estas estão claramente presentes na rotina anestésica. Com o aumento do número de felinos na rotina cirúrgica faz-se necessária uma procura por protocolos anestésicos mais específicos para esta espécie.

O conceito de anestesia balanceada consiste na administração de vários fármacos anestésicos de forma que nenhum agente alcance dose suficiente para produzir toxicidade durante ou após a cirurgia; além de diminuir a necessidade de anestesia inalatória, conseqüentemente diminuindo seus efeitos cardiovasculares (BAILEY; EGAN; STANLEY, 2000).

Desta forma, serão descritos a seguir alguns aspectos considerados importantes no desenvolvimento do presente estudo.

A importância crescente dos gatos como companhia humana tem levado ao aumento da demanda por diagnósticos sofisticados e procedimentos anestésicos que requerem anestesia geral. A mortalidade na anestesia de felinos é altamente preocupante. Clarke e Hall (1990), ao avaliarem dados de diversos clínicos, constataram maior mortalidade de gatos do que de cães saudáveis submetidos à anestesia: um em 522 gatos (0,19\%), comparado com um em 870 cães saudáveis $(0,11 \%)$. Outro estudo demonstrou uma mortalidade de gatos saudáveis (ASA I ou II) de um em 2065 (0,05\%) (DYSON; MAXIE; SCHNURR, 1998). Brodbelt et al. (2007) realizaram um estudo prospecitvo com 117 centros veterinários no Reino Unido, onde observaram uma mortalidade de $0,24 \%$ dos gatos anestesiados ou sedados. 
A medicação pré-anestésica em gatos reduz o estresse de manipulação e pode reduzir a dose necessária para indução e manutenção da anestesia em até 50\% (DYSON; PASCOE; HONEYMAN, 1992). A acepromazina é o tranqüilizante fenotiazínico mais amplamente utilizado em medicina veterinária, considerada desprovida de ação analgésica embora reduza a reação aos estímulos externos (BARNHART; HUBELL; MUIR, 2000). Apresenta efeito anti-emético, antimuscarínico e extra-piramidal. O grau de tranqüilização varia de acordo com o indivíduo. Possui efeito teto, ou seja, o aumento da dose não resulta em maior tranqüilização e sim no aumento de efeitos colaterais (BREARLEY, 1994). Pode promover hipotensão arterial devido ao efeito antagonista alfa-adrenérgico, devendo ser evitado em gatos com função cardiovascular comprometida. Seu uso em felinos saudáveis é considerado seguro (INGWERSEN et al., 1988). Outros efeitos colaterais incluem depressão miocárdica, diminuição da temperatura corpórea e aumento da perfusão cutânea e visceral (CORTOPASSI; FANTONI, 2010). A medicação pré-anestésica com um tranqüilizante e um opióide é desejável, porque oferece contenção, sedação, analgesia e reduz a dose e concentração dos agentes anestésicos indutores e de manutenção (BREARLEY; KELLAGHER; HALL, 1988; WEAVER; RAPTOPOULOS, 1990; BREARLEY; 1994; GEEL, 1991). A associação de acepromazina $(0,05 \mathrm{mg} / \mathrm{kg})$ com morfina $(0,1$ a $0,2 \mathrm{mg} / \mathrm{kg})$, pela via intramuscular, tem sido empregada em gatos (BREARLEY, 1994; EGGER et al., 2009). A morfina, analgésico de escolha para tratamentos de dor aguda intensa, tem início de ação rápido (LASCELLES; WATERMAN, 1997). Após injeção subcutânea (0,2mg/kg) demonstrou ser efetiva no aumento dos limiares dos estímulos térmico e de pressão (STEAGALL et al., 2006) e produz analgesia efetiva durante 6 a 8 horas (LASCELLES; WATERMAN, 1997). Normalmente os gatos se apresentam mais 
tranqüilos com o uso de opióides, sem haver sedação como nos cães (LASCELLES; WATERMAN, 1997).

O propofol (2,6-di-isopropilfenol) é um derivado alquilfenólico desenvolvido como agente intravenoso que produz anestesia caracterizada por um início rápido de ação e duração ultracurta (WEAVER; RAPTOPOULOS, 1990). É formulado como uma emulsão aquosa a 1\% em solução com 10\% de óleo de soja, 2,25\% de glicerol e 1,2\% de fosfolipídio de ovo purificado. Apresenta $\mathrm{pH}$ de 7 e tem a aparência de uma substância leitosa e levemente viscosa. É estável à temperatura ambiente e não é fotossensível. Pelo fato do veículo permitir crescimento bacteriano, devem-se adotar condições assépticas para retirada do propofol de frascos ou ampolas (SHORT; BUFALARI, 1999).

O seu mecanismo de ação consiste na ativação do receptor ácido gamaaminobutírico resultando na abertura dos canais de cloro, causando hiperpolarização celular (PAWSON; FORSYTH, 2002).

O propofol liga-se cerca de 95 a 99\% às proteínas plasmáticas. Promove perda rápida de consciência após a administração intravenosa, devido a sua distribuição rápida para o sistema nervoso central (NOCITI, 2001). A recuperação é rápida devido à redistribuição e metabolização. Ocorre conjugação hepática com eliminação pela urina e a taxa de depuração excede o fluxo hepático, o que sugere que outros órgãos participam da biotransformação (PAWSON; FORSYTH, 2002). Nos gatos há significativa absorção pelos pulmões na primeira passagem de propofol (MATOT et al., 1993). Pode desencadear confusão ou excitação pósoperatória na recuperação (PAWSON; FORSYTH, 2002). 
O seu emprego, em gatos, está associado à indução e recuperação anestésicas suaves (MORGAN; LEGGE, 1989). No entanto, a redução da necessidade de propofol em gatos com a administração prévia de midazolam, pode ser vantajosa, uma vez que nesta espécie a biotransformação do propofol é limitada e há a preocupação com a subsequente inibição da função da enzima citocromo p450 (BLEY; ROSS; PRICE, 2007). O gene associado à produção da enzima glucuronil transferase, responsável pela conjugação de compostos fenólicos, é considerada um pseudogene nos gatos e a proteína produzida não é funcional (COURT; GREENBLATT, 2000).

O propofol promove hipotensão arterial logo após a sua administração decorrente da vasodilatação periférica, diminuição do tônus simpático, ação inotrópica e cronotrópica negativa e depressão do reflexo barorreceptor (YANG; LUK; CHEN, 1997), porém os valores pressóricos retornam ao normal após a indução (WEAVER; RAPTOPOULOS, 1990). Pode ocorrer bradicardia acentuada se os opióides forem utilizados concomitantemente (MASSONE; CORTOPASSI, 2010).

Desencadeia depressão respiratória por atuar diretamente sobre a atividade respiratória central e sobre a resposta ventilatória aos valores de pressão parcial de dióxido de carbono (SMITH; GAYNOR; BEDNARSKI, 1993).

Em gatos, por ser um composto fenólico, pode induzir lesão oxidativa quando administrado repetidamente por vários dias, provavelmente pela dificuldade de conjugação nesta espécie. Podem ser observados corpúsculos de Heinz e sinais clínicos de anorexia e diarréia (ANDRESS; DAY; DAY, 1995).

A redução de sua dose pode levar a uma diminuição da incidência de efeitos adversos como apnéia, hipotensão e excitação. Fenômenos excitatórios como 
movimentos de pedalagem e opistótono têm sido frequentemente relatados (COVEY-CLUMP; MURISON, 2008).

A dose, para indução anestésica em gatos sem medicação pré-anestésica, varia de 5,0 a 10,0 mg/kg, enquanto a dose com medicação pré-anestésica varia de 5,3 a 7,2 mg/kg (BREARLEY; KELLAGHER; HALL, 1988; MORGAN; LEGGE, 1989; WEAVER; RAPTOPOULOS, 1990; SANO et al., 2003). A velocidade de administração também influencia na dose de propofol necessária para indução (SHORT; BUFALARI, 1999; MENDES et al., 2003; TABOADA; MURISON, 2010).

Os benzodiazepínicos são amplamente utilizados na anestesia e, embora sejam classificados como medicação pré-anestésica, seu uso ocorre principalmente na indução da anestesia. Exibem diferentes períodos de latência, duração e intensidade dos efeitos, de acordo com sua farmacocinética (CORTOPASSI; FANTONI, 2010).

O midazolam é um benzodiazepínico que apresenta efeito ansiolítico, sedativo, hipinótico, relaxante muscular e anticonvulsivante. Não produz irritação tecidual por ser hidrossolúvel, diferenciando-se dos demais benzodiazepínicos por seu efeito curto (LAUDA, 1989).

Em relação ao mecanismo de ação, existem dois locais de reconhecimento para os benzodiazepínicos. Um deles é associado aos receptores gabaaminobutíricos do tipo $A\left(G A B A_{A}\right)$ e a outra é denominada receptor periférico de benzodiazepínicos. Os receptores $\mathrm{GABA}_{\mathrm{A}}$ são responsáveis pela atividade inibitória do GABA. A interação dos benzodiazepínicos com locais específicos do SNC promovem o aumento da freqüência da abertura dos canais de cloro (GORENSTEIN; POMPÉIA, 1999). O midazolam é um benzodiazepínico que atua na estimulação do neurônio inibitório GABA no sistema nervoso central, produzindo 
relaxamento muscular, sedação e feito anticonvulsivante. Quando utilizado isoladamente, promove sedação sutil em gatos e suas propriedades ansiolíticas podem resultar em gatos mais difíceis de manipular (BREARLEY, 1994).

Este fármaco apresenta lipossolubilidade elevada e é rapidamente absorvido independentemente da via de administração (AUSTIN; MITCHELL, 1998). Liga-se extensivamente a proteína plasmática (97\%) e sua biotrasnformação ocorre principalmente por ação dos microssomos hepáticos, isoenzimas pertencentes ao sistema do citocromo P-450 (GORENSTEIN; POMPÉIA, 1999). A atividade das subfamílias desta enzima, responsáveis pelo metabolismo oxidativo (fase I da metabolização de fármacos) e relacionadas ao midazolam no gato, é similar a de humanos e cães (SHAH et al., 2007). A eliminação se faz fundamentalmente pela urina em forma de metabólicos conjugados com o ácido glicurônico (SPINOSA; GÓRNIAK, 1996).

O midazolam é hidrossolúvel, com uma meia-vida de 1,3 a 2,2 horas no homem (STOELTING, 1999). As doses de midazolam variam de 0,1 a 0,5 mg/kg em felinos (GROSS; SMITH; TRANQUILLI, 1993; ILKIW et al., 1996; CORTOPASSI; FANTONI, 2010).

Em gatos, a medicação pré-anestésica com neuroleptoanalgesia apropriada, associada ao midazolam $(0,2 \mathrm{mg} / \mathrm{kg})$ antes da indução, permitiu redução de $26 \%$ na dose total de propofol necessária para indução e manutenção da anestesia (BLEY; ROSS; PRICE, 2007). Sams et al. (2008) relataram que a associação propofol e midazolam $(0,3 \mathrm{mg} / \mathrm{kg})$ é uma boa opção para cães jovens e saudáveis. Stegmann e Bester (2001) verificaram que o emprego de midazolam na dose de 0,1 $\mathrm{mg} / \mathrm{kg}$ reduz, em cães, 37\% da dose de propofol necessária para perda do reflexo interdigital. No entanto, Covey-Crump e Murison (2008) verificaram que o midazolam não alterou a 
dose de propofol necessária na indução da anestesia de cães pré-tratados com acepromazina e morfina. Estes autores sugeriram que isso poderia ter ocorrido devido à incidência elevada de excitação após o midazolam. Desta forma, especularam que uma subdose de propofol antes do midazolam poderia prevenir estas excitações. Já o diazepam, na dose de 0,2 mg/kg, reduziu a dose necessária de propofol em 21\%, enquanto a dose de $0,4 \mathrm{mg} / \mathrm{kg}$ reduziu a dose de indução do mesmo agente em 36\% (KO; PAYTON; WHITE, 2006). A diferença entre diazepam e midazolam pode estar relacionada com a maior potência e menor tempo de ação do midazolam (PIERI, 1983; KO; PAYTON; WHITE, 2006).

O isofluorano é um anestésico halogenado freqüentemente empregado na manutenção da anestesia em pequenos animais. Seu coeficiente de partição é baixo $(1,4)$, o qual permite que sua concentração alveolar se eleve rapidamente em relação à concentração inspirada, atingindo em 30 minutos de anestesia, uma concentração alveolar equivalente a 70\% da concentração inspirada (EGER, 1981).

A concentração alveolar mínima (CAM) é o índice que normalmente é utilizado na comparação da potência entre os anestésicos inalatórios. Este índice é definido como a concentração alveolar mínima necessária para prevenir em 50\% da população movimentos voluntários diante de um estímulo doloroso (DRUMMOND; TODD; SHAPIRO, 1983). A CAM do isofluorano em gatos é 1,61-1,63\% (STEFFEY; HOWLAND, 1977; DRUMMOND; TODD; SHAPIRO, 1983).

O isofluorano promove depressão respiratória dose-dependente em gatos (STEFFEY; HOWLAND, 1977; HIKASA et al., 1996; HIKASA et al., 1997). Esta depressão é caracterizada por redução no volume minuto, determinada pela diminuição do volume corrente, com a frequência respiratória mantendo-se 
relativamente constante (STEFFEY; HOWLAND, 1977). Com o aumento da concentração alveolar de anestésico, há aumento da pressão arterial de dióxido de carbono durante a respiração espontânea com conseqüente diminuição do pH arterial, resultando em acidose respiratória marcante em planos profundos (STEFFEY; HOWLAND, 1977; HIKASA et al., 1997; HODGSON; COLIN; CHAPMAN, 1998).

Quanto ao sistema cardiovascular, observou-se, em gatos sob ventilações controlada e espontânea, que o isofluorano promoveu redução na resistência vascular periférica e hipotensão dose-dependente (STEFFEY; HOWLAND, 1977; HIKASA et al., 1997; HODGSON; COLIN; CHAPMAN, 1998).

O uso clínico do isofluorano apresenta várias vantagens, entre elas está a biotransformação mínima (0,2\%), menor ocorrência de arritmias cardíacas e recuperação rápida (HOLADAY; FISEROVA-BERGERUVA; LATTO, 1975; BEDNARSKI; MAJORS, 1986; HODGSON; COLIN; CHAPMAN, 1998).

Quando midazolam foi empregado, em associação com propofol, na indução da anestesia de cadelas submetidas a ovariossalpingo-histerectomia, observou-se redução de 23\% na concentração expirada de isofluorano (STEGMANN; BESTER, 2001). 


\section{OBJETIVOS}

O número de gatos mantidos como animais de estimação é cada vez maior no Brasil. Este aspecto, associado ao aumento da expectativa de vida, tende a ampliar o número de procedimentos cirúrgico-anestésicos. Há poucos estudos sobre a morbi-mortalidade em gatos, mas a maioria aponta para maior mortalidade em felinos do que de cães durante os procedimentos anestésicos. Esse fato faz com que haja a necessidade de se procurar protocolos anestésicos que reduzam a ocorrência de complicações nesta espécie. Com o intuito de formular protocolos anestésicos cada vez mais confiáveis, surgiu o conceito de anestesia balanceada. Deste modo, a indução da anestesia realizada com o midazolam poderia promover melhor qualidade da anestesia geral em gatos, minimizando os efeitos adversos. Entretanto, como existem relatos de excitação após a administração do benzodiazepínico, o emprego prévio de propofol à administração de midazolam poderia proporcionar uma indução com melhores resultados.

Assim sendo, o objetivo deste estudo foi avaliar os efeitos do midazolam, administrado previamente ou posteriormente ao propofol, na indução da anestesia em gatas submetidas a ovariossalpingo-histerectomia por meio das seguintes análises:

- Redução da dose do propofol quando em associação com midazolam;

- Qualidade de intubação endotraqueal e grau de relaxamento muscular das gatas submetidas à indução da anestesia com propofol ou propofol em associação com midazolam; 
- Qualidade de indução da anestesia após a administração de propofol ou propofol em associação com midazolam, analisando qual a melhor seqüência de administração;

- Qualidade e tempo de recuperação nas gatas submetidas à indução da anestesia com propofol ou propofol em associação com midazolam. 


\section{MATERIAL E MÉTODO}

O estudo foi aprovado pela Comissão de Bioética da Faculdade de Medicina Veterinária e Zootecnia da Universidade de São Paulo sob o número de protocolo 1584/2008 e todos os procedimentos foram realizados com a aquiescência dos proprietários.

\subsection{ANIMAIS}

Foram utilizados 30 animais, da espécie felina, fêmeas adultas, de raças variadas, com peso variando de 2,0 a 4,0 kg e classificadas como categoria de risco I, submetidas a ovariossalpingo-histerectomia pelo Serviço de Cirurgia do Departamento de Cirurgia junto ao Hospital Veterinário da Faculdade de Medicina Veterinária da Universidade de São Paulo. Realizou-se exame físico prévio objetivando selecionar apenas animais saudáveis. Desta forma, foi feita inspeção para descartar secreções nasais e oculares, verificação de coloração de mucosa, tempo de preenchimento capilar, qualidade de pulso periférico, auscultação cardíaca e pulmonar, palpação abdominal, avaliação das frequências respiratória e cardíaca, além da temperatura retal. Foram realizadas colheitas de amostras de sangue para realização de hemograma completo, contagem de plaquetas e exame bioquímico renal (uréia e creatinina) e hepático (alanina transaminase, aspartato transaminase e 
fosfatase alcalina). Previamente ao procedimento anestésico-cirúrgico foi instituído jejum alimentar de $12 \mathrm{~h}$ e hídrico de $4 \mathrm{~h}$.

\subsection{PROCEDIMENTO EXPERIMENTAL}

Todos os animais foram pré-tratados com acepromazina ${ }^{1}(0,1 \mathrm{mg} / \mathrm{kg})$ e morfina $^{2}(0,2 \mathrm{mg} / \mathrm{kg})$, na mesma seringa, por via intramuscular, de modo a facilitar a obtenção de acesso venoso na veia cefálica, com cateter de calibre adequado. Posteriormente, foi iniciada a administração de fluidos, no volume de 5 a $10 \mathrm{ml} / \mathrm{kg} / \mathrm{h}$, com solução de Ringer com lactato durante o procedimento peri-operatório.

Os animais foram distribuídos em três grupos aleatórios, e o estudo foi conduzido de modo "cego", onde os avaliadores desconheciam (anestesista e cirurgião) os fármacos empregados na indução da anestesia:

- GP - grupo propofol: a indução foi realizada somente com propofol ${ }^{3}$ por via intravenosa na dose necessária para intubação endotraqueal. A administração foi feita a uma velocidade aproximada de $4 \mathrm{mg} / \mathrm{kg} / \mathrm{min}$, até que ocorresse a perda do reflexo interdigital e palpebral;

- GMP - grupo midazolam-propofol: os animais receberam midazolam ${ }^{4}(0,3$ $\mathrm{mg} / \mathrm{kg}$ ) administrado pela via intravenosa em 30s, e em seguida o propofol foi administrado segundo os critérios do grupo propofol;

\footnotetext{
${ }^{1}$ Acepran a 0,2\% - Univet - São Paulo, SP, Brasil.

${ }^{2}$ Dimorf - Cristália - São Paulo, SP, Brasil.

${ }^{3}$ Propovan - Cristália, São Paulo, SP, Brasil.

${ }^{4}$ Dormire - Cristália, São Paulo, SP, Brasil.
} 
- GPM - grupo propofol-midazolam: Foi administrado, inicialmente, propofol na velocidade de $4 \mathrm{mg} / \mathrm{kg} / \mathrm{min}$ durante $30 \mathrm{~s}$; posteriormente, administrouse, midazolam $(0,3 \mathrm{mg} / \mathrm{kg})$ em $30 \mathrm{~s}$, e o restante da indução foi realizado com propofol na velocidade de $4 \mathrm{mg} / \mathrm{kg} / \mathrm{min}$.

Para que o estudo fosse cego, os grupos GP e GPM receberam solução salina no volume similar à dose de midazolam antes da indução $(0,06 \mathrm{ml} / \mathrm{kg})$. Da mesma forma, os grupos GP e GMP receberam solução salina $(0,06 \mathrm{ml} / \mathrm{kg})$ após $30 \mathrm{~s}$ de administração de propofol. Com objetivo de mimetizar a administração do midazolam, a solução salina foi administrada em 30s.

A indução da anestesia foi realizada 30 min após a administração da medicação pré-anestésica, e a perda do reflexo interdigital do membro torácico esquerdo foi o parâmetro observado para determinar o momento da intubação com sonda orotraqueal. Os animais foram submetidos à anestesia geral inalatória ${ }^{5} \mathrm{com}$ isofluorano ${ }^{6}$ diluído em um fluxo de $500 \mathrm{ml} / \mathrm{kg} / \mathrm{min}$ de oxigênio a $100 \%$, por meio do circuito anestésico de Mapleson D. Na ocorrência de apnéia, os animais receberam ventilação de modo assistido a cada 30 s até que voltassem a respirar espontaneamente.

\subsection{AVALIAÇÃO DO PROCEDIMENTO ANESTÉSICO}

\subsubsection{Frequência e ritmo cardíaco}


Na avaliação pré-anestésica e no período de recuperação, a frequência cardíaca foi mensurada por auscultação dos batimentos cardíacos durante um minuto. Durante o procedimento anestésico e cirúrgico, a frequência e ritmo cardíacos foram avaliados por meio de monitor multiparamétrico ${ }^{7}$.

\subsubsection{Pressão arterial sistólica}

A pressão arterial sistólica foi mensurada por meio de Doppler vascular periférico $^{8}$. Um manguito, com largura de aproximadamente $40 \%$ da circunferência do membro torácico, foi posicionado logo abaixo da articulação úmero-radio-ulnar. Um sensor ultra-sônico foi posicionado sobre a área da artéria digital comum, após a tricotomia da região. Três aferições foram realizadas a cada momento determinado e a média foi anotada.

4.3.3 Freqüência respiratória e fração expirada de dióxido de carbono

Durante a avaliação pré-anestésica e período de recuperação, a freqüência respiratória foi obtida pela observação de movimentos da parede torácica em um minuto. Entretanto, durante o procedimento anestésico, as mensurações da

\footnotetext{
${ }^{5}$ Shogun - Takaoka, São Paulo, SP, Brasil.

${ }^{6}$ Forane - Abbott, São Paulo, SP, Brasil.

${ }^{7}$ Dash 4000 - GE Helthcare, Helsinki, Finland.
} 
freqüência respiratória e da fração de dióxido de carbono foram determinadas com auxílio do analisador de gases ${ }^{9}$. Uma sonda uretral $n^{0} 4$ de policloreto de vinila ${ }^{10}$ foi dirigida pelo lúmen do tubo endotraqueal até que sua ponta atingisse a porção distal do tubo. A colheita de gases foi realizada por meio da sonda diretamente para o analisador de gases.

4.3.4 Saturação da oxi-hemoglobina no sangue periférico

A saturação da oxi-hemoglobina no sangue periférico foi mensurada com auxílio de um sensor ${ }^{7}$ acoplado a língua do animal.

4.3.5 Fração inspirada e expirada de isofluorano

A fração inspirada e expirada de isofluorano foi determinada em porcentagem, por meio de um sensor do analisador de gases. Uma sonda uretral $\mathrm{n}^{0} 4$ de policloreto de vinila ${ }^{8}$ foi dirigida pelo lúmen do tudo endotraqueal até que sua ponta atingisse a porção distal do tubo. A colheita de gases foi realizada por meio da sonda diretamente para o analisador de gases.

\footnotetext{
${ }^{8}$ Modelo 811- B - Parks Medical Inc., Aloha, USA.

${ }^{9}$ Capnomac Ultima SV, Datex-Ohmeda, Helsinki, Finland.

${ }^{10}$ Sonda uretral PVC - Embramed, São Paulo, Brasil.
} 
4.3.6 Potencial hidrogeniônico do sangue arterial $(\mathrm{pH})$, pressão parcial de dióxido de carbono no sangue arterial $\left(\mathrm{PaCO}_{2}\right)$, pressão parcial de oxigênio no sangue arterial $\left(\mathrm{PaO}_{2}\right)$, saturação de oxigênio na hemoglobina no sangue arterial $\left(\mathrm{SaO}_{2}\right)$, concentração plasmática de bicarbonato $\left(\mathrm{HCO}_{3}{ }^{-}\right)$e déficit de base (DB)

Foi realizada a colheita de uma amostra de sangue arterial em seringas heparinizadas com imediata vedação da agulha com tampa de borracha para análise em aparelho de hemogasometria ${ }^{11}$. As amostras foram processadas imediatamente após a colheita.

\subsubsection{Temperatura retal}

A temperatura retal foi mensurada com auxílio de um termômetro digital, em graus Celsius nos períodos antes da indução.

\subsubsection{Grau de relaxamento muscular}

O relaxamento muscular foi avaliado de maneira subjetiva observando a resistência à abertura bucal e flexão do membro pélvico (COVEY-CLUMP; MURISON, 2008) e escore proferido pelo cirurgião, durante o procedimento: 
- Resistência à abertura bucal e à flexão do membro pélvico

1: intenso relaxamento muscular (ausência de resistência a abertura bucal e flexão do membro);

2: moderado relaxamento muscular (discreta resistência a abertura bucal e/ou flexão do membro);

3: discreto relaxamento muscular (moderada resistência a abertura bucal e/ou flexão do membro);

4: tônus do membro e mandíbula normais.

- Escore proferido pelo cirurgião

1: ausência de tônus muscular;

2: leve tônus muscular;

3: importante tônus muscular;

4: contrações sem estímulo cirúrgico.

4.3.9 Período e qualidade de recuperação

Os períodos avaliados no pós-operatório foram:

- Tempo de extubação: período compreendido entre a interrupção da anestesia inalatório e a retirada do tubo endotraqueal quando houve presença de tônus lingual;

\footnotetext{
${ }^{11}$ ABL-5 - Radiometer, Copenhagen, Dinamarca.
} 
- Manutenção da cabeça erguida: período compreendido entre a interrupção do anestésico inalatório e o momento em que o animal conseguiu manter a cabeça erguida;

- Capacidade em se manter em decúbito esternal: período compreendido entre a interrupção do anestésico inalatório e o momento em que o animal foi capaz de ficar em decúbito esternal por si próprio;

- Capacidade de se locomover com ataxia moderada: período compreendido entre a interrupção do anestésico inalatório e o momento em que o animal foi capaz de ficar em posição quadrupedal e se locomover mesmo que moderadamente atáxico.

Em relação à avaliação da qualidade de recuperação, observou-se a incidência de reações indesejáveis como vocalização, tremores, opistótono, comportamento de fuga e/ou agitação, vômito e defecação.

4.3.10 Dose de propofol necessária para intubação endotraqueal

O propofol foi administrado na velocidade de $4 \mathrm{mg} / \mathrm{kg} / \mathrm{min}$ nos três grupos estudados. A administração foi realizada até a perda de reflexo palpebral e interdigital, sendo, em seguida, realizada a intubação endotraqueal. Caso esta não fosse possível, o fármaco foi administrado na mesma velocidade por mais $30 \mathrm{~s}$, e uma nova tentativa foi realizada. Assim que a intubação endotraqueal foi estabelecida, o número de tentativas foi registrado. 


\subsubsection{Qualidade da intubação}

A qualidade da intubação foi determinada a partir do seguinte escore, avaliado por dois observadores:

1: Suave (sem deglutição, tosse, movimento de língua ou maxila);

2: Regular (discreto movimento de língua e tosse);

3: Ruim (marcante movimento de língua/maxila e deglutição ou tosse);

4: Muito ruim (Mesmo que o escore 3 mas requerendo propofol adicional e nova tentativa de intubação).

\subsection{DELINEAMENTO EXPERIMENTAL}

Os valores da freqüência cardíaca, freqüência respiratória, pressão arterial sistólica, temperatura retal e o ritmo cardíaco foram verificados durante a avaliação pré-anestésica e 30 min após a administração da medicação pré-anestésica com acepromazina e morfina. Decorridos 10 minutos da indução da anestesia, no momento da incisão de pele, da abertura da cavidade abdominal, do pinçamento dos pedículos ovarianos, da sutura de musculatura e de sutura de pele foram também avaliados os seguintes atributos: fração expirada de dióxido de carbono, fração inspirada e expirada de isofluorano, saturação da oxi-hemoglobina periférica e avaliação subjetiva do grau de relaxamento muscular. Aos 15 minutos de anestesia inalatória e ao final do procedimento anestésico (interrupção do anestésico 
inalatório) foram realizadas as colheitas de sangue arterial para a realização de hemogasometria.

Como terapia analgésica no período pós-operatório, administrou-se cetoprofeno $^{12}$ na dose de 1,0 mg/kg por via intravenosa, 30 min antes do término do procedimento cirúrgico. Os animais que apresentaram no período pós-operatório sinais de desconforto como: sensibilidade à palpação da ferida cirúrgica, taquipnéia, taquicardia ou agressividade, receberam tramadol $^{13}$, por via intramuscular, na dose de $2 \mathrm{mg} / \mathrm{kg}$.

A qualidade da intubação foi avaliada por dois observadores (anestesista e cirurgião) que desconheciam os fármacos empregados na indução da anestesia. O relaxamento muscular foi analisado por dois observadores nos momentos já descritos, os quais determinaram escores específicos.

Para tentar minimizar a perda de temperatura corporal durante o procedimento anestésico e recuperação, um colchão térmico ${ }^{14}$ foi utilizado.

\subsection{ANÁLISE ESTATÍSTICA}

Os atributos avaliados, com exceção dos hemogasométricos, foram avaliados pela análise de variância, seguida do teste de Tukey, para a comparação dos diferentes tempos de observação de um mesmo grupo e para comparação dos mesmos momentos entre os três grupos.

\footnotetext{
12 Ketofen - Merial, São Paulo, SP, Brasil.

13 Tramadon - Cristália, São Paulo, Sp, Brasil.

${ }^{14}$ Manta térmica - Estek, São Paulo, SP, Brasil.
} 
Os valores hemogasométricos foram submetidos ao teste $\mathrm{t}$ pareado para comparação entre os dois momentos dentro dos grupos e análise de variância seguida de Tukey para comparação entre os grupos nos dois momentos avaliados.

Para a comparação entre os grupos em relação ao relaxamento muscular e qualidade de intubação, realizou-se o teste de Friedman, seguido do teste de Dunn. O grau de significância estabelecido para os testes estatísticos foi o de $5 \%(p<0,05)$. Os testes estatísticos foram realizados em programa de computador ${ }^{15}$.

${ }^{15}$ Graphpad Instat - versão 3.01 e Minitab - versão 15. 


\section{RESULTADOS}

\subsection{ANIMAIS}

A maioria dos animais empregados não apresentou raça definida (SRD) $(n=28)$, sendo que apenas dois animais possuíam raça definida, um pertencente ao $\operatorname{GPM}(3,3 \%)$ e outro pertencente ao $\operatorname{GMP}(3,3 \%)$ (Tabela 1). O peso corpóreo médio dos animais dos grupos GP, GPM e GMP foram, respectivamente, 2,8 $\pm 0,5 \mathrm{~kg}$,

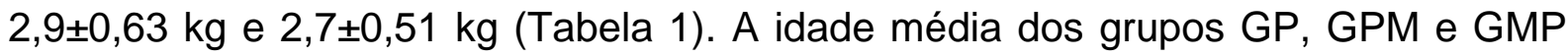
foram, respectivamente, 19,0 $\pm 16,03$ meses, $18,8 \pm 15,44$ meses e $23,9 \pm 25,18$ meses (Tabela 1).

Tabela 1 - Valores médios e respectivos desvios-padrão dos pesos (kg), idades (meses) e raças dos animais dos grupos GP (propofol), GPM (propofol/midazolam) e GMP (midazolam/propofol) - São Paulo - 2010

\begin{tabular}{cccc}
\hline Grupo & Peso $(\mathrm{kg})$ & Idade (meses) & Raça \\
\hline GP & $2,8 \pm 0,50$ & $19 \pm 16,03$ & 10 SRD \\
GPM & $2,9 \pm 0,63$ & $19 \pm 15,44$ & 9 SRD / 1 Persa \\
GMP & $2,7 \pm 0,51$ & $24 \pm 25,18$ & 9 SRD / 1 Persa \\
\hline
\end{tabular}

SRD - sem raça definida

\subsection{RITMO CARDÍACO}


Todos os animais dos três grupos apresentaram ritmo sinusal normal durante todo o procedimento anestésico.

\subsection{FREQÜÊNCIA CARDÍACA}

GP: Houve redução dos valores em todos os momentos em relação ao valor basal $(p<0,001)$, exceto no momento pós-MPA. Houve diminuição de todos os valores de frequência cardíaca em relação ao momento pós-MPA $(P<0,001)$ (Tabela 2 e Apêndice A).

GPM: Em relação aos valores basais de freqüência cardíaca, houve redução de todos os valores avaliados, com exceção do momento pós-MPA $(p<0,05$ na ligadura dos pedículos e p<0,001 nos momentos restantes). Observou-se diminuição dos valores em todos os momentos avaliados em relação ao momento pós MPA (ligadura do primeiro pedículo $p<0,01$ e para os demais momentos $p<0,001$ ). Em relação ao momento incisão de pele houve aumento com diferença significante da freqüência cardíaca nos momentos de ligadura de ambos os pedículos $(p<0,01)$ (Tabela 2 e Apêndice B).

GMP: Houve redução dos valores em todos os momentos avaliados em relação ao valor basal, com exceção da avaliação pós-MPA, com valores de p<0,001. Em relação ao momento pós-MPA, houve redução de todos os valores nos momentos avaliados na seqüência ( $p<0,001)$ (Tabela 2 e Apêndice $C)$. 
Avaliação comparativa entre os grupos: Os valores de freqüência cardíaca, durante a ligadura de ambos os pedículos, foram inferiores no grupo GMP quando comparado ao grupo GPM $(p<0,05)$ (Figura 1 e Tabela 2).

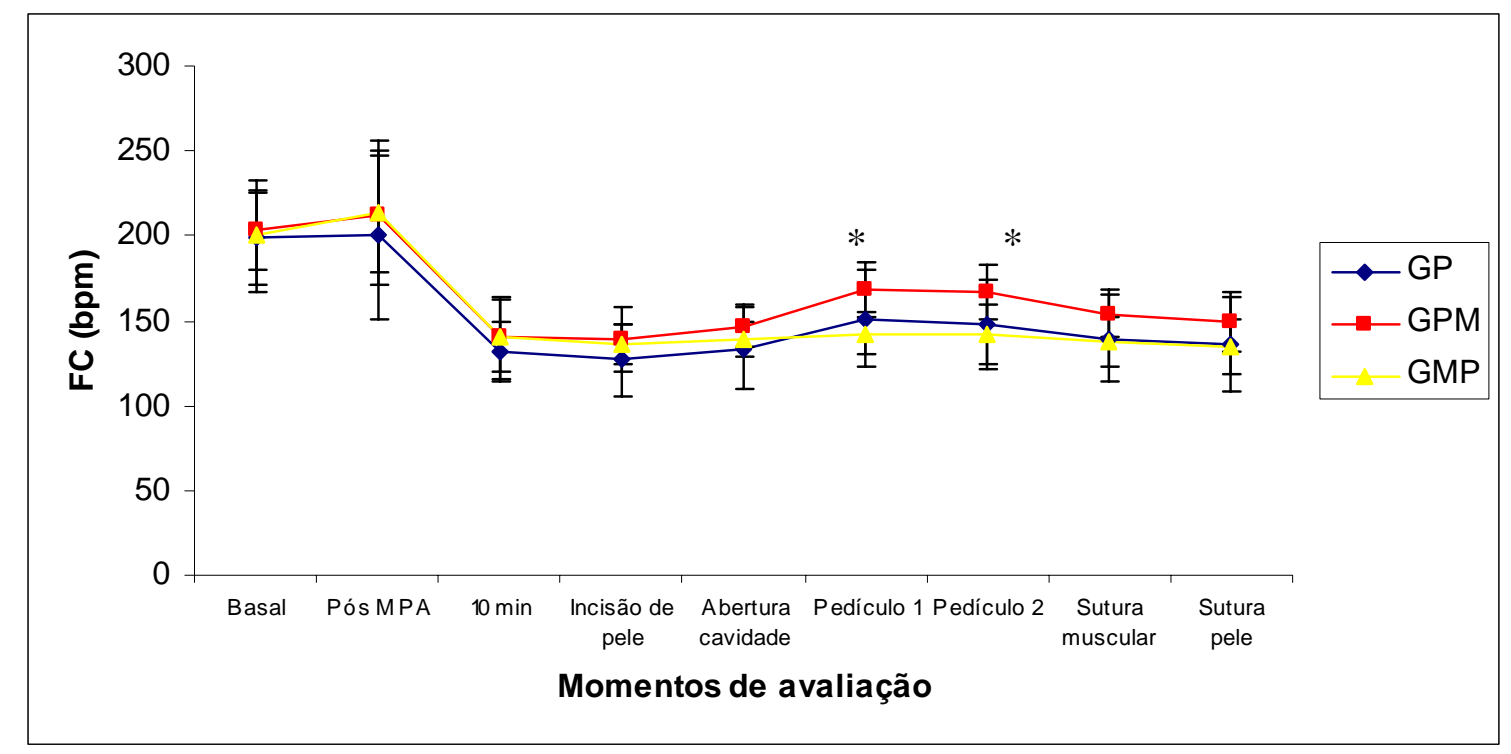

Figura 1 - Variação dos valores médios da freqüência cardíaca (batimentos por minuto) em gatas submetidas a ovariossalpingo-histerectomia, tratadas com propofol (GP), propofol-midazolam (GPM) ou midazolam-propofol (GMP), em diferentes momentos de avaliação (*diferença entre o grupo GPM e GMP com p<0,05) - São Paulo - 2010

\subsection{PRESSÃO ARTERIAL SISTÓLICA}

GP: Houve diminuição da pressão arterial sistólica, em relação aos valores basais, no momento pós-MPA $(p<0,01)$, aos 10 minutos de anestesia inalatória $(p<0,001)$, nos momentos da incisão de pele $(p<0,001)$, da abertura de cavidade $(p<0,001)$, da ligadura do segundo pedículo $(p<0,05)$ e da sutura de musculatura e pele $(p<0,001)$. Em relação ao momento pós-MPA, houve redução da pressão arterial sistólica aos 10 minutos de anestesia inalatória $(p<0,05)$. No atinente ao 
momento 10 minutos de anestesia inalatória, houve aumento da pressão arterial sistólica nos momentos de ligadura do primeiro $(p<0,001)$ e segundo pedículo $(p<0,01)$. Quando se comparou o valor obtido no momento incisão de pele, verificouse incremento dos valores nos momentos de ligadura do primeiro $(p<0,01)$ e segundo pedículo $(p<0,05)$ (Tabela 2 e Apêndice $D)$.

GPM: Houve redução dos valores de pressão arterial sistólica em todos os momentos avaliados quando comparados aos basais $(p<0,001$, com exceção do momento ligadura de pedículos, cujo $\mathrm{p}<0,01)$. Em relação ao momento pós-MPA, houve diminuição dos valores aos 10 minutos de anestesia inalatória $(p<0,05)$. Em relação aos 10 minutos de anestesia inalatória, observou-se aumento dos valores durante a ligadura dos pedículos $(p<0,001)$. No tocante ao momento da abertura da cavidade, houve aumento dos valores durante a ligadura dos pedículos $(p<0,05)$. Além disso, observou-se redução dos valores em relação ao momento de ligadura do primeiro pedículo quando comparada ao momento de sutura de pele $(p<0,05)$ (Tabela 2 e Apêndice E).

GMP: Observou-se redução dos valores obtidos em todos os momentos avaliados quando comparados ao momento basal $(p<0,01)$. O mesmo aconteceu em relação ao momento pós-MPA (aos 10 minutos de anestesia inalatória, na incisão de pele, abertura de cavidade e sutura de musculatura apresentaram o valor de $p<0,01$; na ligadura de pedículos $p<0,05$ e na sutura de pele $p<0,01)$. Em relação aos 10 minutos de anestesia inalatória, houve aumento dos valores no momento de ligadura dos pedículos ovarianos ( $p<0,05)$ (Tabela 2 e Apêndice F). 
Avaliação comparativa entre os grupos: Não houve diferença significante dos valores de pressão arterial sistólica entre os grupos nos diferentes momentos de avaliação (Figura 2 e Tabela 2).

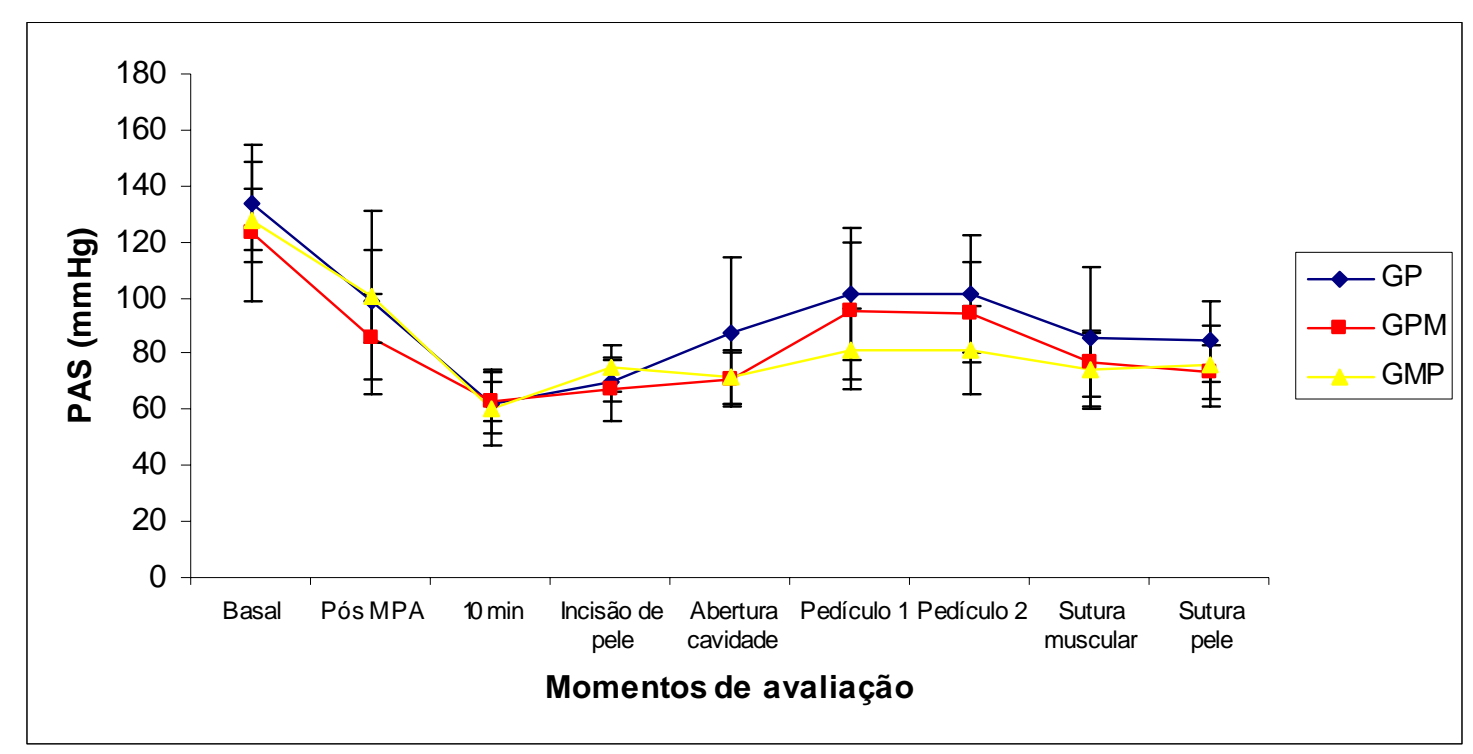

Figura 2 - Variação dos valores médios da pressão arterial sistólica $(\mathrm{mmHg})$ em gatas submetidas à ovariossalpingo-histerectomia, tratadas com propofol (GP), propofol-midazolam (GPM) ou midazolam-propofol (GMP), em diferentes momentos de avaliação - São Paulo - 2010

\subsection{FREQUÊNCIA RESPIRATÓRIA}

GP, GPM e GMP: Nos três grupos estudados, observou-se redução dos valores de freqüência respiratória em todos os momentos avaliados em relação aos valores basais $(p<0,001)$. Em relação ao momento pós-MPA, todos os momentos subseqüentes apresentaram diminuição da freqüência respiratória $(p<0,001)$ (Tabela 2 e Apêndices $\mathrm{G}, \mathrm{H}$ e I). 
Avaliação comparativa entre os grupos: Não houve diferença entre os grupos (Figura 3 e Tabela 2).

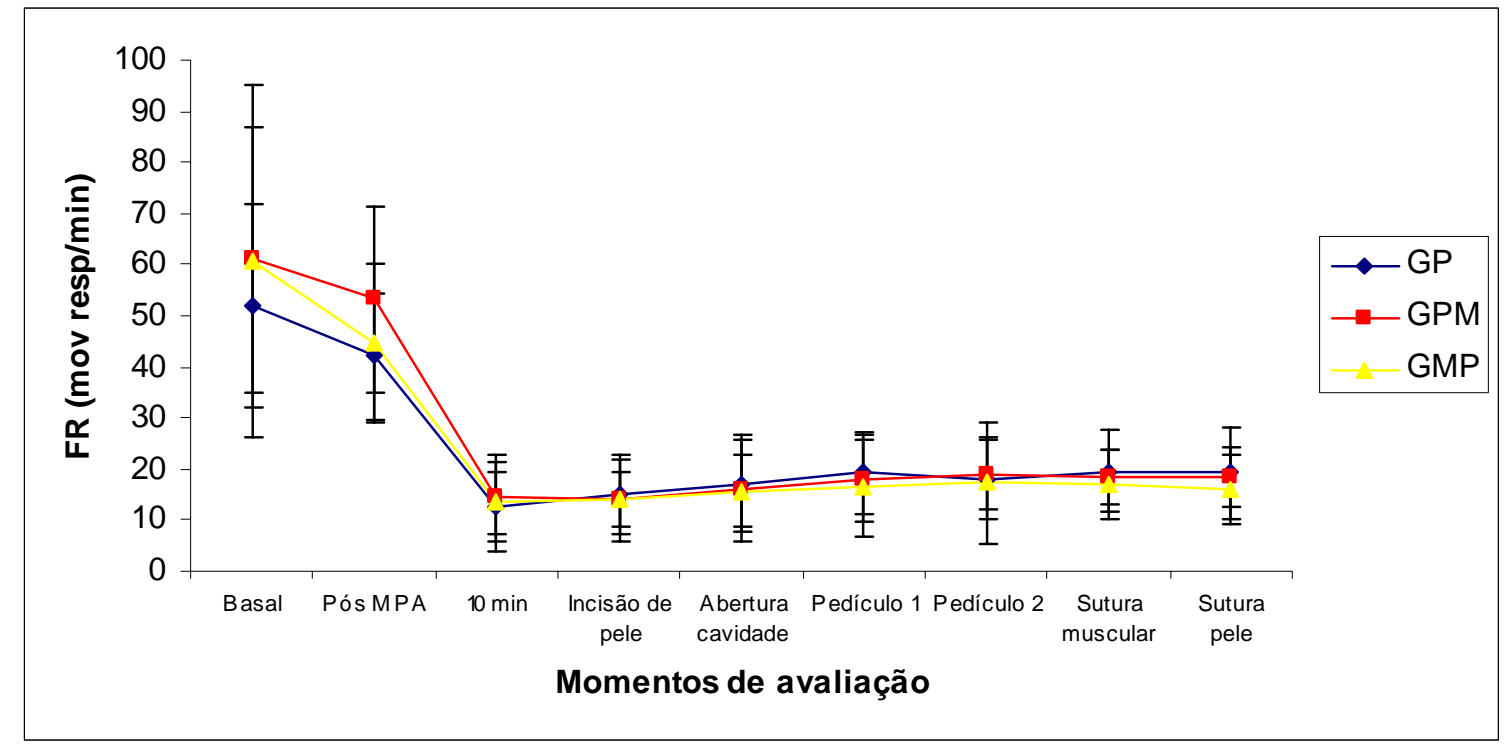

Figura 3 - Variação dos valores médios da freqüência respiratória (movimentos respiratórios por minuto) em gatas submetidas a ovariossalpingohisterectomia, tratadas com propofol (GP), propofol-midazolam (GPM) ou midazolam-propofol (GMP), em diferentes momentos de avaliação - São Paulo - 2010 
Tabela 2 - Valores médios e respectivos desvios-padrão da frequência cardíaca (batimentos por minuto), frequência respiratória (movimentos respiratórios por minuto) e pressão arterial sistólica (mmH) avaliados nos animais dos grupos GP (propofol), GPM (propofol/midazolam) e GMP (midazolam/propofol), em diferentes momentos de avaliação - São Paulo - 2010

\begin{tabular}{ccccccccccc}
\hline & & \multicolumn{10}{c}{ Momentos de Avaliação } \\
\cline { 3 - 11 } & Grupos & Basal & Pós MPA & 10 min & $\begin{array}{c}\text { Incisão } \\
\text { pele }\end{array}$ & $\begin{array}{c}\text { Abertura } \\
\text { cavidade }\end{array}$ & $\begin{array}{c}\text { Pedículo } \\
1\end{array}$ & Pedículo 2 & $\begin{array}{c}\text { Sutura } \\
\text { muscular }\end{array}$ & $\begin{array}{c}\text { Sutura } \\
\text { pele }\end{array}$ \\
\hline \multirow{2}{*}{ FC } & GP & $198 \pm 27,93$ & $200 \pm 49,54$ & $131 \pm 17,66$ & $127 \pm 21,15$ & $134 \pm 23,92$ & $151 \pm 8,20$ & $148 \pm 6,28$ & $148 \pm 26,28$ & $140 \pm 26,06$ \\
(bat/min) & GPM & $204 \pm 22,83$ & $213 \pm 33,99$ & $141 \pm 21,47$ & $127 \pm 42,79$ & $147 \pm 12,22$ & $169 \pm 16,16$ & $167 \pm 16,17$ & $154 \pm 14,26$ & $150 \pm 17,69$ \\
& GMP & $200 \pm 33,31$ & $213 \pm 42,64$ & $140 \pm 23,5$ & $137 \pm 11,47$ & $140 \pm 10,08$ & $143 \pm 12,44$ & $142 \pm 17,08$ & $138 \pm 14,77$ & $135 \pm 16,4$ \\
& GP & $52 \pm 19,78$ & $42 \pm 12,26$ & $13 \pm 6,73$ & $15 \pm 7,58$ & $17 \pm 9,28$ & $19 \pm 8,07$ & $18 \pm 7,57$ & $20 \pm 7,95$ & $19 \pm 8,90$ \\
$f$ & GPM & $61 \pm 25,81$ & $53 \pm 18,32$ & $14 \pm 7,17$ & $14 \pm 5,4$ & $16 \pm 6,94$ & $18 \pm 8,36$ & $19 \pm 6,99$ & $18 \pm 5,42$ & $18 \pm 5,78$ \\
(mov/min) & GMP & $61 \pm 34,36$ & $45 \pm 15,53$ & $13 \pm 9,42$ & $14 \pm 8,02$ & $16 \pm 10,01$ & $16 \pm 9,31$ & $17 \pm 11,83$ & $17 \pm 6,81$ & $16 \pm 6,77$ \\
& GP & $134 \pm 20,95$ & $98 \pm 32,92$ & $62 \pm 11,28$ & $70 \pm 7,31$ & $88 \pm 26,92$ & $101 \pm 23,57$ & $102 \pm 21,03$ & $86 \pm 25,14$ & $85 \pm 14,31$ \\
$\begin{array}{c}\text { PAS } \\
\text { (mmHg) }\end{array}$ & GPM & $123 \pm 24,77$ & $86 \pm 15,33$ & $63 \pm 7,01$ & $67 \pm 11,44$ & $71 \pm 8,99$ & $95 \pm 24,59$ & $95 \pm 18,09$ & $77 \pm 11,58$ & $73 \pm 9,48$ \\
& GMP & $128 \pm 10,98$ & $101 \pm 16,92$ & $61 \pm 13,33$ & $75 \pm 7,97$ & $71 \pm 9,62$ & $82 \pm 14,67$ & $81 \pm 15,77$ & $74 \pm 13,38$ & $76 \pm 14,08$ \\
\hline
\end{tabular}




\subsection{TENSÃO DE DIÓXIDO DE CARBONO NO FINAL DA EXPIRAÇÃO}

GP, GPM E GMP: Não houve diferença entre os momentos de um mesmo grupo (Tabela 3 e Apêndices J, K e L).

Avaliação comparativa entre os grupos: os valores da tensão de dióxido de carbono no final da expiração durante o momento sutura de musculatura foram inferiores no GP comparado ao GPM $(p<0,01)$ e GMP $(p<0,05)$. Durante a ligadura do primeiro pedículo, o GP apresentou valores inferiores em relação ao GPM $(p<0,01)$, ocorrendo o mesmo durante a ligadura do segundo pedículo e sutura de pele $(p<0,05)$ (Figura 4 e Tabela 3).

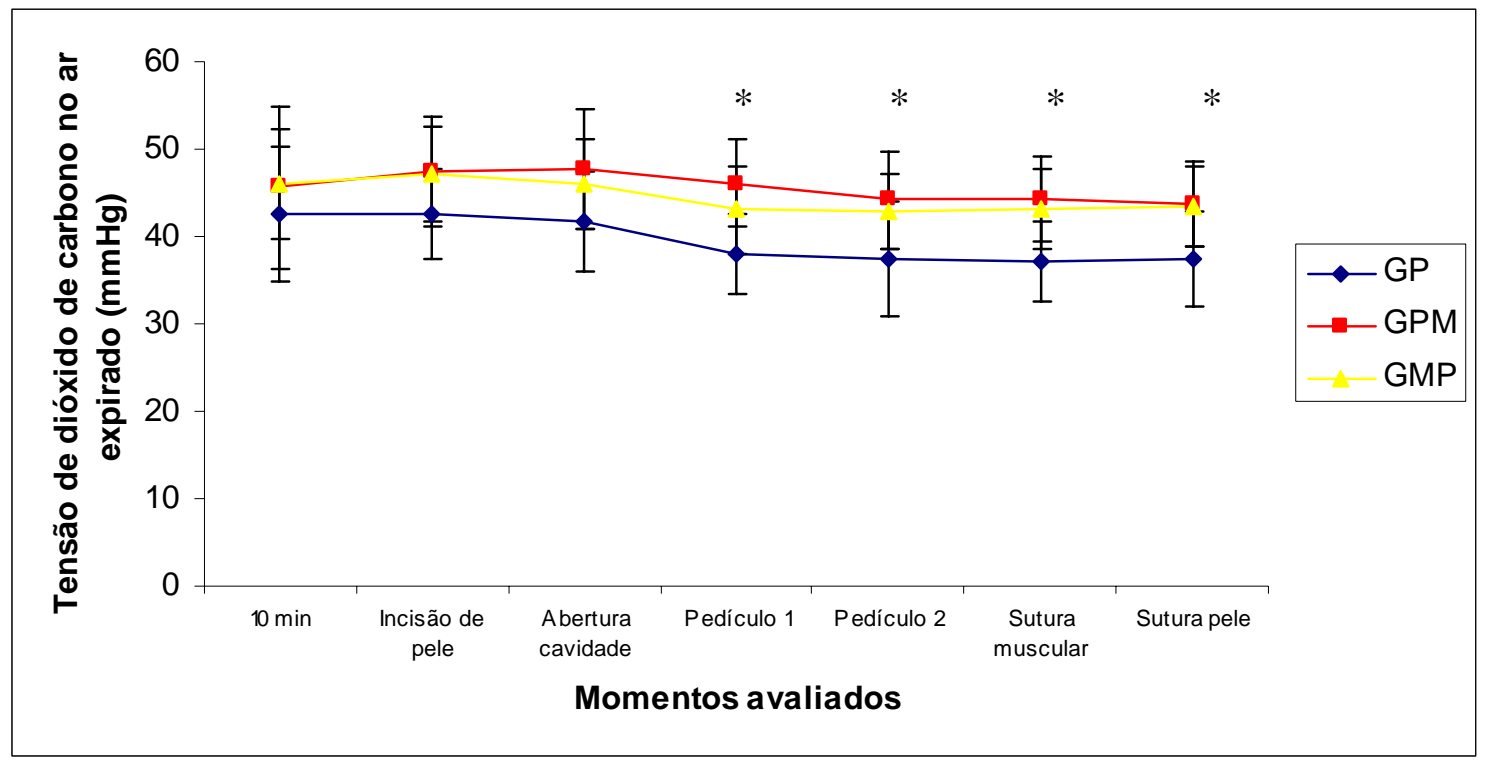

Figura 4 - Variação dos valores médios da tensão de dióxido de carbono no final da expiração (mmHg) em gatas submetidas a ovariossalpingohisterectomia, tratadas com propofol (GP), propofol-midazolam (GPM) ou midazolam-propofol (GMP), em diferentes momentos de avaliação ( ${ }^{*} \mathrm{GP}$ apresentou valores inferiores em relação aos demais grupos) - São Paulo - 2010 


\subsection{SATURAÇÃO DA OXI-HEMOGLOBINA NO SANGUE PERIFÉRICO}

GP, GPM e GMP: Não houve diferença entre os momentos de um mesmo grupo (Tabela 3 e Apêndices M, N e O).

Avaliação comparativa entre os grupos: Não houve diferença entre os grupos (Figura 5 e Tabela 3).

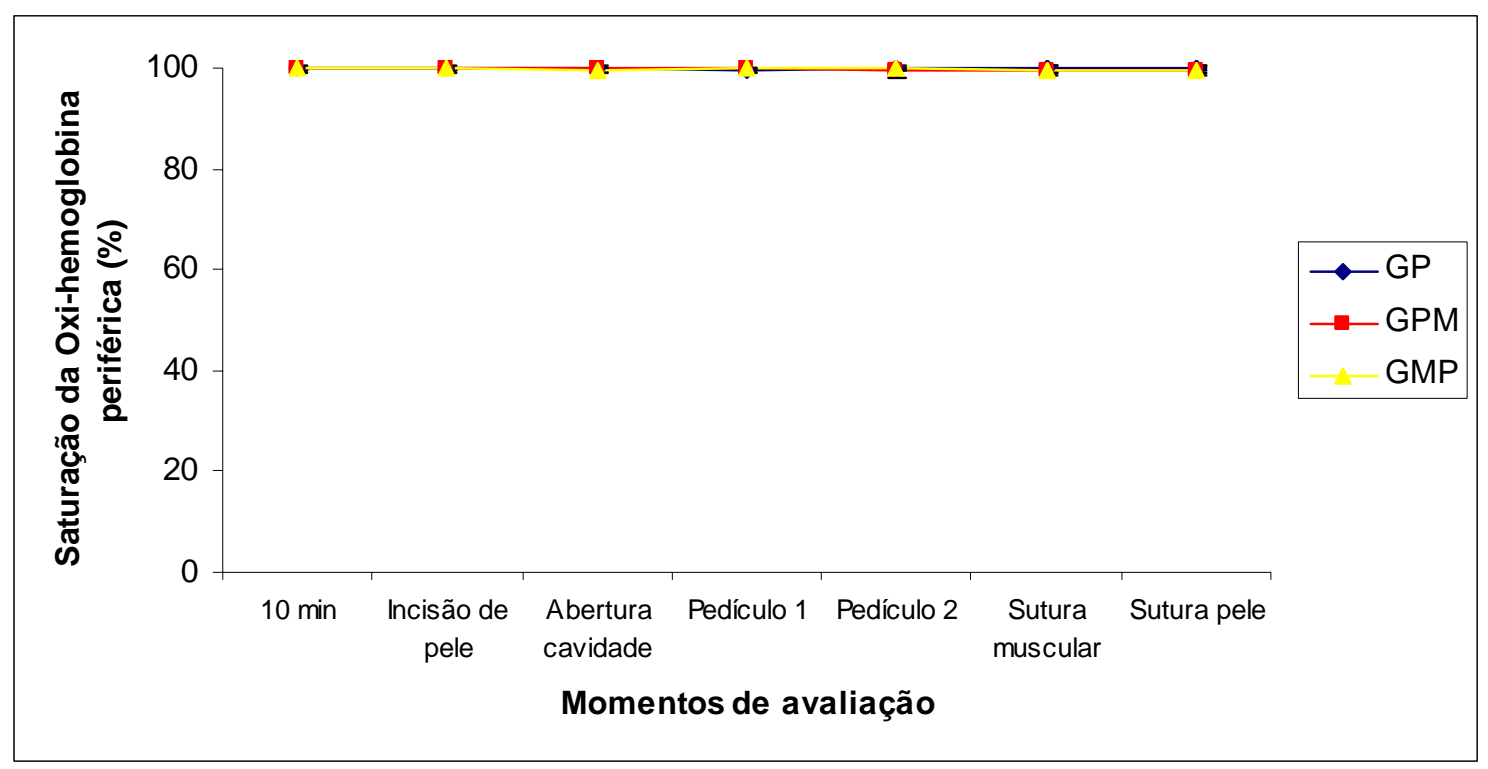

Figura 5 - Variação dos valores médios da saturação da oxi-hemoglobina periférica (\%) em gatas submetidas a ovariossalpingo-histerectomia, tratadas com propofol (GP), propofol-midazolam (GPM) ou midazolam-propofol (GMP), em diferentes momentos de avaliação - São Paulo - 2010

\subsection{FRAÇÃO INSPIRADA DE ISOFLUORANO}

GP e GMP: Não houve diferença entre os momentos avaliados (Tabela 3 e Apêndices P e R). 
GPM: Houve redução dos valores de fração inspirada de isofluorano no momento da sutura de pele, quando comparados aos 10 minutos da indução da anestesia $(p<0,05)$ (Tabela 3 e Apêndice Q).

Avaliação comparativa entre os grupos: Não houve diferença entre os grupos (Figura 6 e Tabela 3).

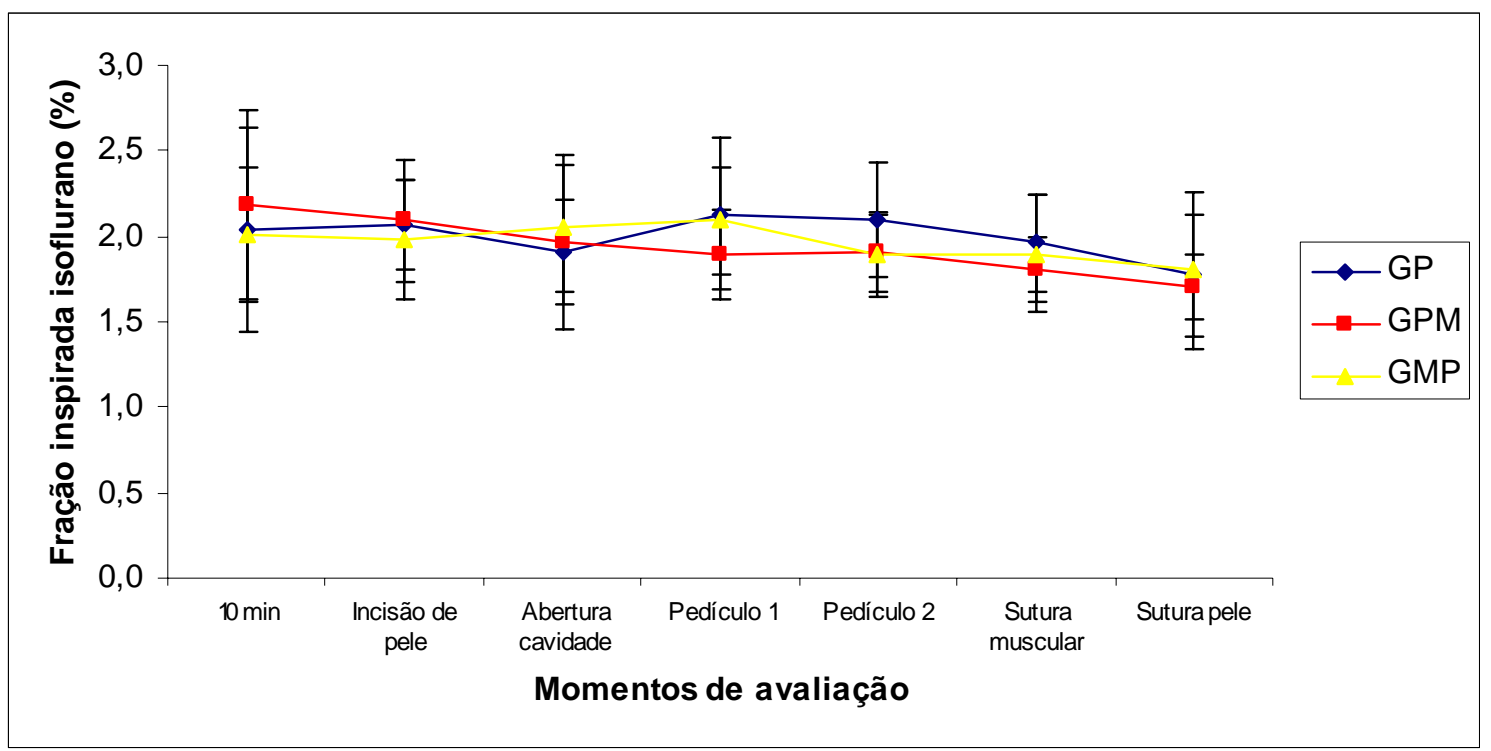

Figura 6 - Variação dos valores médios da fração inspirada de isofluorano (\%) em gatas submetidas a ovariossalpingo-histerectomia, tratadas com propofol (GP), propofol-midazolam (GPM) ou midazolam-propofol (GMP), em diferentes momentos de avaliação - São Paulo - 2010

\subsection{FRAÇÃO EXPIRADA DE ISOFLUORANO}

GP: Houve diminuição dos valores da fração expirada de isofluorano no momento abertura da cavidade em relação aos valores observados durante a ligadura do segundo pedículo $(p<0,05)$ e sutura de musculatura $(p<0,05)$ (Tabela 3 e Apêndice S). 
GPM: Não houve diferença entre os momentos avaliados (Tabela 3 e Apêndice T).

GMP: Houve aumento dos valores da fração expirada de isofluorano aos 10 minutos de anestesia inalatória em relação aos momentos de ligadura do primeiro pedículo $(p<0,01)$, ligadura do segundo pedículo $(p<0,05)$, sutura da musculatura $(p<0,05)$ e sutura de pele $(p<0,05)$ (Tabela 3 e Apêndice $U)$.

Avaliação comparativa entre os grupos: Não houve diferença entre os grupos (Figura 7 e Tabela 3).

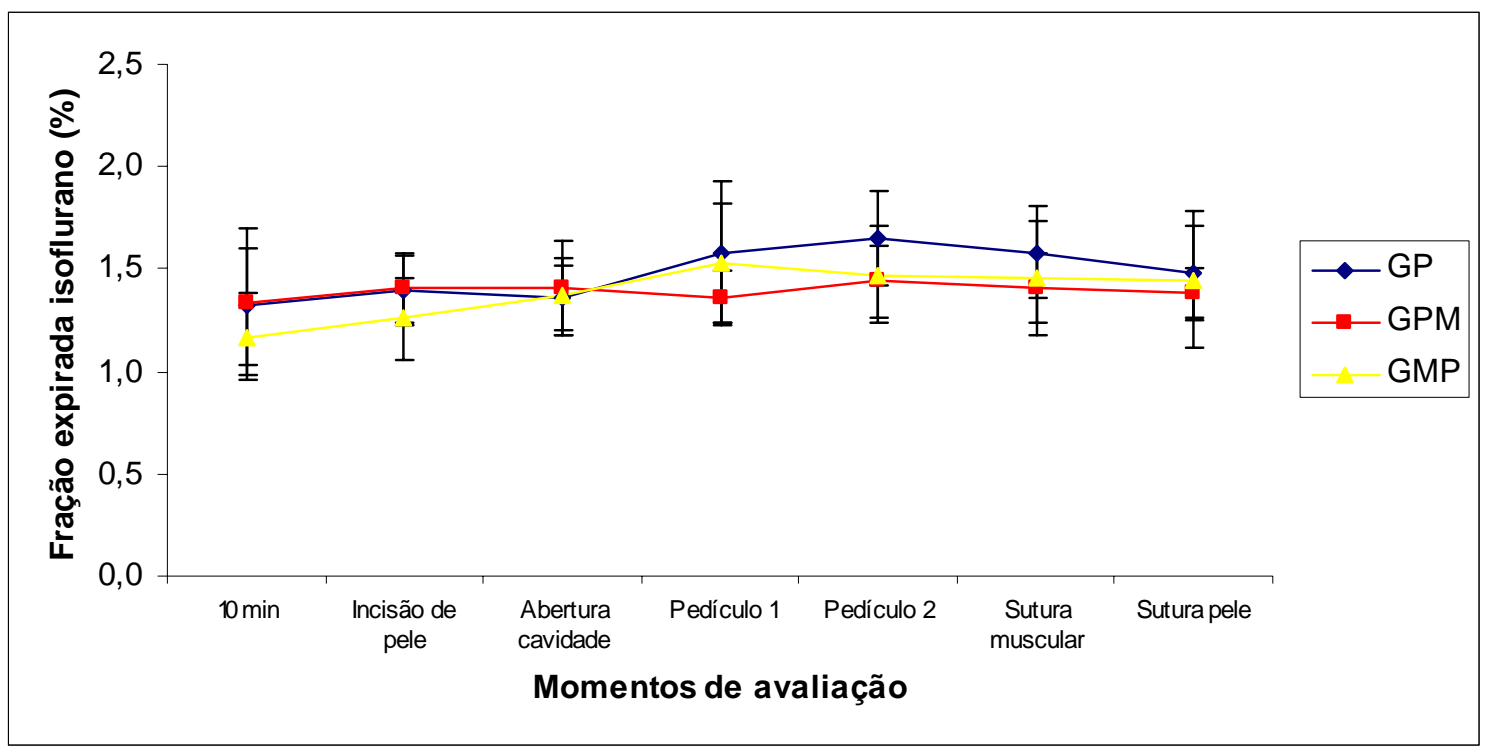

Figura 7 - Variação dos valores médios da fração expirada de isofluorano (\%) em gatas submetidas a ovariossalpingo-histerectomia, tratadas com propofol (GP), propofol-midazolam (GPM) ou midazolam-propofol (GMP), em diferentes momentos de avaliação - São Paulo - 2010 
Tabela 3 - Valores médios e respectivos desvios-padrão da tensão de dióxido de carbono no final da expiração (mmHg), saturação da oxi-hemoglobina do sangue periférico $\left(\mathrm{SpO}_{2}\right)(\%)$, concentração de isofluorano inspirado (ISOi) (\%) e concentração de isofluorano expirado (ISOe) avaliados dos animais dos grupos GP (propofol), GPM (propofol/midazolam) e GMP (midazolam/propofol), em diferentes momentos de avaliação - São Paulo - 2010

\begin{tabular}{ccccccccc}
\hline & & \multicolumn{6}{c}{ Momentos de Avaliação } \\
\cline { 3 - 8 } & Grupos & 10 min & $\begin{array}{c}\text { Incisão } \\
\text { pele }\end{array}$ & $\begin{array}{c}\text { Abertura } \\
\text { cavidade }\end{array}$ & $\begin{array}{c}\text { Pedículo } \\
\text { Pedículo }\end{array}$ & $\begin{array}{c}\text { Sutura } \\
\text { muscular }\end{array}$ & $\begin{array}{c}\text { Sutura } \\
\text { pele }\end{array}$ \\
\hline & GP & $43 \pm 7,69$ & $43 \pm 5,15$ & $42 \pm 5,67$ & $38 \pm 4,61$ & $38 \pm 6,50$ & $37 \pm 4,59$ & $38 \pm 5,40$ \\
$\begin{array}{c}\text { ETCO }_{2} \\
(\mathrm{mmHg})\end{array}$ & GPM & $46 \pm 9,25$ & $47 \pm 6,26$ & $48 \pm 6,80$ & $46 \pm 4,98$ & $44 \pm 5,65$ & $44 \pm 4,90$ & $44 \pm 4,92$ \\
& GMP & $41 \pm 15,02$ & $42 \pm 15,35$ & $41 \pm 14,76$ & $39 \pm 14,10$ & $39 \pm 13,82$ & $39 \pm 14,12$ & $39 \pm 14,14$ \\
\hline $\begin{array}{c}\mathrm{SpO}_{2} \\
(\%)\end{array}$ & GPM & $100 \pm 0,32$ & $100 \pm 0,42$ & $100 \pm 0,42$ & $100 \pm 0,48$ & $100 \pm 0,32$ & $100 \pm 0,63$ & $100 \pm 0,32$ \\
& GMP & $100 \pm 0,63$ & $100 \pm 0,63$ & $100 \pm 0,67$ & $100 \pm 0,42$ & $100 \pm 0,42$ & $100 \pm 0,67$ & $100 \pm 0,67$ \\
& GP & $1,3 \pm 0,29$ & $1,4 \pm 0,17$ & $1,4 \pm 0,16$ & $1,6 \pm 0,35$ & $1,7 \pm 0,23$ & $1,6 \pm 0,23$ & $1,5 \pm 0,23$ \\
ISOe & GPM & $1,3 \pm 0,36$ & $1,4 \pm 0,17$ & $1,4 \pm 0,23$ & $1,4 \pm 0,13$ & $1,4 \pm 0,18$ & $1,4 \pm 0,17$ & $1,4 \pm 0,12$ \\
& GMP & $1,2 \pm 0,21$ & $1,3 \pm 0,20$ & $1,4 \pm 0,19$ & $1,5 \pm 0,29$ & $1,5 \pm 0,24$ & $1,5 \pm 0,28$ & $1,5 \pm 0,33$ \\
\hline & GP & $2,0 \pm 0,60$ & $2,1 \pm 0,27$ & $1,9 \pm 0,30$ & $2,1 \pm 0,44$ & $2,1 \pm 0,33$ & $2,0 \pm 0,29$ & $1,8 \pm 0,36$ \\
ISOi & GPM & $2,2 \pm 0,56$ & $2,1 \pm 0,35$ & $2,0 \pm 0,51$ & $1,9 \pm 0,26$ & $1,9 \pm 0,23$ & $1,8 \pm 0,19$ & $1,7 \pm 0,19$ \\
& GMP & $2,0 \pm 0,39$ & $2,0 \pm 0,35$ & $2,1 \pm 0,37$ & $2,1 \pm 0,31$ & $1,9 \pm 0,24$ & $1,9 \pm 0,34$ & $1,8 \pm 0,45$ \\
\hline
\end{tabular}


5.10 POTENCIAL HIDROGENIÔNICO DO SANGUE ARTERIAL

GP, GPM e GPM: Não houve diferença entre os momentos avaliados de um mesmo grupo (Tabela 4 e Apêndices $V, W, X, Y, Z$ e AA).

Avaliação comparativa entre os grupos: Não houve diferença entre os grupos (Tabela 4).

5.11 PRESSÃO PARCIAL DE DIÓXIDO DE CARBONO NO SANGUE ARTERIAL

GP, GPM e GPM: Não houve diferença entre os momentos avaliados de um mesmo grupo (Tabela 4 e Apêndices V, W, X, Y, Z e AA).

Avaliação comparativa entre os grupos: Não houve diferença entre os grupos (Tabela 4)

5.12 PRESSÃO PARCIAL DE OXIGÊNIO NO SANGUE ARTERIAL

GP, GPM e GPM: Não houve diferença entre os momentos avaliados de um mesmo grupo (Tabela 4 e Apêndices V, W, X, Y, Z e AA).

Avaliação comparativa entre os grupos: Não houve diferença entre os grupos (Tabela 4). 
5.13 SATURAÇÃO DE OXIGÊNIO NA HEMOGLOBINA NO SANGUE ARTERIAL

GP, GPM e GPM: Não houve diferença entre os momentos avaliados de um mesmo grupo (Tabela 4 e Apêndices $\mathrm{V}, \mathrm{W}, \mathrm{X}, \mathrm{Y}, \mathrm{Z}$ e AA).

Avaliação comparativa entre os grupos: Não houve diferença entre os grupos (Tabela 4).

\subsection{CONCENTRAÇÃO PLASMÁTICA DE BICARBONATO}

GP, GPM e GPM: Não houve diferença entre os momentos avaliados de um mesmo grupo (Tabela 4 e Apêndices $V, W, X, Y, Z$ e AA).

Avaliação comparativa entre os grupos: Não houve diferença entre os grupos (Tabela 4).

\subsection{DÉFICIT DE BASE (DB)}

GP, GPM e GPM: Não houve diferença entre os momentos avaliados de um mesmo grupo (Tabela 4 e Apêndices V, W, X, Y, Z e AA). 
Avaliação comparativa entre os grupos: Não houve diferença entre os grupos (Tabela 4).

Tabela 4 - Valores médios e respectivos desvios-padrão do potencial hidrogeniônico do sangue arterial $(\mathrm{pH})$, pressão parcial de dióxido de carbono no sangue arterial $\left(\mathrm{PaCO}_{2}\right)$, pressão parcial de oxigênio no sangue arterial $\left(\mathrm{PaO}_{2}\right)$, saturação de oxigênio na hemoglobina no sangue arterial $\left(\mathrm{SaO}_{2}\right)$, concentração plasmática de bicarbonato $\left(\mathrm{HCO}_{3}{ }^{-}\right)$e déficit de base (DB) avaliados dos animais dos grupos GP (propofol), GPM (propofol/midazolam) e GMP (midazolam/propofol), aos $15 \mathrm{mi}$ de anestesia inalatória (M0) e no final do procedimento cirúrgico (M1) - São Paulo - 2010

\begin{tabular}{cccccccc}
\hline Momentos & Grupos & $\mathrm{pH}$ & $\begin{array}{c}\mathrm{PaCO}_{2} \\
(\mathrm{mmHg})\end{array}$ & $\begin{array}{c}\mathrm{PaO}_{2} \\
(\mathrm{mmHg})\end{array}$ & $\begin{array}{c}\mathrm{SaO}_{2} \\
(\%)\end{array}$ & $\begin{array}{c}\mathrm{HCO}_{3}{ }^{-} \\
(\mathrm{mmol} / \mathrm{L})\end{array}$ & $\begin{array}{c}\mathrm{DB} \\
(\mathrm{mEq} / \mathrm{l})\end{array}$ \\
\hline & $\mathrm{GP}$ & $7,23 \pm 0,06$ & $46 \pm 6,94$ & $327 \pm 145,12$ & $99 \pm 1,32$ & $19 \pm 1,32$ & $-8 \pm 2,38$ \\
M0 & GPM & $7,19 \pm 0,06$ & $48 \pm 6,38$ & $303 \pm 154,58$ & $99 \pm 1,88$ & $18 \pm 2,86$ & $-10 \pm 3,26$ \\
& GMP & $7,22 \pm 0,05$ & $45 \pm 8,76$ & $400 \pm 103,25$ & $100 \pm 0,31$ & $18 \pm 3,04$ & $-9,5 \pm 2,95$ \\
& GP & $7,35 \pm 0,06$ & $33 \pm 5,63$ & $374 \pm 129,47$ & $99,8 \pm 0,63$ & $18,3 \pm 1,33$ & $-6 \pm 1,70$ \\
M1 & GPM & $7,28 \pm 0,06$ & $40 \pm 5,75$ & $338 \pm 143,42$ & $100 \pm 0,69$ & $19 \pm 2,34$ & $-7 \pm 2,71$ \\
& & & & & & & \\
& GMP & $7,30 \pm 0,49$ & $37 \pm 5,03$ & $335 \pm 139$ & $100 \pm 0,67$ & $18,3 \pm 2,63$ & $-7,8 \pm 2,82$ \\
\hline
\end{tabular}

M0 - 15 minutos de anestesia inalatória; M1 - Final do procedimento cirúrgico

\subsection{TEMPERATURA RETAL}

GP, GPM e GPM: Não houve diferença entre os momentos avaliados de um mesmo grupo (Tabela 5 e Apêndices AB, AC e AD). 
Avaliação comparativa entre os grupos: Não houve diferença entre os grupos (Tabela 5).

Tabela 5 - Valores médios e respectivos desvios-padrão da temperatura retal dos animais dos grupos GP (propofol), GPM (propofol/midazolam) e GMP (midazolam/propofol), nos momentos basal e pós-MPA

\begin{tabular}{ccc}
\hline \multirow{2}{*}{ Grupos } & \multicolumn{2}{c}{ Temperatura Retal $\left({ }^{\circ} \mathrm{C}\right)$} \\
\cline { 2 - 3 } & $38,1 \pm 0,85$ & Pós-MPA \\
\hline GP & $38,2 \pm 0,50$ & $37,8 \pm 0,73$ \\
GPM & $38,4 \pm 0,49$ & $37,9 \pm 0,69$ \\
GMP & \\
\hline
\end{tabular}

\subsection{GRAU DE RELAXAMENTO MUSCULAR}

GP, GPM e GPM: Não houve diferença entre os momentos avaliados de um mesmo grupo (Tabela 6 e Apêndices AE, AF, AG, AH, Al e AJ).

Avaliação comparativa entre os grupos: Não houve diferença entre os grupos (Tabela 6). 
Tabela 6 - Escores e desvios-padrão do grau de relaxamento muscular dos grupos GP (propofol), GPM (propofol/midazolam) e GMP (midazolam/propofol), atribuídos pelos dois observadores (anestesista e cirurgião) - São Paulo $-2010$

\begin{tabular}{ccccc}
\hline \multirow{2}{*}{ Avaliadores } & Momentos de & \multicolumn{3}{c}{ Grupos } \\
\cline { 3 - 5 } & Avaliação & GP & GPM & GMP \\
\hline \multirow{7}{*}{ Anestesista } & 10 min & $1 \pm 0,00$ & $1 \pm 0,00$ & $1 \pm 0,00$ \\
& Incisão & $1 \pm 0,00$ & $1 \pm 0,00$ & $1 \pm 0,00$ \\
& Cavidade & $1 \pm 0,00$ & $1 \pm 0,00$ & $1 \pm 0,00$ \\
& Ped 1 & $1 \pm 0,00$ & $1,1 \pm 0,31$ & $1,1 \pm 0,31$ \\
& Ped 2 & $1 \pm 0,00$ & $1,2 \pm 0,63$ & $1,2 \pm 0,63$ \\
& Musc & $1 \pm 0,00$ & $1,1 \pm 0,31$ & $1,1 \pm 0,31$ \\
& Pele & $1 \pm 0,00$ & $1 \pm 0,00$ & $1 \pm 0,00$ \\
& 10 min & $1 \pm 0,00$ & $1 \pm 0,00$ & $1 \pm 0,00$ \\
& Incisão & $1,1 \pm 0,31$ & $1 \pm 0,00$ & $1 \pm 0,00$ \\
& Cavidade & $1,1 \pm 0,31$ & $1 \pm 0,00$ & $1 \pm 0,00$ \\
& Ped 1 & $1 \pm 0,00$ & $1,3 \pm 0,94$ & $1,3 \pm 0,94$ \\
& Ped 2 & $1,1 \pm 0,31$ & $1,3 \pm 0,94$ & $1,3 \pm 0,94$ \\
& Musc & $1,4 \pm 0,69$ & $1,6 \pm 0,96$ & $1,6 \pm 0,96$ \\
& Pele & $1 \pm 0,00$ & $1 \pm 0,00$ & $1 \pm 0,00$ \\
\hline
\end{tabular}

Ped - pedículo; musc - musculatura

\subsection{PERÍODO DE RECUPERAÇÃO E QUALIDADE DE RECUPERAÇÃO}

GP, GPM e GMP: Não houve diferença em nenhum dos tempos de recuperação dentro dos grupos (Tabela 7 e Apêndices AK, AL e AM).

Avaliação comparativa entre os grupos: Nos momentos extubação, manutenção de cabeça erguida e locomoção, não houve diferença entre os grupos. 
Já no momento decúbito esternal, o grupo GP apresentou valores inferiores em relação ao grupo GPM $(p<0,01)$ (Tabela 7).

Tabela 7 - Valores médios e respectivos desvios-padrão dos tempos (minutos) de anestesia e de recuperação (extubação, manutenção de cabeça erguida, posição esternal e locomoção) dos grupos GP (propofol), GPM (propofol/midazolam) e GMP (midazolam/propofol) - São Paulo - 2010

\begin{tabular}{cccc}
\hline \multirow{2}{*}{$\begin{array}{c}\text { Períodos de Recuperação } \\
(\text { min) }\end{array}$} & \multicolumn{3}{c}{ Grupos } \\
\cline { 2 - 4 } & GP & GPM & GMP \\
\hline Tempo anestésico & $67 \pm 13,7$ & $62 \pm 16,7$ & $67 \pm 19,6$ \\
Extubação & $3 \pm 2,3$ & $3 \pm 1,6$ & $5 \pm 5,7$ \\
Cabeça erguida & $14 \pm 6,2$ & $27 \pm 14,0$ & $18 \pm 11,3$ \\
Esternal & $15 \pm 6,0^{*}$ & $34 \pm 16,6^{*}$ & $25 \pm 11,1$ \\
Locomoção & $24 \pm 11,1$ & $43 \pm 18,1$ & $40,9 \pm 23,6$ \\
\hline$\left.{ }^{*} \mathrm{p}<0,01\right)$ & & &
\end{tabular}

\subsection{DOSE DE PROPOFOL NECESSÁRIA PARA INTUBAÇÃO ENDOTRAQUEAL}

As doses de propofol empregadas para indução anestésica nos grupos GP,

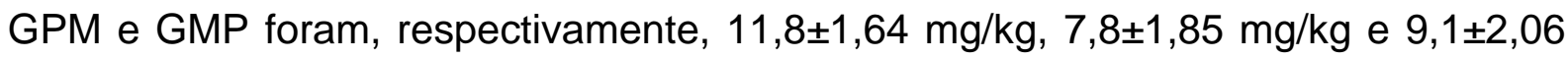
mg/kg. Quando se comparou os três grupos, verificou-se que os valores do GP foram superiores aos observados no GPM $(p<0,001)$ e no GMP $(P<0,01)$ (Tabela 8 e Apêndices AK, AL e AM). 
Tabela 8 - Valores médios e respectivos desvios-padrão das doses de propofol (mg/kg) empregadas na indução dos animais dos grupos GP (propofol), GPM (propofol/midazolam) e GMP (midazolam/propofol) São Paulo - 2010

\begin{tabular}{cc}
\hline Grupos & $\begin{array}{c}\text { Dose de propofol } \\
(\mathrm{mg} / \mathrm{kg})\end{array}$ \\
\hline GP & $11,8 \pm 1,64$ \\
GPM & $7,8 \pm 1,85$ \\
GMP & $9,1 \pm 2,06$ \\
\hline
\end{tabular}

\subsection{QUALIDADE DA INTUBAÇÃO}

Não houve diferença significante quanto aos escores de intubação, tanto nas observações do anestesista como nas do cirurgião (Tabela 9 e Apêndices AQ, AR e AS).

Tabela 9 - Escores de intubação e desvios-padrão dos grupos GP (propofol), GPM (propofol/midazolam) e GMP (midazolam/propofol), atribuídos pelos observadores (anestesista e cirurgião) - São Paulo - 2010

\begin{tabular}{cccc}
\hline \multirow{2}{*}{ Avaliadores } & \multicolumn{3}{c}{ Grupos } \\
\cline { 2 - 4 } & GP & GPM & GMP \\
\hline Anestesista & $1,6 \pm 0,70$ & $1,5 \pm 0,97$ & $1,6 \pm 1,07$ \\
Cirurgião & $1,8 \pm 0,92$ & $1,5 \pm 0,97$ & $1,5 \pm 0,97$ \\
\hline
\end{tabular}




\section{DISCUSSÃo}

No presente estudo, a indução da anestesia com propofol ou propofol e midazolam em felinos foi suave e clinicamente efetiva. Outros estudos já haviam demonstrado a eficácia do propofol como agente indutor isolado ou associado a diferentes medicações pré-anestésicas em gatos (MORGAN; LEGGE, 1989; WEAVER; RAPTOPOULOS, 1990; SANO et al., 2003). Bley, Ross e Price (2007) relataram a eficiência da associação midazolam-propofol na anestesia em felinos. O mesmo foi descrito sobre a associação quando administrada em cães (SAMS et al., 2008). No entanto, Covey-Crump e Murison (2008) observaram excitação no cão após a administração de midazolam $(0,2 \mathrm{mg} / \mathrm{kg})$ quando utilizado como co-indutor com propofol.

As doses médias de propofol necessárias para intubação endotraqueal nos grupos GP $(11,8 \pm 1,64 \mathrm{mg} / \mathrm{kg})$ e GMP $(9,1 \pm 2,06 \mathrm{mg} / \mathrm{kg})$ foram superiores às relatadas na literatura consultada, considerando que os animais do estudo em tela receberam acepromazina e morfina como medicação pré-anestésica. Brearley, Kellagher e Hall (1988) descreveram como dose de indução, 7,2 $\mathrm{mg} / \mathrm{kg}$, Morgan e Legge (1989) 5,97 mg/kg e Weaver e Raptopoulos (1990) a dose de $5,3 \mathrm{mg} / \mathrm{kg}$. Os valores médios do grupo GPM foram próximos $(7,8 \pm 1,85 \mathrm{mg} / \mathrm{kg})$ aos relatados por Brearley, Kellagher e Hall (1988) $(7,2$ $\mathrm{mg} / \mathrm{kg}$ ), porém estes autores utilizaram somente acepromazina como medicação pré-anestésica. Certamente, uma das razões para tais diferenças entre doses pode ser o nível de tranquilização dos gatos. Infelizmente os estudos em discussão, assim como o estudo em tela, não realizaram um análise, por meio de escore, da sedação/tranquilização prévia a 
administração dos agentes indutores. Apesar da neuroleptoanalgesia empregada, algumas gatas se apresentaram agitadas no momento da punção venosa. Outra provável razão para as diferenças encontradas é a velocidade de administração do propofol, que interfere de forma direta na dose de indução (SHORT; BUFALARI, 1999; MENDES et al., 2003; TABOADA; MURISON, 2010). Os estudos nos quais as doses encontradas foram comparadas não descreviam a velocidade de administração (BREARLEY; KELLAGHER; HALL, 1988; MORGAN; LEGGE, 1989; WEAVER; RAPTOPOULOS, 1990). O presente estudo preconizou a velocidade de $4 \mathrm{mg} / \mathrm{kg} / \mathrm{min}$, assim como Covey-Crump e Murison (2008) utilizaram para a indução da anestesia em cães. Taboada e Murison (2010), ao utilizarem a velocidade de $6 \mathrm{mg} / \mathrm{kg} / \mathrm{min}$ para indução da anestesia em gatos não pré-tratados, relataram uma dose média de indução de 7,5 mg/kg.

Um dos objetivos foi avaliar a redução de dose do propofol utilizando o midazolam como agente co-indutor. Desta forma, foi possível verificar redução de $33,9 \%$ da dose de propofol no grupo GPM e 22,9\% no grupo GMP em relação ao grupo GP. Bley, Ross e Price (2007) observaram diminuição de $26 \%$ da dose de propofol em gatos, após a administração intravenosa de midazolam (0,2 mg/kg), enquanto Ko, Payton e Withe (2006), utilizando doses de 0,4 e 0,2 mg/kg de diazepam em cães, obtiveram reduções de $36 \%$ e $21 \%$, respectivamente. Entretanto, Covey-Crump e Murison (2008) não obtiveram a redução da dose de propofol após administração prévia de midazolam $(0,2 \mathrm{mg} / \mathrm{kg})$. Adicionalmente, relataram que a dose de propofol não foi reduzida quando associada ao midazolam, pelo fato deste último ter causado excitação em cães no momento da 
administração intravenosa. A excitação citada não foi observada nos animais do presente estudo.

O emprego da medicação pré-anestésica com acepromazina e morfina causou vômito em apenas um animal (3,3\%). Steagall et al. (2006), ao utilizarem morfina na dose $0,2 \mathrm{mg} / \mathrm{kg}$ pela via subcutânea em felinos, constataram vômito em $75 \%$ dos animais. É possível que o efeito antiemético da acepromazina possa ter reduzido esta ocorrência nos gatos (BREARLEY, 1994).

A associação acepromazina e morfina não reduziu os valores de frequência cardíaca. Este resultado corrobora com os achados de Dyson et al. (1988) em gatos pré-tratados com acepromazina $(0,2 \mathrm{mg} / \mathrm{kg})$, meperidina (4,0 mg/kg) e atropina (0,05 mg/kg). No entanto, o emprego do anticolinérgico não permite uma adequada comparação, tendo em vista que este fármaco causa um efeito taquicardizante. No estudo de Covey-Crump e Murison (2008) em cães, a medicação pré-anestésica com os mesmo fármacos resultou em redução da frequência cardíaca. Os autores atribuíram o fato ao efeito tranquilizante e à ação simpatolítica da morfina. Os valores médios de freqüência cardíaca, durante a ligadura de ambos os pedículos, foram superiores no grupo GPM quando comparado ao grupo GMP. Da mesma forma o grupo GPM também apresentou aumento de valores nos momentos de ligadura de ambos os pedículos quando comparado com o momento incisão de pele. Isto pode ser decorrente da superficialização da anestesia frente ao estímulo nociceptivo. A redução progressiva dos valores de frequência cardíaca, após indução com propofol e manutenção com 
isofluorano também já foi observada em gatos (TABOADA; MURISON, 2010) e em cães (COVEY-CRUMP; MURISON, 2008).

Um total de 14 animais (46,7\%) apresentaram valores de pressão arterial sistólica clinicamente inaceitáveis (inferior a $90 \mathrm{mmHg}$ ), 30 minutos após receberem a medicação pré-anestésica. O efeito antagonista alfaadrenérgico da acepromazina deve ter sido o principal responsável pela hipotensão arterial (INGWERSEN et al., 1988). Uma vez que os efeitos da acepromazina são potencializados quando este fármaco é associado aos opióides (STEAGALL et al., 2008), a morfina utilizada neste estudo pode ter agravado a hipotensão arterial.

Após a indução com propofol ou midazolam e propofol, os três grupos apresentaram redução dos valores de pressão arterial sistólica, apresentando melhora somente a partir do momento da incisão de pele. A redução da pressão arterial após indução da anestesia com propofol já foi demonstrada em gatos (MENDES et al., 2003; TABOADA; MURISON, 2010) e em cães (COVEY-CRUMP; MURISON, 2008), devido ao efeito inotrópico negativo e vasodilatador do propofol, os quais determinam hipotensão dose-dependente (SAMS et al., 2008). Os valores médios de pressão arterial sistólica se apresentaram, em alguns momentos, clinicamente inaceitáveis, variando de hipotensão leve (inferior a $90 \mathrm{mmHg}$ ) a intensa (inferior a $60 \mathrm{mmHg}$ ) (CAULKETT; CANTWELL; HOUSTON, 1998). Os valores pressóricos aferidos pelo método indireto com Doppler, em gatos anestesiados com protocolos similares, tiveram resultados próximos aos deste estudo (EGGER et al., 2009; TABOADA; MURISON, 2010). Como relatado em estudo anterior por Hodgson, Colin e Chapman (1998), o efeito depressor do isofluorano 
provavelmente contribuiu para a sustentação da hipotensão arterial após o momento da indução.

Caulkett, Cantwell e Houston (1998) relataram que a pressão arterial avaliada com o Doppler em gatos anestesiados com isofluorano, quando comparada com a técnica invasiva, representa de forma acurada o valor da pressão arterial média, e não os valores de pressão arterial sistólica. Considerando tal informação, nenhum grupo neste estudo teria apresentado valores de pressão arterial considerados baixos (inferior a $60 \mathrm{mmHg}$ para pressão arterial média).

Quando comparados os momentos, todos os grupos apresentaram um incremento da pressão arterial sistólica durante a ligadura dos pedículos. Este aumento ocorreu, provavelmente, devido ao estímulo nociceptivo causado pelo momento da cirurgia. Certamente, o aumento da pressão decorrente de tal fato não é recomendável (EGGER et al., 2009). O emprego prévio da morfina objetivava promover analgesia suficiente para a realização do procedimento cirúrgico, porém foi possível observar que, em alguns momentos do procedimento cirúrgico, houve aumento da pressão arterial sistólica, das frequências respiratória e cardíaca, como conseqüência do estímulo cirúrgico. Este foi um fato inesperado, uma fez que a morfina apresentou melhores resultados analgésicos em gatos, na mesma dose deste estudo, quando comparada à metadona e buprenorfina (STEAGALL et al., 2006).

Cinco animais $(16,7 \%)$ apresentaram apnéia após a indução (dois do grupo GP, dois do grupo GPM e um do grupo GMP). No entanto, em quatro animais, a apnéia foi decorrente ou estava associada à obstrução da sonda 
endotraqueal devido presença de secreção na via aérea, não sendo, portanto, relacionada ao emprego dos fármacos propofol e midazolam. Certamente a velocidade de indução empregada neste estudo foi adequada em prevenir a apnéia, como foi sugerido por Brearley, Kellagher e Hall (1988). A apnéia também não foi observada em gatos anestesiados com propofol por Taboada e Murison (2010), nem por Sams et al. (2008), em cães. Entretanto, a ocorrência de apnéia já foi citada como o efeito adverso mais comum na indução com propofol em cães e gatos (MORGAN; LEGGE, 1989).

Houve redução dos valores médios da frequência respiratória em relação aos valores basais nos três grupos estudados, sendo que os valores mais baixos foram observados aos 10 minutos de anestesia. A depressão respiratória após indução com propofol também já foi relatada em gatos (BREARLEY; KELLAGHER; HALL, 1988; TABOADA; MURISON, 2010). É possível que o isofluorano tenha sido responsável pela manutenção da bradipnéia após a indução, devido sua ação depressora no centro respiratório no sistema nervoso central (STEFFEY; HOWLAND, 1977), embora Hodgson, Colin e Chapman (1998) não tenham observado a redução da frequência respiratória em gatos anestesiados exclusivamente com isofluorano. Da mesma forma, Covey-Crump e Murison (2010) relataram menores valores em cães cuja indução da anestesia foi realizada com propofol e midazolam do que naqueles onde a indução da anestesia foi exclusivamente com propofol, diferença que não foi observada no presente estudo.

Na comparação entre os três grupos, os valores médios da tensão de dióxido de carbono no ar expirado do grupo GP foram menores em relação aos outros dois grupos nos momentos de ligadura dos pedículos, sutura de 
musculatura e sutura de pele. Com estes resultados, pode-se presumir que o midazolam causou agravamento da hipoventilação, uma vez que a frequência respiratória se manteve similar entre os grupos. Souza et al. (2005), assim como no estudo em tela, não avaliaram o volume corrente; no entanto afirmam que há possibilidade da depressão dos centros ventilatórios e do relaxamento dos músculos intercostais terem reduzido a ventilação alveolar e contribuído para o aumento dos valores da tensão de dióxido de carbono no ar expirado. Cabe ressaltar que a hipoventilação pode ser esperada em gatas anestesiadas com isofluorano e sob respiração espontânea (HODGSON; COLIN; CHAPMAN, 1998). Os três grupos apresentaram valores médios de tensão de dióxido de carbono no ar expirado acima de $40 \mathrm{mmHg}$ durante 0 procedimento anestésico, principalmente após a indução da anestesia. Hikasa et al. (1997) encontraram valores semelhantes em gatos anestesiados com isofluorano (1,5 e 2,0 CAM), respirando espontaneamente, devido à ação depressora respiratória deste fármaco, associada à depressão respiratória causada pelo propofol.

Em relação à análise do pH e gases sanguíneos, foi possível observar que, aos 15 minutos de procedimento em todos os grupos, os valores de $\mathrm{pH}$ foram inferiores a 7,25 e retornaram para valores de normalidade ao término do procedimento cirúrgico. A mesma dinâmica ocorreu com os valores médios de pressão parcial de dióxido de carbono no sangue arterial que se apresentaram acima de $40 \mathrm{mmHg}$ no primeiro momento e abaixo deste valor na avaliação ao final da cirurgia. Estes resultados podem ser decorrentes da depressão respiratória causada pela indução da anestesia com propofol e midazolam e sugerem a ocorrência de acidose respiratória, corroborando 
com estudos anteriores (HIKASA et al., 1997; HODGSON; COLIN; CHAPMAN, 1998).

A fração inspirada de isofluorano foi menor no momento sutura de pele quando comparada aos 10 minutos de anestesia no grupo GPM. Embora esta tenha sido uma tendência dentro dos três grupos, somente o GPM apresentou diferença significante. Provavelmente isto ocorreu devido ao fato do momento sutura de pele representar estímulo cirúrgico limitado quando comparado ao momento da transição da indução com propofol para a anestesia inalatória, quando é necessário equilibrar as concentrações alveolar e sanguínea de isofluorano. Weaver e Raptopoulos (1990) recomendaram doses complementares de propofol após a intubação até que o anestésico inalatório alcançasse doses necessárias para anestesia, para evitar a administração de doses elevadas de anestésico inalatório neste momento. Doses complementares de propofol foram empregadas neste estudo (quando necessário), após a intubação, para complementar a indução. Estas doses foram contabilizadas como parte da indução.

No grupo GMP, nos momentos de ligadura do primeiro pedículo, ligadura do segundo pedículo, sutura da musculatura e sutura de pele, os valores foram inferiores aos observados aos 10 minutos de anestesia inalatória, provavelmente pelo mesmo motivo discutido na fração inspirada de isofluorano em relação aos valores observados no grupo GPM.

Embora não tenha havido diferença significante entre os momentos de temperatura retal avaliados (basal e pós-MPA), todos os valores médios foram menores no segundo momento. A diminuição da temperatura corpórea é um efeito usual da acepromazina, devido seu efeito vasodilatador bem 
como sua ação no centro da termorregulação (CORTOPASSI; FANTONI, 2010).

Os três formatos de indução não determinaram diferença no tempo de recuperação apesar da diferença da dose de propofol empregada. O grupo $\mathrm{GP}$, apesar de ter recebido a maior dose $(11,0 \pm 1,38 \mathrm{mg} / \mathrm{kg})$ teve o menor tempo de recuperação em quase todos os momentos (exceto na extubação, onde apresentou o mesmo tempo do grupo GPM). Isto se deve, provavelmente, a dificuldade de biotransformação do midazolam, uma vez que os gatos apresentam deficiência da enzima glucuronil transferase, levando ao prolongamento da recuperação dos animais dos grupos que receberam o benzodiazepínico (COURT; GREENBLATT, 2000).

A associação com midazolam não determinou alteração na intubação endotraqueal, uma vez que a qualidade foi similar entre os grupos (suave a regular). Entretanto, Covey-Crump e Murison (2008) observaram, em cães, melhores condições de intubação quando o midazolam foi associado ao propofol; o mesmo já havia sido relatado em humanos (MURPHY; ERSKINE; LANGTON, 1994).

A associação de fármacos, visando uma anestesia balanceada e mais segura é uma opção com muitas possibilidades a serem exploradas na medicina veterinária, principalmente em felinos.

Os protocolos avaliados neste estudo podem ser empregados em outros procedimentos cirúrgicos, assim como outras doses podem ser testadas, visando buscar estabilidade cardiovascular e respiratória e melhor analgesia transoperatória. 


\section{CONCLUSÃO}

De acordo com os resultados obtidos, foi possível concluir:

- A dose de propofol para indução da anestesia em gatas é reduzida em 34\% quando o propofol é precedido pelo midazolam;

- A associação com midazolam não intensificou o relaxamento muscular promovido pelo propofol, não interferindo assim na qualidade de intubação endotraqueal das gatas;

- O uso prévio de midazolam em relação ao propofol na indução da anestesia não determinou agitação, tampouco excitação nas gatas; ambas as seqüências de administração da associação propofolmidazolam são factíveis, porém a seqüência propofol-midazolam se mostrou superior devido a menor dose empregada de propofol;

- Do ponto de vista clínico, a associação com midazolam determinou prolongamento do tempo de recuperação das gatas, mas não desencadeou efeitos adversos no momento de despertar. 


\section{REFERÊNCIAS}

ANDRESS, J. L.; DAY, T. K.; DAY, D. G. The effects of consecutive day propofol anesthesia on feline red blood cells. Veterinary Surgery, v. 24, n. 3, p. 277-282, 1995.

AUSTIN, M. P.; MITCHELL, P. B. Psychotropic medication in pregnant woman: treatment dilemmas. The Medical Journal of Australia, v. 169, n. 8, p. 428-431, 1998.

BAILEY, P. L.; EGAN, T. D.; STANLEY, T. H. Intravenous opioid anesthetics. In: MILLER, R. D. Miller's anesthesia. 5. ed. New York: Churchill, 2000. v. 5, p. 273-376.

BARNHART, M. D.; HUBELL, J. A. N.; MUIR, W. W. Evaluation of the analgesic properties of acepromazine maleate, oxymorphone and a combination of acepromazine-oxymorphone. Veterinary Anesthesia and Analgesia, v. 27, n. 2, p. 89-96, 2000.

BEDNARSKI, R. M.; MAJORS, L. J. Ketamine and the arrhythmogenic dose of epinephrine in cats anesthetized with halothane and isoflurane. American Journal of Veterinary Research, v. 47, n. 10, p. 2122-2125, 1986.

BLEY, C. R.; ROSS, M.; PRICE, J. Clinical assessment of repeated propofolassociated anesthesia in cats. Journal of the American Veterinary Medical Association, v. 231, n. 9, p. 1347-1353, 2007.

BREARLEY, J. C. Sedation, premedication and analgesia. In: HALL, L. M.; TAYLOR, P. M. Anesthesia of the cat. London: Baillière Tindall, 1994. p. 111-128.

BREARLEY, J. C.; KELLAGHER, R. E. B.; HALL, L. W. Propofol anesthesia in cats. Journal of Small Animal Practice, v. 29, n. 5, p. 315-322, 1988.

BRODBELT, D. C.; PFEIFFER, D. U.; YOUNG, L. E.; WOOD, J. L. N. Risk factors for anaesthetic-related death in cats: results from the confidential enquiry into perioperative small animal fatalities (CEPSAF). British Journal of Anaesthesia, v. 99, n. 5, p. 617-623, 2007. 
CAULKETT, N. A.; CANTWELL, S. L.; HOUSTON, D. M. A comparison of indirect blood pressure monitoring techniques in the anesthetized cat. Veterinary Surgery, v. 27, n. 4, p. 370-377, 1998.

CLAEYS, M. A.; GEPTS, E.; CAMU, F. Haemodynamic changes during anaesthesia induced and maintained with propofol. British Journal of Anesthesia, v. 60, n. 1, p. 3-9, 1988.

CLARKE, K. W.; HALL, L. W. A survey of anesthesia in small animal practice: AVA/BSAVA report. Veterinary Anaesthesia and Analgesia, v. 17, n. 1, p. 4-10, 1990.

CORTOPASSI, S. R. G.; FANTONI, D. T. Medicação pré-anestésica. In: FANTONI, D. T.; CORTOPASSI, S. R. G. Anestesia em cães e gatos. 2. ed. São Paulo: Roca, 2010. p. 228- 236.

COURT, M. H.; GREENBLATT, D. J. Molecular genetic basis for deficient acetaminophen glucuronidation by cats: UGT1A6 is a pseudogene, and evidence for reduced diversity of expressed hepatic UGT1 isoforms.

Pharmacogenetics, v. 10, n. 4, p. 355-396, 2000.

COVEY-CRUMP, G. L.; MURISON, P. J. Fentanyl or midazolam for coinduction for anesthesia with propofol in dogs. Veterinary Anesthesia and Analgesia, v. 35, n. 6, p. 463-472, 2008.

DRUMMOND, J. C.; TODD, M. M.; SHAPIRO, M. Minimal alveolar concentration for halothane, enflurane, and isoflurane in the cat. Journal of the American Veterinary Medical Association, v. 182, n. 10, p. 1099-1101, 1983.

DYSON, D. H.; ALLEN, D. G.; INGWERSEN, W.; PASCOE, P. J. Evaluatian of acepromazine/meperidine/atropine premedication followed by thiopental anesthesia in the cat. Canadian Journal of veterinary research. v. 52, n. 4, p. 419-422, 1988.

DYSON, D. H.; MAXIE, M. G.; SCHNURR, D. Morbidity and mortality associated with anesthetic management in small animal veterinary practice in ontario. Jornal of american animal hospital association. v. 34, n. 4, p. 32535, 1998. 
DYSON, D. H.; PASCOE, P. J.; HONEYMAN, V. Comparison of the efficacy of three premedicants administered to cats. Canadian Veterinary Journal, v. 33, n. 7, p. 462-464, 1992.

EGER, E. I. Isoflurane: a review. Anesthesiology, v. 55, n. 5, p. 559-576, 1981.

EGGER, C.; MCCRACKIN, M. A.; HOFMEISTER, E.; TOUZOT-JOURDE, G.; ROHRBACH, B. Efficacy of preanesthetic intramuscular administration of ephedrine for prevention of anesthesia-induced hypotension in cats and dogs. The Canadian Veterinary Journal, v. 50, n. 2, p. 179-184, 2009.

GEEL, J. K. The effect of premedication on the induction dose of propofol in dogs and cats. Journal of South African Veterinary Association, v. 62, n. 3, p. 118-123, 1991.

GORENSTEIN, C.; POMPÉIA, S. Farmacocinética e farmacodinâmica dos benzodiazepínicos. In: BERNIK, M. A. Benzodiazepínicos: quatro décadas de uso. São Paulo: Edusp, 1999. p. 29-44.

GROSS, M. E.; SMITH, J. A.; TRANQUILLI, W. J. Cardiorespiratory effects of combined midazolam and butorphanol in isoflurane-anesthetized cats.

Veterinary Surgery, v. 22, n. 2, p. 159-162, 1993.

HIKASA, Y.; KAWANABE, H.; TAKASE, K.; OGASAWARA, S. Comparisons of sevoflurane, isoflurane and halothane anesthesia in spontaneously breathing cats. Veterinary Surgery, v. 25, p. 234-243, 1996.

HIKASA, Y; OHE, N.; TAKASE, K.; OGASAWARA, S. Cardiovascular effects of sevoflurane in cats: comparison with isoflurane, halothane, and enflurane. Research in Veterinary Science, v. 63, n. 3, p. 205-210, 1997.

HODGSON, D. S.; COLIN, I. D.; CHAPMAN, P. L. Cardiopulmonary effects of anesthesia induced and maintained with isoflurane in cats. American Journal of Veterinary Research, v. 59, n. 2, p. 182-185, 1998.

HOLADAY, D. A.; FISEROVA-BERGERUVA, V.; LATTO, I. P. Resistence of isoflurane to biotransformation in man. Anesthesiology, v. 43, n. 3, p. 325332, 1975. 
ILKIW, J. E.; SUTER, C. M.; FARVER, T. B.; MCNEAL, D.; STEFFEY, E. P. The behavior of healthy cats following intravenous and intramuscular administration of midazolam. Veterinary Journal of Pharmacology and Therapeutics, v. 19, n. 3, p. 205-216, 1996.

INGWERSEN, W.; ALLEN, D. G.; DYSON, D. H.; PASCOE, P. J.; O'GRADY, M. R. Cardiovascular effects of a ketamine hydrochloride / acepromazine combination in healthy cats. Canadian Journal of Veterinary Research, $v$. 52, n. 1, p. 1-4, 1988.

KO, J. C. H.; PAYTON, M. E.; WHITE, A. G. Effects of intravenous diazepam or microdose medetomidine in propofol-induced sedation. Journal of the American Animal Hospital Association, v. 42, n. 1, p. 18-27, 2006.

LASCELLES, D.; WATERMAN, A. Analgesia in cats. In Practice, v. 19, n. 4, p. 203-213, 1997.

LAUDA, J. P. Midazolam: avaliação clínica como agente indutor em anestesia geral. Revista Brasileira de Anestesiologia, v. 39, n. 1, p. 65-68, 1989.

MASSONE, F.; CORTOPASSI, S. R. G. Anestesia intrevenosa. In: FANTONI, D. T.; CORTOPASSI, S. R. G. Anestesia em cães e gatos. 2. ed. São Paulo: Roca, 2010. p. 228- 236.

MATOT, I.; NEELY, C. F.; KATZ, R. Y.; NEUFELD, G. R. Pulmonary uptake of propofol in cats. Anestthesiology, v. 78, n. 6, p. 1157-1165, 1993.

MENDES, G. M.; SELMI, A. L.; BARBUDO-SELMI, G. R.; LINS, B. T.; FIGUEIREDO, J. P. Clinical use of dexmedetomidine as premedicant in cats undergoing propofol-sevoflurane anesthesia. Journal of Feline Medicine and Surgery, v. 5, n. 5, p. 265-270, 2003.

MORGAN, D. W. T.; LEGGE, K. Clinical evaluation of propofol as intravenous anesthetic agent in cats and dogs. Veterinary Record, v. 124, n. 2, p. 31-33, 1989.

NOCITI, J. R. Anestesia venosa: farmacologia. In: YAMAHITA, A. M.; TAKAOKA, F.; AULER JR., J. O. C.; IWATA, N. M. Anestesiologia. 5. ed. São Paulo: Atheneu, 2001. p. 523-538. 
PASCOE, P. J.; ILKIW, J. E.; KOLLIAS-BAKER, C. The effects of ketamine on the minimum alveolar concentration os isoflurane in cats. Veterinary

Anaesthesia and Analgesia, v. 34, n. 1, p. 31-39, 2007.

PAWSON, P.; FORSYTH, S. Anesthetic agents. In: MADDISON, J.; PAGE, S.; $\mathrm{CHURCH}$, D. Small animal clinical pharmacology. London: Saunders, 2002. p. 69-100.

PIERI, L. Preclinical pharmacology of midazolam. British Journal of Clinical Pharmacology, v. 16, p. 17S-27S, 1983.

SAMS, L.; BRAUN, C.; ALLMAN, D.; HOFMEISTER, E. A comparison of the effects of propofol and etomidate on the induction of anesthesia and on cardiopulmonary parameters in dog. Veterinary Anaesthesia and Analgesia, v. 35, n. 6, p. 488-494, 2008.

SANO, T.; NISHIMURA, R.; MOCHIZUKI, M.; HARA, Y.; TAGAWA, M.; SASAKI, N. Clinical usefulness of propofol as an anesthetic induction agent in dogs and cats. Journal of Veterinary Medical Science, v. 65, n. 5, p. 641643, 2003.

SHAH, S. S.; SANDA, S.; REGMI, N. L.; SASAKI, K.; SHIMODA, M. Caracterization of cytochrome P450-mediated drug metabolism in cats. Journal of Veterinary Pharmacology and Therapeutics, v. 30, n. 5, p. 422428, 2007.

SHORT, E.; BUFALARI, A. Propofol anesthesia. Veterinary Clinics of North America: small animal practice, v. 29, n. 3, p. 747-778, 1999.

SMITH, J. A.; GAYNOR, J. S.; BEDNARSKI, R. M. Adverses effects of administration of propofol with various preanesthetic regimens in dog. Journal of the American Veterinary Medical Association, v. 202, n. 7, p. 11111115, 1993.

SOUZA, A. P.; GUERRERO, P. N. H.; NISHIMORI, C. T.; PAULA, D. P.; SANTOS, P. S. P.; REZENDE, M. L.; NUNES, N. Cardiopulmonary and acidbase effects of desflurane and sevoflurane in spontaneously breathing cats. Journal of Feline Medicine and Surgery, v. 7, n. 2, p. 95-100, 2005.

SPINOSA, H. S.; GÓRNIAK, S. L. Tranqüilizantes relaxantes musculares de ação central. In: SPINOSA, H. S.; GÓRNIAK, S. L.; BERNARDI, M. M. 
Farmacologia aplicada à medicina veterinária. 3. ed. Rio de Janeiro: Guanabara Koogan, 1996. p. 131-139.

STEAGALL, P. V. M.; CARNICELLI, P.; TAYLOR, P. M.; LUNA, S. P. L.; DIXON, M. J.; FERREIRA, T. H. Effects of subcutaneous methadone, morphine, buprenorphine or saline on thermal and pressure thresholds in cats. Journal of Veterinary Pharmacology and Therapeutics, v. 29, n. 6, p. 531-537, 2006.

STEAGALL, P. V. M.; TAYLOR, P. M.; BRONDANI, J. T.; LUNA, S. P. L.; DIXON, M. J. Antinociceptive effects of tramadol and acepromazina in cats. Journal of Feline Medicine and Surgery, v. 10, n. 1, p. 24-31, 2008.

STEFFEY, E. P.; HOWLAND, D. Isoflurane potency in the dog and cat. American Journal of Veterinary Research, v. 38, n. 11, p. 1833-1836, 1977.

STEGMANN, G. F.; BESTER, L. Some clinical effects of midazolam premedication in propofol-induced and isofluorane-maintained anesthesia in dogs during ovariohysterectomy. Journal of South Africa Veterinary Association, v. 72, n. 4, p. 214-216, 2001.

STOELTING, R. K. Benzodiazepines. In: STOELTING, R. K. Pharmacology \& physiology in anesthesia practice. 3. ed. Philadelphia: Lippincott Willians \& Wilkins, 1999. p. 128-132.

TABOADA, F. M.; MURISON, P. J. Induction of anesthesia with alfaxalone or propofol before isoflurane maintenance in cats. Veterinary Record, v. 167, n. 3, p. 85-89, 2010.

WEAVER, B. M. Q.; RAPTOPOULOS, D. Induction of anesthesia in dogs and cats with propofol. Veterinary Record, v. 126, n. 25, p. 617-620, 1990.

YANG, C. Y.; LUK, H. N.; CHEN, S. Y. Propofol inhibits medular pressor mechanism in cats. Canadian Journal of Anaesthesiology, v. 44, n. 7, p. 775-781, 1997. 


\section{APÊNDICES}

Apêndice A - Valores individuais, médias e desvios-padrão da freqüência cardíaca (batimentos por minuto) dos animais do grupo propofol (GP), nos diferentes momentos de avaliação

\begin{tabular}{|c|c|c|c|c|c|c|c|c|c|}
\hline \multicolumn{10}{|c|}{ Momentos de Avaliação } \\
\hline Animais & Basal & $\begin{array}{l}\text { Pós } \\
\text { MPA }\end{array}$ & $\begin{array}{l}10 \\
\mathrm{~min}\end{array}$ & $\begin{array}{c}\text { Incisão } \\
\text { pele }\end{array}$ & $\begin{array}{l}\text { Abertura } \\
\text { cavidade }\end{array}$ & $\begin{array}{c}\text { Pedículo } \\
1\end{array}$ & $\begin{array}{c}\text { Pedículo } \\
2\end{array}$ & $\begin{array}{l}\text { Sutura } \\
\text { muscular }\end{array}$ & $\begin{array}{c}\text { Sutura } \\
\text { pele }\end{array}$ \\
\hline 1 & 258 & 204 & 120 & 115 & 129 & 138 & 126 & 123 & 112 \\
\hline 2 & 192 & 140 & 108 & 129 & 147 & 155 & 153 & 152 & 150 \\
\hline 3 & 200 & 250 & 141 & 116 & 115 & 114 & 117 & 107 & 106 \\
\hline 4 & 158 & 290 & 146 & 144 & 170 & 193 & 173 & 177 & 168 \\
\hline 5 & 200 & 200 & 143 & 138 & 145 & 165 & 163 & 158 & 158 \\
\hline 6 & 180 & 180 & 101 & 105 & 108 & 132 & 135 & 119 & 103 \\
\hline 7 & 180 & 116 & 134 & 110 & 116 & 123 & 124 & 120 & 120 \\
\hline 8 & 204 & 200 & 145 & 131 & 125 & 132 & 123 & 115 & 116 \\
\hline 9 & 188 & 204 & 153 & 173 & 173 & 194 & 191 & 177 & 176 \\
\hline 10 & 224 & 220 & 121 & 106 & 110 & 168 & 174 & 148 & 150 \\
\hline Media & 198 & 200 & 131 & 127 & 134 & 151 & 148 & 140 & 136 \\
\hline $\mathrm{DP}$ & 27,29 & 49,54 & 17,66 & 21,15 & 23,92 & 28,20 & 26,28 & 26,06 & 27,33 \\
\hline
\end{tabular}


Apêndice B - Valores individuais, médias e desvios-padrão da freqüência cardíaca (batimentos por minuto) dos animais do grupo propofol-midazolam (GPM), nos diferentes momentos de avaliação

\begin{tabular}{|c|c|c|c|c|c|c|c|c|c|}
\hline \multirow[b]{2}{*}{ Animais } & \multicolumn{8}{|c|}{ Momentos de Avaliação } & \multirow[b]{2}{*}{$\begin{array}{c}\text { Sutura } \\
\text { pele }\end{array}$} \\
\hline & Basal & $\begin{array}{l}\text { Pós } \\
\text { MPA }\end{array}$ & $\begin{array}{l}10 \\
\text { min }\end{array}$ & $\begin{array}{c}\text { Incisão } \\
\text { pele }\end{array}$ & $\begin{array}{l}\text { Abertura } \\
\text { cavidade }\end{array}$ & $\begin{array}{c}\text { Pedículo } \\
1 \\
\end{array}$ & $\begin{array}{c}\text { Pedículo } \\
2\end{array}$ & $\begin{array}{c}\text { Sutura } \\
\text { muscular }\end{array}$ & \\
\hline 11 & 200 & 280 & 146 & 147 & 148 & 175 & 180 & 165 & 164 \\
\hline 12 & 200 & 250 & 123 & 143 & 143 & 142 & 146 & 143 & 142 \\
\hline 13 & 160 & 232 & 171 & 17 & 152 & 175 & 181 & 171 & 156 \\
\hline 14 & 182 & 172 & 151 & 128 & 130 & 154 & 151 & 148 & 134 \\
\hline 15 & 208 & 204 & 105 & 102 & 129 & 152 & 145 & 147 & 151 \\
\hline 16 & 190 & 171 & 158 & 157 & 159 & 190 & 178 & 149 & 143 \\
\hline 17 & 240 & 196 & 124 & 120 & 135 & 177 & 187 & 131 & 115 \\
\hline 18 & 210 & 220 & 155 & 142 & 156 & 157 & 154 & 148 & 158 \\
\hline 19 & 220 & 196 & 120 & 147 & 163 & 187 & 177 & 161 & 155 \\
\hline 20 & 225 & 208 & 158 & 166 & 155 & 177 & 171 & 178 & 180 \\
\hline Media & 204 & 213 & 141 & 127 & 147 & 169 & 167 & 154 & 150 \\
\hline DP & 23 & 34 & 21 & 43 & 12 & 16 & 16 & 14 & 18 \\
\hline
\end{tabular}


Apêndice C - Valores individuais, médias e desvios-padrão da freqüência cardíaca (batimentos por minuto) dos animais do grupo midazolam-propofol (GMP), nos diferentes momentos de avaliação

\begin{tabular}{cccccccccc}
\hline & \multicolumn{7}{c}{ Momentos de Avaliação } \\
\cline { 2 - 10 } Animais & Basal & Pós & $\begin{array}{c}10 \\
\text { MPA }\end{array}$ & $\begin{array}{c}\text { Incisão } \\
\text { min }\end{array}$ & $\begin{array}{c}\text { Abertura } \\
\text { cavidade }\end{array}$ & $\begin{array}{c}\text { Pedículo } \\
\text { calículo }\end{array}$ & $\begin{array}{c}\text { Peditura } \\
\text { Se }\end{array}$ & $\begin{array}{c}\text { Sutura } \\
\text { muscular }\end{array}$ & pele \\
\hline 21 & 200 & 280 & 146 & 147 & 148 & 175 & 180 & 165 & 164 \\
22 & 200 & 250 & 123 & 143 & 143 & 142 & 146 & 143 & 142 \\
23 & 160 & 232 & 171 & 17 & 152 & 175 & 181 & 171 & 156 \\
24 & 182 & 172 & 151 & 128 & 130 & 154 & 151 & 148 & 134 \\
25 & 208 & 204 & 105 & 102 & 129 & 152 & 145 & 147 & 151 \\
26 & 190 & 171 & 158 & 157 & 159 & 190 & 178 & 149 & 143 \\
27 & 240 & 196 & 124 & 120 & 135 & 177 & 187 & 131 & 115 \\
28 & 210 & 220 & 155 & 142 & 156 & 157 & 154 & 148 & 158 \\
29 & 220 & 196 & 120 & 147 & 163 & 187 & 177 & 161 & 155 \\
30 & 225 & 208 & 158 & 166 & 155 & 177 & 171 & 178 & 180 \\
\hline Media & 200 & 213 & 140 & 137 & 139 & 143 & 142 & 138 & 135 \\
\hline DP & 33 & 43 & 24 & 11 & 10 & 12 & 17 & 15 & 16 \\
\hline DP - desvio-padrão & & & & & & &
\end{tabular}


Apêndice D - Valores individuais, médias e desvios-padrão da pressão arterial sistólica $(\mathrm{mmHg})$ dos animais do grupo propofol (GP), nos diferentes momentos de avaliação

\begin{tabular}{cccccccccc}
\hline & \multicolumn{10}{c}{ Momentos de Avaliação } \\
\cline { 2 - 10 } Animais & Basal & $\begin{array}{c}\text { Pós } \\
\text { MPA }\end{array}$ & $\begin{array}{c}\text { 10 } \\
\text { min }\end{array}$ & $\begin{array}{l}\text { Incisão } \\
\text { pele }\end{array}$ & $\begin{array}{c}\text { Abertura } \\
\text { cavidade }\end{array}$ & $\begin{array}{c}\text { Pedículo } \\
1\end{array}$ & $\begin{array}{c}\text { Pedículo } \\
2\end{array}$ & $\begin{array}{c}\text { Sutura } \\
\text { muscular }\end{array}$ & $\begin{array}{c}\text { Sutura } \\
\text { pele }\end{array}$ \\
\hline 1 & 106 & 81 & 60 & 66 & 78 & 122 & 121 & 86 & 80 \\
2 & 130 & 98 & 45 & 68 & 138 & 80 & 110 & 150 & 113 \\
3 & 138 & 190 & 63 & 58 & 65 & 74 & 76 & 68 & 74 \\
4 & 152 & 97 & 58 & 71 & 64 & 84 & 72 & 80 & 90 \\
5 & 130 & 78 & 80 & 66 & 118 & 140 & 126 & 80 & 80 \\
6 & 108 & 86 & 50 & 70 & 70 & 89 & 92 & 80 & 70 \\
7 & 150 & 90 & 60 & 68 & 76 & 86 & 90 & 69 & 92 \\
8 & 175 & 80 & 60 & 70 & 78 & 90 & 88 & 60 & 63 \\
9 & 128 & 92 & 80 & 84 & 70 & 120 & 110 & 100 & 94 \\
10 & 122 & 92 & 68 & 80 & 120 & 128 & 132 & 86 & 90 \\
\hline Media & 134 & 98 & 62 & 70 & 88 & 101 & 102 & 86 & 85 \\
\hline DP & 20,95 & 32,92 & 11,28 & 7,31 & 26,92 & 23,57 & 21,03 & 25,14 & 14,31 \\
\hline DP- desvio-padrão & & 70 & & & & &
\end{tabular}


Apêndice E - Valores individuais, médias e desvios-padrão da pressão arterial sistólica $(\mathrm{mmHg})$ dos animais do grupo propofol-midazolam (GPM), nos diferentes momentos de avaliação

\begin{tabular}{cccccccccc}
\hline & \multicolumn{7}{c}{ Momentos de Avaliação } \\
\cline { 2 - 10 } Animais & Basal & $\begin{array}{c}\text { Pós } \\
\text { MPA }\end{array}$ & $\begin{array}{c}10 \\
\text { min }\end{array}$ & $\begin{array}{c}\text { Incisão } \\
\text { pele }\end{array}$ & $\begin{array}{c}\text { Abertura } \\
\text { cavidade }\end{array}$ & $\begin{array}{c}\text { Pedículo } \\
1\end{array}$ & $\begin{array}{c}\text { Pedículo } \\
2\end{array}$ & $\begin{array}{c}\text { Sutura } \\
\text { muscular }\end{array}$ & $\begin{array}{c}\text { Sutura } \\
\text { pele }\end{array}$ \\
\hline 11 & 112 & 80 & 50 & 63 & 62 & 90 & 112 & 88 & 88 \\
12 & 110 & 80 & 54 & 60 & 60 & 70 & 86 & 66 & 60 \\
13 & 110 & 83 & 64 & 62 & 68 & 150 & 120 & 96 & 74 \\
14 & 105 & 87 & 60 & 50 & 60 & 80 & 84 & 70 & 68 \\
15 & 110 & 81 & 64 & 78 & 80 & 80 & 78 & 72 & 74 \\
16 & 120 & 96 & 68 & 70 & 70 & 102 & 114 & 90 & 82 \\
17 & 187 & 79 & 70 & 62 & 75 & 78 & 68 & 60 & 58 \\
18 & 137 & 72 & 60 & 64 & 85 & 80 & 95 & 73 & 78 \\
19 & 110 & 74 & 70 & 92 & 81 & 122 & 110 & 70 & 70 \\
20 & 133 & 125 & 70 & 70 & 70 & 100 & 80 & 80 & 80 \\
\hline Media & 123 & 86 & 63 & 67 & 71 & 95 & 95 & 77 & 73 \\
\hline DP & 24,77 & 15,33 & 7,01 & 11,44 & 8,99 & 24,59 & 18,09 & 11,58 & 9,48 \\
\hline DP - desvio-padrão & & & & & & &
\end{tabular}


Apêndice F - Valores individuais, médias e desvios-padrão da pressão arterial sistólica $(\mathrm{mmHg})$ dos animais do grupo midazolam-propofol (GMP), nos diferentes momentos de avaliação

\begin{tabular}{cccccccccc}
\hline & \multicolumn{7}{c}{ Momentos de Avaliação } \\
\cline { 2 - 10 } Animais & Basal & $\begin{array}{c}\text { Pós } \\
\text { MPA }\end{array}$ & $\begin{array}{c}10 \\
\text { min }\end{array}$ & $\begin{array}{c}\text { Incisão } \\
\text { pele }\end{array}$ & $\begin{array}{c}\text { Abertura } \\
\text { cavidade }\end{array}$ & $\begin{array}{c}\text { Pedículo } \\
1\end{array}$ & $\begin{array}{c}\text { Pedículo } \\
2\end{array}$ & $\begin{array}{c}\text { Sutura } \\
\text { muscular }\end{array}$ & $\begin{array}{c}\text { Sutura } \\
\text { pele }\end{array}$ \\
\hline 21 & 143 & 92 & 55 & 66 & 60 & 105 & 84 & 74 & 74 \\
22 & 138 & 111 & 46 & 76 & 82 & 80 & 110 & 90 & 90 \\
23 & 135 & 135 & 65 & 84 & 78 & 98 & 70 & 62 & 66 \\
24 & 110 & 87 & 80 & 72 & 68 & 84 & 90 & 74 & 70 \\
25 & 140 & 112 & 40 & 60 & 60 & 68 & 68 & 65 & 68 \\
26 & 123 & 104 & 60 & 70 & 79 & 78 & 68 & 58 & 70 \\
27 & 122 & 96 & 50 & 80 & 60 & 52 & 59 & 68 & 63 \\
28 & 125 & 94 & 80 & 80 & 70 & 84 & 80 & 65 & 65 \\
29 & 126 & 102 & 67 & 75 & 86 & 87 & 82 & 83 & 82 \\
30 & 115 & 72 & 63 & 85 & 70 & 80 & 100 & 100 & 108 \\
\hline Media & 128 & 101 & 61 & 75 & 71 & 82 & 81 & 74 & 76 \\
\hline DP & 10,98 & 16,92 & 13,33 & 7,97 & 9,62 & 14,67 & 15,77 & 13,38 & 14,08 \\
\hline DP - desvio-padrão & & & & & & &
\end{tabular}


Apêndice G - Valores individuais, médias e desvios-padrão da freqüência respiratória (movimentos por minuto) dos animais do grupo propofol (GP), nos diferentes momentos de avaliação

\begin{tabular}{|c|c|c|c|c|c|c|c|c|c|}
\hline \multirow[b]{2}{*}{ Animais } & \multicolumn{8}{|c|}{ Momentos de Avaliação } & \multirow[b]{2}{*}{$\begin{array}{c}\text { Sutura } \\
\text { pele }\end{array}$} \\
\hline & Basal & $\begin{array}{l}\text { Pós } \\
\text { MPA }\end{array}$ & $\begin{array}{l}10 \\
\min \end{array}$ & $\begin{array}{c}\text { Incisão } \\
\text { pele }\end{array}$ & $\begin{array}{l}\text { Abertura } \\
\text { cavidade }\end{array}$ & $\begin{array}{c}\text { Pedículo } \\
1\end{array}$ & $\begin{array}{c}\text { Pedículo } \\
2\end{array}$ & $\begin{array}{l}\text { Sutura } \\
\text { muscular }\end{array}$ & \\
\hline 1 & 80 & 44 & 14 & 15 & 20 & 21 & 18 & 21 & 16 \\
\hline 2 & 44 & 40 & 5 & 25 & 22 & 24 & 24 & 26 & 25 \\
\hline 3 & 84 & 28 & 7 & 6 & 5 & 7 & 5 & 6 & 8 \\
\hline 4 & 52 & 52 & 14 & 11 & 14 & 18 & 16 & 17 & 16 \\
\hline 5 & 36 & 44 & 27 & 23 & 29 & 26 & 22 & 23 & 24 \\
\hline 6 & 72 & 68 & 13 & 12 & 9 & 15 & 17 & 15 & 13 \\
\hline 7 & 48 & 36 & 20 & 28 & 33 & 34 & 32 & 32 & 36 \\
\hline 8 & 28 & 24 & 8 & 8 & 7 & 8 & 9 & 9 & 7 \\
\hline 9 & 36 & 40 & 7 & 10 & 13 & 19 & 21 & 25 & 25 \\
\hline 10 & 40 & 44 & 12 & 13 & 20 & 20 & 16 & 22 & 22 \\
\hline Media & 52 & 42 & 13 & 15 & 17 & 19 & 18 & 20 & 19 \\
\hline DP & 19,78 & 12,26 & 6,73 & 7,58 & 9,28 & 8,07 & 7,57 & 7,95 & 8,90 \\
\hline
\end{tabular}


Apêndice H - Valores individuais, médias e desvios-padrão da freqüência respiratória (movimentos por minuto) dos animais do grupo propofol-midazolam (GPM), nos diferentes momentos de avaliação

\begin{tabular}{lccccccccc}
\hline & \multicolumn{7}{c}{ Momentos de Avaliação } \\
\cline { 2 - 10 } & Basal & $\begin{array}{c}\text { Pós } \\
\text { MPA }\end{array}$ & $\begin{array}{c}10 \\
\text { min }\end{array}$ & $\begin{array}{c}\text { Incisão } \\
\text { pele }\end{array}$ & $\begin{array}{c}\text { Abertura } \\
\text { cavidade }\end{array}$ & $\begin{array}{c}\text { Pedículo } \\
\text { Pedículo }\end{array}$ & $\begin{array}{c}\text { Sutura } \\
\text { muscular }\end{array}$ & $\begin{array}{c}\text { Sutura } \\
\text { pele }\end{array}$ \\
\hline 11 & 28 & 44 & 10 & 10 & 10 & 16 & 16 & 17 & 17 \\
12 & 56 & 33 & 8 & 10 & 12 & 14 & 17 & 14 & 12 \\
13 & 96 & 44 & 26 & 18 & 25 & 25 & 25 & 24 & 22 \\
14 & 48 & 60 & 10 & 9 & 9 & 9 & 14 & 14 & 13 \\
15 & 88 & 96 & 25 & 21 & 26 & 36 & 32 & 29 & 31 \\
16 & 40 & 36 & 11 & 20 & 20 & 25 & 23 & 21 & 20 \\
17 & 88 & 52 & 16 & 12 & 19 & 14 & 16 & 15 & 15 \\
18 & 26 & 43 & 17 & 14 & 15 & 15 & 13 & 14 & 19 \\
19 & 80 & 64 & 17 & 20 & 18 & 18 & 25 & 22 & 22 \\
20 & 60 & 60 & 4 & 6 & 5 & 9 & 9 & 13 & 13 \\
\hline Media & 61 & 53 & 14 & 14 & 16 & 18 & 19 & 18 & 18 \\
\hline DP & 25,81 & 18,32 & 7,17 & 5,40 & 6,94 & 8,36 & 6,99 & 5,42 & 5,78 \\
\hline \multicolumn{7}{c}{ DP - desvio-padrão } & & &
\end{tabular}


Apêndice I - Valores individuais, médias e desvios-padrão da freqüência respiratória (movimentos por minuto) dos animais do grupo midazolam-propofol (GMP), nos diferentes momentos de avaliação

\begin{tabular}{cccccccccc}
\hline & \multicolumn{7}{c}{ Momentos de Avaliação } \\
\cline { 2 - 10 } Animais & Basal & $\begin{array}{c}\text { Pós } \\
\text { MPA }\end{array}$ & $\begin{array}{c}10 \\
\text { min }\end{array}$ & $\begin{array}{c}\text { Incisão } \\
\text { pele }\end{array}$ & $\begin{array}{c}\text { Abertura } \\
\text { cavidade }\end{array}$ & $\begin{array}{c}\text { Pedículo } \\
\text { Pedículo }\end{array}$ & $\begin{array}{c}\text { Sutura } \\
\text { muscular }\end{array}$ & $\begin{array}{c}\text { Sutura } \\
\text { pele }\end{array}$ \\
\hline 21 & 96 & 63 & 13 & 11 & 12 & 12 & 13 & 13 & 13 \\
22 & 48 & 52 & 6 & 12 & 15 & 14 & 17 & 22 & 21 \\
23 & 60 & 72 & 24 & 33 & 39 & 38 & 49 & 25 & 22 \\
24 & 128 & 45 & 35 & 20 & 21 & 27 & 23 & 29 & 31 \\
25 & 32 & 37 & 10 & 13 & 13 & 13 & 13 & 14 & 13 \\
26 & 28 & 20 & 5 & 8 & 9 & 10 & 11 & 8 & 9 \\
27 & 20 & 28 & 6 & 6 & 8 & 13 & 13 & 15 & 13 \\
28 & 60 & 46 & 11 & 10 & 11 & 15 & 14 & 13 & 11 \\
29 & 90 & 48 & 15 & 18 & 24 & 15 & 14 & 20 & 15 \\
30 & 44 & 36 & 9 & 8 & 5 & 6 & 7 & 10 & 11 \\
\hline Media & 61 & 45 & 13 & 14 & 16 & 16 & 17 & 17 & 16 \\
\hline DP & 34,36 & 15,53 & 9,42 & 8,02 & 10,01 & 9,31 & 11,83 & 6,81 & 6,77 \\
\hline DP - desvio-padrão & & & & & & &
\end{tabular}


Apêndice J - Valores individuais, médias e desvios-padrão da tensão de dióxido de carbono no final da expiração $(\mathrm{mmHg})$ dos animais do grupo propofol (GP), nos diferentes momentos de avaliação

\begin{tabular}{|c|c|c|c|c|c|c|c|}
\hline \multirow[b]{2}{*}{ Animais } & \multicolumn{7}{|c|}{ Momentos de Avaliação } \\
\hline & $\begin{array}{l}10 \\
\min \end{array}$ & $\begin{array}{l}\text { Incisão } \\
\text { pele }\end{array}$ & $\begin{array}{l}\text { Abertura } \\
\text { cavidade }\end{array}$ & $\begin{array}{c}\text { Pedículo } \\
1\end{array}$ & $\begin{array}{c}\text { Pedículo } \\
2\end{array}$ & $\begin{array}{l}\text { Sutura } \\
\text { muscular }\end{array}$ & $\begin{array}{c}\text { Sutura } \\
\text { pele }\end{array}$ \\
\hline 1 & 47 & 44 & 42 & 37 & 38 & 40 & 42 \\
\hline 2 & 39 & 35 & 31 & 34 & 35 & 33 & 33 \\
\hline 3 & 37 & 39 & 39 & 42 & 44 & 38 & 35 \\
\hline 4 & 44 & 51 & 50 & 44 & 40 & 40 & 42 \\
\hline 5 & 33 & 41 & 41 & 40 & 42 & 41 & 40 \\
\hline 6 & 41 & 42 & 43 & 39 & 38 & 42 & 45 \\
\hline 7 & 46 & 43 & 40 & 34 & 31 & 30 & 32 \\
\hline 8 & 35 & 38 & 39 & 37 & 33 & 35 & 37 \\
\hline 9 & 60 & 51 & 51 & 44 & 48 & 42 & 41 \\
\hline 10 & 43 & 42 & 42 & 30 & 26 & 31 & 28 \\
\hline Media & 43 & 43 & 42 & 38 & 38 & 37 & 38 \\
\hline DP & 7,69 & 5,15 & 5,67 & 4,61 & 6,50 & 4,59 & 5,40 \\
\hline
\end{tabular}


Apêndice $K$ - Valores individuais, médias e desvios-padrão da tensão de dióxido de carbono no final da expiração $(\mathrm{mmHg})$ dos animais do grupo propofol-midazolam (GPM), nos diferentes momentos de avaliação

\begin{tabular}{cccccccc}
\hline & \multicolumn{7}{c}{ Momentos de Avaliação } \\
\cline { 2 - 8 } Animais & $\begin{array}{c}10 \\
\text { min }\end{array}$ & $\begin{array}{c}\text { Incisão } \\
\text { pele }\end{array}$ & $\begin{array}{c}\text { Abertura } \\
\text { cavidade }\end{array}$ & $\begin{array}{c}\text { Pedículo } \\
\text { cavedículo }\end{array}$ & $\begin{array}{c}\text { Sutura } \\
\text { muscular }\end{array}$ & $\begin{array}{c}\text { Sutura } \\
\text { pele }\end{array}$ \\
\hline 11 & 42 & 48 & 48 & 44 & 46 & 45 & 45 \\
12 & 53 & 54 & 57 & 53 & 49 & 46 & 44 \\
13 & 53 & 53 & 46 & 46 & 48 & 47 & 46 \\
14 & 48 & 53 & 51 & 46 & 49 & 48 & 50 \\
15 & 45 & 44 & 43 & 42 & 44 & 42 & 40 \\
16 & 64 & 54 & 59 & 53 & 48 & 48 & 50 \\
17 & 37 & 40 & 38 & 48 & 40 & 45 & 44 \\
18 & 42 & 47 & 50 & 50 & 48 & 50 & 45 \\
19 & 32 & 36 & 40 & 39 & 33 & 37 & 39 \\
20 & 40 & 45 & 45 & 40 & 37 & 35 & 34 \\
\hline Media & 46 & 47 & 48 & 46 & 44 & 44 & 44 \\
\hline DP & 9,25 & 6,26 & 6,80 & 4,98 & 5,65 & 4,90 & 4,92 \\
\hline DP - desvio-padrão & & & & & &
\end{tabular}


Apêndice L - Valores individuais, médias e desvios-padrão da tensão de dióxido de carbono no final da expiração $(\mathrm{mmHg})$ dos animais do grupo midazolam-propofol (GMP), nos diferentes momentos de avaliação

\begin{tabular}{cccccccc}
\hline & \multicolumn{7}{c}{ Momentos de Avaliação } \\
\cline { 2 - 8 } Animais & 10 min & $\begin{array}{c}\text { Incisão } \\
\text { pele }\end{array}$ & $\begin{array}{c}\text { Abertura } \\
\text { cavidade }\end{array}$ & $\begin{array}{c}\text { Pedículo } \\
\text { cancúculo }\end{array}$ & $\begin{array}{c}\text { Putura } \\
\text { Puscular }\end{array}$ & $\begin{array}{c}\text { Sutura } \\
\text { pele }\end{array}$ \\
\hline 21 & 41 & 41 & 39 & 41 & 38 & 41 & 39 \\
22 & 55 & 55 & 51 & 48 & 50 & 53 & 53 \\
23 & 47 & 46 & 42 & 39 & 42 & 44 & 44 \\
24 & 37 & 41 & 45 & 41 & 40 & 42 & 40 \\
25 & 43 & 51 & 48 & 48 & 48 & 46 & 48 \\
26 & 48 & 55 & 54 & 50 & 42 & 44 & 44 \\
27 & 53 & 51 & 51 & 44 & 43 & 43 & 44 \\
28 & 42 & 44 & 42 & 44 & 44 & 40 & 40 \\
29 & 53 & 44 & 40 & 33 & 36 & 35 & 38 \\
30 & 40 & 44 & 47 & 43 & 45 & 44 & 44 \\
\hline Media & 46 & 47 & 46 & 43 & 43 & 43 & 43 \\
\hline DP & 6,24 & 5,37 & 5,13 & 5,00 & 4,26 & 4,59 & 4,55 \\
\hline DP
\end{tabular}

DP - desvio-padrão 
Apêndice M - Valores individuais, médias e desvios-padrão da saturação da oxi-hemoglobina do sangue periférico (\%) dos animais do grupo propofol (GP), nos diferentes momentos de avaliação

\begin{tabular}{cccccccc}
\hline & \multicolumn{7}{c}{ Momentos de Avaliação } \\
\cline { 2 - 8 } Animais & $\begin{array}{c}10 \\
\text { min }\end{array}$ & $\begin{array}{c}\text { Incisão } \\
\text { pele }\end{array}$ & $\begin{array}{c}\text { Abertura } \\
\text { cavidade }\end{array}$ & $\begin{array}{c}\text { Pedículo } \\
\text { Pedículo }\end{array}$ & $\begin{array}{c}\text { Sutura } \\
\text { muscular }\end{array}$ & $\begin{array}{c}\text { Sutura } \\
\text { pele }\end{array}$ \\
\hline 1 & 100 & 100 & 99 & 100 & 100 & 100 & 100 \\
2 & 100 & 100 & 100 & 100 & 100 & 100 & 100 \\
3 & 100 & 100 & 100 & 100 & 100 & 100 & 100 \\
4 & 100 & 99 & 100 & 100 & 100 & 100 & 100 \\
5 & 100 & 100 & 100 & 100 & 100 & 100 & 100 \\
6 & 100 & 100 & 100 & 100 & 100 & 100 & 100 \\
7 & 100 & 99 & 99 & 99 & 99 & 98 & 100 \\
8 & 100 & 100 & 100 & 99 & 100 & 100 & 100 \\
9 & 99 & 100 & 100 & 99 & 100 & 100 & 99 \\
10 & 100 & 100 & 100 & 100 & 100 & 100 & 100 \\
\hline Media & 100 & 100 & 100 & 100 & 100 & 100 & 100 \\
\hline DP & 0,32 & 0,42 & 0,42 & 0,48 & 0,32 & 0,63 & 0,32 \\
\hline DP -desvio-padrão & & & & & &
\end{tabular}

DP - desvio-padrão 
Apêndice N - Valores individuais, médias e desvios-padrão da saturação da oxi-hemoglobina do sangue periférico (\%) dos animais do grupo propofol-midazolam (GPM), nos diferentes momentos de avaliação

\begin{tabular}{cccccccc}
\hline & \multicolumn{7}{c}{ Momentos de Avaliação } \\
\cline { 2 - 8 } Animais & $\begin{array}{c}10 \\
\text { min }\end{array}$ & $\begin{array}{c}\text { Incisão } \\
\text { pele }\end{array}$ & $\begin{array}{c}\text { Abertura } \\
\text { cavidade }\end{array}$ & $\begin{array}{c}\text { Pedículo } \\
1\end{array}$ & $\begin{array}{c}\text { Pedículo } \\
2\end{array}$ & $\begin{array}{c}\text { Sutura } \\
\text { muscular }\end{array}$ & $\begin{array}{c}\text { Sutura } \\
\text { pele }\end{array}$ \\
\hline 11 & 99 & 100 & 100 & 100 & 100 & 100 & 100 \\
12 & 100 & 100 & 100 & 100 & 100 & 100 & 100 \\
13 & 100 & 100 & 100 & 100 & 100 & 100 & 100 \\
14 & 100 & 100 & 100 & 100 & 100 & 100 & 100 \\
15 & 100 & 100 & 100 & 100 & 100 & 100 & 100 \\
16 & 100 & 99 & 100 & 100 & 98 & 100 & 100 \\
17 & 99 & 100 & 99 & 100 & 96 & 97 & 97 \\
18 & 100 & 99 & 99 & 100 & 99 & 100 & 100 \\
19 & 100 & 100 & 100 & 100 & 100 & 100 & 100 \\
20 & 100 & 100 & 100 & 100 & 100 & 100 & 100 \\
\hline Media & 100 & 100 & 100 & 100 & 99 & 100 & 100 \\
\hline DP & 0,42 & 0,42 & 0,42 & 0,00 & 1,34 & 0,95 & 0,95 \\
\hline DP - desvio-padrão & & & & & &
\end{tabular}


Apêndice O - Valores individuais, médias e desvios-padrão da saturação da oxi-hemoglobina do sangue periférico (\%) dos animais do grupo midazolam-propofol (GMP), nos diferentes momentos de avaliação

\begin{tabular}{cccccccc}
\hline & \multicolumn{7}{c}{ Momentos de Avaliação } \\
\cline { 2 - 8 } Animais & $\begin{array}{c}10 \\
\text { min }\end{array}$ & $\begin{array}{c}\text { Incisão } \\
\text { pele }\end{array}$ & $\begin{array}{c}\text { Abertura } \\
\text { cavidade }\end{array}$ & $\begin{array}{c}\text { Pedículo } \\
1\end{array}$ & $\begin{array}{c}\text { Pedículo } \\
2\end{array}$ & $\begin{array}{c}\text { Sutura } \\
\text { muscular }\end{array}$ & $\begin{array}{c}\text { Sutura } \\
\text { pele }\end{array}$ \\
\hline 21 & 98 & 98 & 98 & 99 & 99 & 100 & 100 \\
22 & 100 & 100 & 99 & 99 & 99 & 98 & 99 \\
23 & 100 & 100 & 100 & 100 & 100 & 100 & 100 \\
24 & 100 & 100 & 100 & 100 & 100 & 100 & 100 \\
25 & 100 & 100 & 100 & 100 & 100 & 100 & 100 \\
26 & 100 & 100 & 100 & 100 & 100 & 100 & 100 \\
27 & 100 & 100 & 100 & 100 & 100 & 100 & 100 \\
28 & 100 & 100 & 100 & 100 & 100 & 99 & 98 \\
29 & 100 & 100 & 100 & 100 & 100 & 100 & 100 \\
30 & 100 & 100 & 100 & 100 & 100 & 100 & 100 \\
\hline Media & 100 & 100 & 100 & 100 & 100 & 100 & 100 \\
\hline DP & 0,63 & 0,63 & 0,67 & 0,42 & 0,42 & 0,67 & 0,67 \\
\hline DP - desvio-padrão & & & & & &
\end{tabular}


Apêndice $P$ - Valores individuais, médias e desvios-padrão da fração expirada de isofluorano (\%) dos animais do grupo propofol (GP), nos diferentes momentos de avaliação

\begin{tabular}{|c|c|c|c|c|c|c|c|}
\hline \multirow[b]{2}{*}{ Animais } & \multicolumn{7}{|c|}{ Momentos de Avaliação } \\
\hline & $\begin{array}{l}10 \\
\min \end{array}$ & $\begin{array}{l}\text { Incisão } \\
\text { pele }\end{array}$ & $\begin{array}{l}\text { Abertura } \\
\text { cavidade }\end{array}$ & $\begin{array}{c}\text { Pedículo } \\
1\end{array}$ & $\begin{array}{c}\text { Pedículo } \\
2\end{array}$ & $\begin{array}{l}\text { Sutura } \\
\text { muscular }\end{array}$ & $\begin{array}{c}\text { Sutura } \\
\text { pele }\end{array}$ \\
\hline 1 & 1,3 & 1,5 & 1,4 & 1,4 & 1,7 & 1,8 & 1,8 \\
\hline 2 & 1,2 & 1,5 & 1,7 & 2,5 & 2 & 1,7 & 1,7 \\
\hline 3 & 1,2 & 1,4 & 1,2 & 1,3 & 1,4 & 1,2 & 1,1 \\
\hline 4 & 1,3 & 1,1 & 1,3 & 1,5 & 1,6 & 1,5 & 1,5 \\
\hline 5 & 1,2 & 1,7 & 1,3 & 1,6 & 2 & 1,4 & 1,4 \\
\hline 6 & 1,2 & 1,4 & 1,4 & 1,5 & 1,5 & 1,6 & 1,5 \\
\hline 7 & 1,4 & 1,2 & 1,2 & 1,3 & 1,3 & 1,9 & 1,2 \\
\hline 8 & 2,1 & 1,5 & 1,5 & 1,7 & 1,7 & 1,7 & 1,6 \\
\hline 9 & 1,2 & 1,4 & 1,4 & 1,5 & 1,7 & 1,7 & 1,7 \\
\hline 10 & 1,1 & 1,3 & 1,2 & 1,5 & 1,6 & 1,3 & 1,3 \\
\hline Media & 1,3 & 1,4 & 1,4 & 1,6 & 1,7 & 1,6 & 1,5 \\
\hline DP & 0,29 & 0,17 & 0,16 & 0,35 & 0,23 & 0,23 & 0,23 \\
\hline
\end{tabular}


Apêndice Q - Valores individuais, médias e desvios-padrão da fração expirada de isofluorano (\%) dos animais do grupo propofolmidazolam (GPM), nos diferentes momentos de avaliação

\begin{tabular}{|c|c|c|c|c|c|c|c|}
\hline \multirow[b]{2}{*}{ Animais } & \multicolumn{7}{|c|}{ Momentos de Avaliação } \\
\hline & $\begin{array}{c}10 \\
\min \end{array}$ & $\begin{array}{c}\text { Incisão } \\
\text { pele }\end{array}$ & $\begin{array}{l}\text { Abertura } \\
\text { cavidade }\end{array}$ & $\begin{array}{c}\text { Pedículo } \\
1\end{array}$ & $\begin{array}{c}\text { Pedículo } \\
2\end{array}$ & $\begin{array}{c}\text { Sutura } \\
\text { muscular }\end{array}$ & $\begin{array}{c}\text { Sutura } \\
\text { pele }\end{array}$ \\
\hline 11 & 1,6 & 1,2 & 1,2 & 1,1 & 1,2 & 1,2 & 1,3 \\
\hline 12 & 1,1 & 1,2 & 1,2 & 1,3 & 1,2 & 1,3 & 1,2 \\
\hline 13 & 1,2 & 1,4 & 1,5 & 1,5 & 1,4 & 1,4 & 1,5 \\
\hline 14 & 1,3 & 1,4 & 1,2 & 1,2 & 1,3 & 1,3 & 1,6 \\
\hline 15 & 1 & 1,3 & 1,3 & 1,4 & 1,4 & 1,3 & 1,3 \\
\hline 16 & 1,2 & 1,4 & 1,3 & 1,4 & 1,5 & 1,7 & 1,4 \\
\hline 17 & 1,5 & 1,7 & 1,6 & 1,3 & 1,5 & 1,4 & 1,4 \\
\hline 18 & 1,7 & 1,6 & 1,3 & 1,4 & 1,5 & 1,4 & 1,3 \\
\hline 19 & 2 & 1,3 & 1,6 & 1,5 & 1,7 & 1,7 & 1,5 \\
\hline 20 & 0,8 & 1,6 & 1,9 & 1,5 & 1,7 & 1,4 & 1,3 \\
\hline Media & 1,3 & 1,4 & 1,4 & 1,4 & 1,4 & 1,4 & 1,4 \\
\hline $\mathrm{DP}$ & 0,36 & 0,17 & 0,23 & 0,13 & 0,18 & 0,17 & 0,12 \\
\hline
\end{tabular}


Apêndice R - Valores individuais, médias e desvios-padrão da fração expirada de isofluorano (\%) dos animais do grupo midazolam-propofol (GMP), nos diferentes momentos de avaliação

\begin{tabular}{cccccccc}
\hline & \multicolumn{7}{c}{ Momentos de Avaliação } \\
\cline { 2 - 8 } Animais & $\begin{array}{c}10 \\
\text { min }\end{array}$ & $\begin{array}{c}\text { Incisão } \\
\text { pele }\end{array}$ & $\begin{array}{c}\text { Abertura } \\
\text { cavidade }\end{array}$ & $\begin{array}{c}\text { Pedículo } \\
\text { Pedículo }\end{array}$ & $\begin{array}{c}\text { Sutura } \\
\text { muscular }\end{array}$ & $\begin{array}{c}\text { Sutura } \\
\text { pele }\end{array}$ \\
\hline 21 & 1,2 & 1 & 1,3 & 1,3 & 1,4 & 1,3 & 1,3 \\
22 & 0,8 & 1,3 & 1,4 & 1,6 & 1,5 & 1,7 & 1,8 \\
23 & 1,2 & 1,3 & 1,4 & 1,8 & 1,7 & 1,8 & 1,8 \\
24 & 1,5 & 1,6 & 1,7 & 1,5 & 1,5 & 1,5 & 1,4 \\
25 & 1,5 & 1,2 & 1,3 & 1,3 & 1,3 & 1,3 & 1,2 \\
26 & 1,1 & 1,2 & 1,3 & 1,4 & 1,3 & 1,2 & 1 \\
27 & 1,2 & 1,1 & 1,2 & 1,3 & 1,2 & 1 & 1 \\
28 & 1,1 & 1,6 & 1,7 & 2,1 & 1,5 & 1,7 & 1,7 \\
29 & 1 & 1,1 & 1,2 & 1,8 & 2 & 1,8 & 1,9 \\
30 & 1,1 & 1,2 & 1,2 & 1,2 & 1,3 & 1,3 & 1,4 \\
\hline Media & 1,2 & 1,3 & 1,4 & 1,5 & 1,5 & 1,5 & 1,5 \\
\hline DP & 0,21 & 0,20 & 0,19 & 0,29 & 0,24 & 0,28 & 0,33 \\
\hline DP - desvio-padrão & & & & & &
\end{tabular}


Apêndice S - Valores individuais, médias e desvios-padrão da fração inspirada de isofluorano (\%) dos animais do grupo propofol (GP), nos diferentes momentos de avaliação

\begin{tabular}{cccccccc}
\hline & \multicolumn{7}{c}{ Momentos de Avaliação } \\
\cline { 2 - 8 } Animais & $\begin{array}{c}10 \\
\text { min }\end{array}$ & $\begin{array}{c}\text { Incisão } \\
\text { pele }\end{array}$ & $\begin{array}{c}\text { Abertura } \\
\text { cavidade }\end{array}$ & $\begin{array}{c}\text { Pedículo } \\
\text { Pedículo }\end{array}$ & $\begin{array}{c}\text { Sutura } \\
\text { muscular }\end{array}$ & $\begin{array}{c}\text { Sutura } \\
\text { pele }\end{array}$ \\
\hline 1 & 1,9 & 2,1 & 1,8 & 1,8 & 2,1 & 2,3 & 2,3 \\
2 & 1,5 & 1,9 & 2 & 3,1 & 2,3 & 1,9 & 1,9 \\
3 & 2,2 & 2,2 & 1,8 & 1,9 & 1,8 & 1,7 & 1,4 \\
4 & 2,1 & 2,4 & 2,3 & 2,4 & 2,2 & 1,9 & 1,9 \\
5 & 1,7 & 2,2 & 1,6 & 2,1 & 2,6 & 1,6 & 1,7 \\
6 & 1,7 & 2,1 & 2,1 & 2,1 & 2 & 2,1 & 1,8 \\
7 & 2,2 & 1,5 & 1,5 & 1,5 & 1,4 & 2,2 & 1,2 \\
8 & 3,6 & 2,4 & 2,4 & 2,5 & 2,3 & 2,3 & 2,3 \\
9 & 1,9 & 2 & 2 & 2 & 2,3 & 2,1 & 1,7 \\
10 & 1,6 & 1,9 & 1,6 & 1,9 & 1,9 & 1,5 & 1,5 \\
\hline Media & 2,0 & 2,1 & 1,9 & 2,1 & 2,1 & 2,0 & 1,8 \\
\hline DP & 0,60 & 0,27 & 0,30 & 0,44 & 0,33 & 0,29 & 0,36 \\
\hline DP - desvio-padrão & \multicolumn{7}{c}{}
\end{tabular}


Apêndice $T$ - Valores individuais, médias e desvios-padrão da fração inspirada de isofluorano (\%) dos animais do grupo propofolmidazolam (GPM), nos diferentes momentos de avaliação

\begin{tabular}{cccccccc}
\hline & \multicolumn{7}{c}{ Momentos de Avaliação } \\
\cline { 2 - 8 } Animais & $\begin{array}{c}10 \\
\text { min }\end{array}$ & $\begin{array}{c}\text { Incisão } \\
\text { pele }\end{array}$ & $\begin{array}{c}\text { Abertura } \\
\text { cavidade }\end{array}$ & $\begin{array}{c}\text { Pedículo } \\
\text { Pedículo }\end{array}$ & $\begin{array}{c}\text { Sutura } \\
\text { muscular }\end{array}$ & $\begin{array}{c}\text { Sutura } \\
\text { pele }\end{array}$ \\
\hline 11 & 2,5 & 1,9 & 1,8 & 1,4 & 1,6 & 1,7 & 1,7 \\
12 & 1,8 & 2 & 2 & 2,1 & 1,7 & 1,7 & 1,6 \\
13 & 1,8 & 2,2 & 2,2 & 2,2 & 1,8 & 1,8 & 1,8 \\
14 & 2,5 & 2,1 & 1,5 & 1,6 & 1,8 & 1,8 & 2 \\
15 & 1,4 & 1,6 & 1,7 & 1,7 & 1,7 & 1,5 & 1,5 \\
16 & 2,3 & 1,9 & 1,9 & 1,9 & 1,9 & 2,1 & 1,5 \\
17 & 2,1 & 2,4 & 1,2 & 1,9 & 2 & 1,9 & 1,9 \\
18 & 2,9 & 2,3 & 1,8 & 2,2 & 2,2 & 1,7 & 1,6 \\
19 & 3 & 1,7 & 2,5 & 2 & 2,1 & 2,1 & 1,9 \\
20 & 1,5 & 2,8 & 3 & 2 & 2,3 & 1,7 & 1,5 \\
\hline Media & 2,2 & 2,1 & 2,0 & 1,9 & 1,9 & 1,8 & 1,7 \\
\hline DP & 0,56 & 0,35 & 0,51 & 0,26 & 0,23 & 0,19 & 0,19 \\
\hline DP - desvio-padrão & \multicolumn{7}{c}{}
\end{tabular}


Apêndice U - Valores individuais, médias e desvios-padrão da fração inspirada de isofluorano (\%) dos animais do grupo midazolam-propofol (GMP), nos diferentes momentos de avaliação

\begin{tabular}{|c|c|c|c|c|c|c|c|}
\hline \multirow[b]{2}{*}{ Animais } & \multicolumn{7}{|c|}{ Momentos de Avaliação } \\
\hline & $\begin{array}{l}10 \\
\min \end{array}$ & $\begin{array}{l}\text { Incisão } \\
\text { pele }\end{array}$ & $\begin{array}{l}\text { Abertura } \\
\text { cavidade }\end{array}$ & $\begin{array}{c}\text { Pedículo } \\
1\end{array}$ & $\begin{array}{c}\text { Pedículo } \\
2\end{array}$ & $\begin{array}{l}\text { Sutura } \\
\text { muscular }\end{array}$ & $\begin{array}{c}\text { Sutura } \\
\text { pele }\end{array}$ \\
\hline 21 & 1,4 & 1,7 & 2,2 & 1,9 & 2,0 & 1,7 & 1,7 \\
\hline 22 & 1,7 & 2,1 & 2,1 & 2,2 & 1,8 & 2,2 & 2,2 \\
\hline 23 & 1,8 & 1,6 & 1,6 & 2,3 & 1,9 & 2,3 & 2,3 \\
\hline 24 & 2,1 & 2,4 & 2,4 & 1,8 & 1,8 & 1,9 & 1,6 \\
\hline 25 & 2,8 & 2,2 & 2,1 & 1,9 & 1,8 & 1,8 & 1,4 \\
\hline 26 & 2,2 & 2,0 & 2,0 & 2,0 & 1,7 & 1,5 & 1,2 \\
\hline 27 & 2,2 & 2,0 & 2,1 & 1,8 & 1,5 & 1,3 & 1,2 \\
\hline 28 & 2,0 & 2,5 & 2,7 & 2,8 & 2,1 & 2,3 & 2,4 \\
\hline 29 & 1,7 & 1,4 & 1,4 & 2,3 & 2,4 & 2,1 & 2,2 \\
\hline 30 & 2,2 & 1,9 & 1,9 & 1,9 & 1,9 & 1,9 & 1,8 \\
\hline Media & 2,0 & 2,0 & 2,1 & 2,1 & 1,9 & 1,9 & 1,8 \\
\hline $\mathrm{DP}$ & 0,39 & 0,35 & 0,37 & 0,31 & 0,24 & 0,34 & 0,45 \\
\hline
\end{tabular}


Apêndice $V$ - Valores individuais, médias e desvios-padrão dos exames de hemogasometria dos animais do grupo propofol (GP), avaliado após quinze minutos de anestesia inalatória

\begin{tabular}{ccccccc}
\hline \multirow{2}{*}{ Animais } & $\mathrm{pH}$ & $\begin{array}{c}\mathrm{PaCO}_{2} \\
(\mathrm{mmHg})\end{array}$ & $\begin{array}{c}\mathrm{PaO}_{2} \\
(\mathrm{mmHg})\end{array}$ & $\begin{array}{c}\mathrm{SaO}_{2} \\
(\%)\end{array}$ & $\begin{array}{c}\mathrm{HCO}_{3} \\
(\mathrm{mg} / \mathrm{dl})\end{array}$ & $\mathrm{BE}$ \\
\hline 1 & 7,23 & 43 & 209 & 99 & 18 & -10 \\
2 & 7,28 & 39 & 94 & 96 & 18 & -8 \\
3 & 7,30 & 42 & 423 & 100 & 20 & -6 \\
4 & 7,17 & 55 & 467 & 100 & 19 & -10 \\
5 & 7,31 & 42 & 480 & 100 & 20 & -5 \\
6 & - & - & - & - & - & - \\
7 & 7,29 & 38 & 237 & 100 & 18 & -8 \\
8 & 7,18 & 54 & 196 & 99 & 20 & -10 \\
9 & 7,18 & 54 & 472 & 100 & 19 & -9 \\
10 & 7,14 & 51 & 369 & 100 & 16 & -13 \\
\hline Média & 7,23 & 46,44 & 327,44 & 99,33 & 18,67 & $-8,78$ \\
\hline DP & 0,07 & 6,95 & 145,12 & 1,32 & 1,32 & 2,39 \\
\hline
\end{tabular}

DP - desvio-padrão 
Apêndice W - Valores individuais, médias e desvios-padrão dos exames de hemogasometria dos animais do grupo propofol-midazolam (GPM), avaliado após quinze minutos de indução da anestesia

\begin{tabular}{ccccccc}
\hline \multirow{2}{*}{ Animais } & $\mathrm{pH}$ & $\begin{array}{c}\mathrm{PaCO}_{2} \\
(\mathrm{mmHg})\end{array}$ & $\begin{array}{c}\mathrm{PaO}_{2} \\
(\mathrm{mmHg})\end{array}$ & $\begin{array}{c}\mathrm{SaO}_{2} \\
(\%)\end{array}$ & $\begin{array}{c}\mathrm{HCO}_{3} \\
(\mathrm{mg} / \mathrm{dl})\end{array}$ & $\mathrm{BE}$ \\
\hline 11 & 7,22 & 49 & 182 & 99 & 19 & -8 \\
12 & 7,13 & 49 & 441 & 100 & 16 & -14 \\
13 & 7,16 & 47 & 333 & 100 & 16 & -13 \\
14 & 7,14 & 39 & 95 & 95 & 13 & -14 \\
15 & 7,26 & 43 & 501 & 100 & 19 & -8 \\
16 & 7,11 & 55 & 508 & 100 & 16 & -13 \\
17 & 7,24 & 56 & 287 & 100 & 23 & -5 \\
18 & 7,25 & 48 & 216 & 100 & 21 & -7 \\
19 & 7,28 & 39 & 94 & 96 & 18 & -8 \\
20 & 7,15 & 56 & 370 & 100 & 19 & -10 \\
\hline Média & 7,19 & 48,10 & 302,70 & 99,00 & 18,00 & $-10,00$ \\
\hline DP & 0,06 & 6,38 & 154,59 & 1,89 & 2,87 & 3,27 \\
\hline
\end{tabular}

DP - desvio-padrão 
Apêndice $X$ - Valores individuais, médias e desvios-padrão dos exames de hemogasometria dos animais do grupo midazolam-propofol (GMP), avaliado após quinze minutos de indução da anestesia

\begin{tabular}{ccccccc}
\hline \multirow{2}{*}{ Animais } & $\mathrm{pH}$ & $\begin{array}{c}\mathrm{PaCO}_{2} \\
(\mathrm{mmHg})\end{array}$ & $\begin{array}{c}\mathrm{PaO}_{2} \\
(\mathrm{mmHg})\end{array}$ & $\begin{array}{c}\mathrm{SaO}_{2} \\
(\%)\end{array}$ & $\begin{array}{c}\mathrm{HCO}_{3} \\
(\mathrm{mg} / \mathrm{dl})\end{array}$ & $\mathrm{BE}$ \\
\hline 21 & 7,24 & 42 & 450 & 100 & 17 & -9 \\
22 & 7,23 & 62 & 415 & 100 & 25 & -4 \\
23 & 7,26 & 47 & 475 & 100 & 20 & -6 \\
24 & 7,26 & 41 & 489 & 100 & 18 & -8 \\
25 & 7,18 & 38 & 334 & 100 & 14 & -14 \\
26 & 7,17 & 45 & 432 & 100 & 16 & -12 \\
27 & 7,19 & 47 & 195 & 99 & 18 & -11 \\
28 & 7,34 & 29 & 257 & 100 & 15 & -9 \\
29 & 7,16 & 53 & 490 & 100 & 18 & -11 \\
30 & 7,19 & 45 & 461 & 100 & 17 & -11 \\
\hline Média & 7,22 & 44,90 & 399,80 & 99,90 & 17,80 & $-9,50$ \\
\hline DP & 0,06 & 8,76 & 103,25 & 0,32 & 3,05 & 2,95 \\
\hline
\end{tabular}

DP - desvio-padrão 
Apêndice $Y$ - Valores individuais, médias e desvios-padrão dos exames de hemogasometria dos animais do grupo propofol (GP), avaliado ao término do procedimento cirúrgico

\begin{tabular}{ccccccc}
\hline \multirow{2}{*}{ Animais } & $\mathrm{pH}$ & $\begin{array}{c}\mathrm{PaCO}_{2} \\
(\mathrm{mmHg})\end{array}$ & $\begin{array}{c}\mathrm{PaO}_{2} \\
(\mathrm{mmHg})\end{array}$ & $\begin{array}{c}\mathrm{SaO}_{2} \\
(\%)\end{array}$ & $\begin{array}{c}\mathrm{HCO}_{3} \\
(\mathrm{mg} / \mathrm{dl})\end{array}$ & $\mathrm{BE}$ \\
\hline 1 & 7,44 & 29 & 397 & 100 & 19 & -4 \\
2 & 7,32 & 36 & 477 & 100 & 18 & -6 \\
3 & 7,40 & 31 & 378 & 100 & 20 & -5 \\
4 & 7,30 & 38 & 411 & 100 & 18 & -7 \\
5 & 7,38 & 33 & 435 & 100 & 19 & -5 \\
6 & 7,23 & 45 & 473 & 100 & 19 & -9 \\
7 & 7,44 & 25 & 232 & 100 & 17 & -5 \\
8 & 7,33 & 38 & 279 & 100 & 20 & -6 \\
9 & 7,34 & 32 & 543 & 100 & 17 & -7 \\
10 & 7,33 & 31 & 115 & 98 & 16 & -9 \\
\hline Média & 7,35 & 33,80 & 374,00 & 99,80 & 18,30 & $-6,30$ \\
\hline DP & 0,07 & 5,63 & 129,48 & 0,63 & 1,34 & 1,70 \\
\hline DP - desvio-padrão & & & & & &
\end{tabular}

DP - desvio-padrão 
Apêndice $Z$ - Valores individuais, médias e desvios-padrão dos exames de hemogasometria dos animais do grupo propofol-midazolam (GPM), avaliado ao término do procedimento cirúrgico

\begin{tabular}{ccccccc}
\hline \multirow{2}{*}{ Animais } & $\mathrm{pH}$ & $\begin{array}{c}\mathrm{PaCO}_{2} \\
(\mathrm{mmHg})\end{array}$ & $\begin{array}{c}\mathrm{PaO}_{2} \\
(\mathrm{mmHg})\end{array}$ & $\begin{array}{c}\mathrm{SaO}_{2} \\
(\%)\end{array}$ & $\begin{array}{c}\mathrm{HCO}_{3} \\
(\mathrm{mg} / \mathrm{dl})\end{array}$ & $\mathrm{BE}$ \\
\hline 11 & 7,26 & 45 & 432 & 100 & 20 & -7 \\
12 & 7,25 & 42 & 459 & 100 & 19 & -9 \\
13 & 7,2 & 42 & 126 & 98 & 16 & -12 \\
14 & 7,23 & 43 & 178 & 99 & 17 & -10 \\
15 & 7,32 & 38 & 519 & 100 & 19 & -6 \\
16 & 7,22 & 43 & 452 & 100 & 18 & -10 \\
17 & 7,38 & 38 & 336 & 100 & 22 & -3 \\
18 & 7,27 & 49 & 261 & 100 & 23 & -5 \\
19 & 7,32 & 36 & 447 & 100 & 18 & -6 \\
20 & 7,37 & 28 & 172 & 99 & 16 & -7 \\
\hline Média & 7,28 & 40,40 & 338,20 & 99,60 & 18,80 & $-7,50$ \\
\hline DP & 0,06 & 5,76 & 143,43 & 0,70 & 2,35 & 2,72 \\
\hline DP - desvio-padrão & & & & &
\end{tabular}

DP - desvio-padrão 
Apêndice AA - Valores individuais, médias e desvios-padrão dos exames de hemogasometria dos animais do grupo midazolam-propofol (GMP), avaliado ao término do procedimento cirúrgico

\begin{tabular}{ccccccc}
\hline Animais & $\mathrm{pH}$ & $\begin{array}{c}\mathrm{PaCO}_{2} \\
(\mathrm{mmHg})\end{array}$ & $\begin{array}{c}\mathrm{PaO}_{2} \\
(\mathrm{mmHg})\end{array}$ & $\begin{array}{c}\mathrm{SaO}_{2} \\
(\%)\end{array}$ & $\begin{array}{c}\mathrm{HCO}_{3} \\
(\mathrm{mg} / \mathrm{dl})\end{array}$ & $\mathrm{BE}$ \\
\hline 21 & 7,33 & 31 & 394 & 100 & 16 & -9 \\
22 & 7,33 & 46 & 235 & 100 & 24 & -2 \\
23 & 7,28 & 41 & 158 & 99 & 20 & -8 \\
24 & 7,31 & 37 & 459 & 100 & 18 & -8 \\
25 & 7,22 & 40 & 114 & 98 & 16 & -12 \\
26 & 7,3 & 32 & 467 & 100 & 15 & -10 \\
27 & 7,24 & 42 & 505 & 100 & 17 & -10 \\
28 & 7,38 & 33 & 439 & 100 & 20 & -5 \\
29 & 7,34 & 35 & 316 & 100 & 19 & -7 \\
30 & 7,35 & 33 & 264 & 100 & 18 & -7 \\
\hline Média & 7,31 & 37,00 & 335,10 & 99,70 & 18,30 & $-7,80$ \\
\hline DP & 0,05 & 5,03 & 138,07 & 0,67 & 2,63 & 2,82 \\
\hline DP - desvio-padrão & & & & & &
\end{tabular}

DP - desvio-padrão 
Apêndice $A B$ - Valores individuais, médias e desvios-padrão da temperatura retal $\left({ }^{0} \mathrm{C}\right)$ dos animais do grupo propofol (GP), nos diferentes momentos de avaliação

\begin{tabular}{ccc}
\hline \multirow{2}{*}{ Animal } & \multicolumn{2}{c}{ Momentos } \\
\cline { 2 - 3 } & $\begin{array}{c}\text { Basal } \\
\left({ }^{0} \mathrm{C}\right)\end{array}$ & $\begin{array}{c}\text { Pós-MPA } \\
\left({ }^{0} \mathrm{C}\right)\end{array}$ \\
\hline 1 & 37,2 & 37,9 \\
2 & 38,2 & 37,6 \\
3 & 38,8 & 37,8 \\
4 & 39,4 & 39,1 \\
5 & 37,9 & 38,1 \\
6 & 38,7 & 37,6 \\
7 & 36,8 & 37,7 \\
8 & 39,0 & 36,1 \\
9 & 37,4 & 37,9 \\
10 & 37,8 & 37,7 \\
\hline Média & 38,1 & 37,8 \\
\hline DP & 0,85 & 0,73 \\
\hline DP - desvio-padrão &
\end{tabular}


Apêndice AC - Valores individuais, médias e desvios-padrão da temperatura retal $\left({ }^{0} \mathrm{C}\right)$ dos animais do grupo propofol midazolam (GPM), nos diferentes momentos de avaliação

\begin{tabular}{ccc}
\hline & \multicolumn{2}{c}{ Momentos } \\
\cline { 2 - 3 } Animal & $\begin{array}{c}\text { Basal } \\
\left({ }^{0} \mathrm{C}\right)\end{array}$ & $\begin{array}{c}\text { Pós-MPA } \\
\left({ }^{0} \mathrm{C}\right)\end{array}$ \\
\hline 11 & 38,1 & 37,5 \\
12 & 37,3 & 37,0 \\
13 & 38,4 & 38,2 \\
14 & 37,6 & 37,2 \\
15 & 38,3 & 37,7 \\
16 & 38,5 & 38,2 \\
17 & 38,7 & 38,7 \\
18 & 38,0 & 37,2 \\
19 & 38,4 & 37,7 \\
20 & 39,0 & 38,2 \\
\hline Média & 38,23 & 37,76 \\
\hline DP & 0,50 & 0,55 \\
\hline DP - desvio-padrão &
\end{tabular}


Apêndice AD - Valores individuais, médias e desvios-padrão da temperatura retal $\left({ }^{0} \mathrm{C}\right)$ dos animais do grupo midazolam propofol (GMP), nos diferentes momentos de avaliação

\begin{tabular}{ccc}
\hline \multirow{2}{*}{ Animal } & \multicolumn{2}{c}{ Momentos } \\
\cline { 2 - 3 } & $\begin{array}{c}\text { Basal } \\
\left({ }^{0} \mathrm{C}\right)\end{array}$ & $\begin{array}{c}\text { Pós-MPA } \\
\left({ }^{0} \mathrm{C}\right)\end{array}$ \\
\hline 21 & 39,1 & 38,8 \\
22 & 38,0 & 37,6 \\
23 & 38,3 & 39,0 \\
24 & 38,4 & 38,0 \\
25 & 38,3 & 37,4 \\
26 & 37,5 & 37,0 \\
27 & 37,8 & 37,6 \\
28 & 38,8 & 37,0 \\
29 & 38,7 & 38,3 \\
30 & 38,7 & 38,1 \\
\hline Média & 38,36 & 37,88 \\
\hline DP & 0,49 & 0,69 \\
\hline DP - desvio-padrão &
\end{tabular}


Apêndice AE - Escores do grau de relaxamento muscular atribuídos pelo anestesista aos animais do grupo propofol (GP), nos diferentes momentos de avaliação

\begin{tabular}{cccccccc}
\hline \multirow{2}{*}{ Animal } & \multicolumn{7}{c}{ GP escores anestesista } \\
\cline { 2 - 8 } & min & incisão & cavidade & ped 1 & ped 2 & musc & pele \\
\hline 1 & 1 & 1 & 1 & 1 & 1 & 1 & 1 \\
2 & 1 & 1 & 1 & 1 & 1 & 1 & 1 \\
3 & 1 & 1 & 1 & 1 & 1 & 1 & 1 \\
4 & 1 & 1 & 1 & 1 & 1 & 1 & 1 \\
5 & 1 & 1 & 1 & 1 & 1 & 1 & 1 \\
6 & 1 & 1 & 1 & 1 & 1 & 1 & 1 \\
7 & 1 & 1 & 1 & 1 & 1 & 1 & 1 \\
8 & 1 & 1 & 1 & 1 & 1 & 1 & 1 \\
9 & 1 & 1 & 1 & 1 & 1 & 1 & 1 \\
10 & 1 & 1 & 1 & 1 & 1 & 1 & 1 \\
\hline Média & 1,0 & 1,0 & 1 & 1 & 1 & 1 & 1 \\
\hline DP & 0,00 & 0,00 & 0,00 & 0,00 & 0,00 & 0,00 & 0,00 \\
\hline DP - desvio-padrão & & & & & &
\end{tabular}




$$
\begin{aligned}
\text { Apêndice AF - } & \text { Escores do grau de relaxamento muscular atribuídos pelo } \\
& \text { anestesista aos animais do grupo propofol midazolam (GPM), } \\
& \text { nos diferentes momentos de avaliação }
\end{aligned}
$$

\begin{tabular}{cccccccc}
\hline \multirow{2}{*}{ Animal } & \multicolumn{7}{c}{ GP escores anestesista } \\
\cline { 2 - 7 } & $\begin{array}{c}10 \\
\text { min }\end{array}$ & incisão & cavidade & ped 1 & ped 2 & musc & pele \\
\hline 11 & 1 & 1 & 1 & 1 & 3 & 1 & 1 \\
13 & 1 & 1 & 1 & 1 & 1 & 1 & 1 \\
14 & 1 & 1 & 1 & 1 & 1 & 1 & 1 \\
15 & 1 & 1 & 1 & 1 & 1 & 1 & 1 \\
16 & 1 & 1 & 1 & 1 & 1 & 1 & 1 \\
17 & 1 & 1 & 1 & 1 & 1 & 1 & 1 \\
18 & 1 & 1 & 1 & 1 & 1 & 1 & 1 \\
19 & 1 & 1 & 1 & 2 & 1 & 2 & 1 \\
20 & 1 & 1 & 1 & 1 & 1 & 1 & 1 \\
\hline Média & 1,0 & 1,0 & 1,0 & 1,1 & 1,2 & 1,1 & 1,0 \\
\hline DP & 0,00 & 0,00 & 0,00 & 0,32 & 0,63 & 0,32 & 0,00 \\
\hline DP - desvio-padrão & & & & & & 1 \\
\hline
\end{tabular}


Apêndice AG - Escores do grau de relaxamento muscular atribuídos pelo anestesista aos animais do grupo midazolam propofol (GMP), nos diferentes momentos de avaliação

\begin{tabular}{cccccccc}
\hline \multirow{2}{*}{ Animal } & \multicolumn{7}{c}{ GP escores anestesista } \\
\cline { 2 - 8 } & min & incisão & cavidade & ped 1 & ped 2 & musc & pele \\
\hline 21 & 1 & 1 & 1 & 1 & 1 & 1 & 1 \\
22 & 1 & 1 & 1 & 1 & 1 & 1 & 1 \\
23 & 1 & 1 & 1 & 1 & 1 & 1 & 1 \\
24 & 1 & 1 & 1 & 1 & 1 & 1 & 1 \\
25 & 1 & 1 & 1 & 1 & 1 & 1 & 1 \\
26 & 1 & 1 & 1 & 1 & 1 & 1 & 1 \\
27 & 1 & 1 & 1 & 1 & 1 & 1 & 1 \\
28 & 1 & 1 & 1 & 1 & 1 & 1 & 1 \\
29 & 1 & 1 & 1 & 3 & 1 & 1 & 1 \\
30 & 1 & 1 & 1 & 1 & 1 & 1 & 1 \\
\hline Média & 1,0 & 1,0 & 1,0 & 1,2 & 1,0 & 1,0 & 1,0 \\
\hline DP & 0,00 & 0,00 & 0,00 & 0,63 & 0,00 & 0,00 & 0,00 \\
\hline DP - desvio-padrão & & & & & &
\end{tabular}




\begin{abstract}
Apêndice $\mathrm{AH}$ - Escores do grau de relaxamento muscular atribuídos pelo cirurgião aos animais do grupo propofol (GP), nos diferentes momentos de avaliação
\end{abstract}

\begin{tabular}{cccccccc}
\hline \multirow{2}{*}{ Animal } & \multicolumn{7}{c}{ GP escores cirurgião } \\
\cline { 2 - 8 } & min & incisão & cavidade & ped 1 & ped 2 & musc & pele \\
\hline 1 & 1 & 1 & 1 & 1 & 1 & 1 & 1 \\
2 & 1 & 1 & 1 & 1 & 1 & 1 & 1 \\
3 & 1 & 1 & 2 & 1 & 1 & 1 & 1 \\
4 & 1 & 1 & 1 & 1 & 1 & 1 & 1 \\
5 & 1 & 1 & 1 & 1 & 1 & 2 & 1 \\
6 & 1 & 1 & 1 & 1 & 1 & 3 & 1 \\
7 & 1 & 1 & 1 & 1 & 2 & 1 & 1 \\
8 & 1 & 2 & 1 & 1 & 1 & 1 & 1 \\
9 & 1 & 1 & 1 & 1 & 1 & 1 & 1 \\
10 & 1 & 1 & 1 & 1 & 1 & 2 & 1 \\
\hline Média & 1,0 & 1,1 & 1,1 & 1 & 1,1 & 1,4 & 1 \\
\hline DP & 0 & 0,32 & 0,32 & 0 & 0,32 & 0,70 & 0,00 \\
\hline DP - desvio-padrão & & & & & &
\end{tabular}


Apêndice $\mathrm{Al}$ - Escores do grau de relaxamento muscular atribuídos pelo cirurgião aos animais do grupo propofol midazolam (GPM), nos diferentes momentos de avaliação

\begin{tabular}{cccccccc}
\hline \multirow{2}{*}{ Animal } & \multicolumn{7}{c}{ GP escores cirurgião } \\
\cline { 2 - 8 } & min & incisão & cavidade & ped 1 & ped 2 & musc & pele \\
\hline 11 & 1 & 1 & 1 & 1 & 4 & 1 & 1 \\
12 & 1 & 1 & 1 & 1 & 1 & 1 & 1 \\
13 & 1 & 1 & 1 & 1 & 1 & 1 & 1 \\
14 & 1 & 1 & 1 & 1 & 1 & 1 & 1 \\
15 & 1 & 1 & 1 & 1 & 1 & 1 & 1 \\
16 & 1 & 1 & 1 & 1 & 1 & 2 & 1 \\
17 & 1 & 1 & 1 & 1 & 1 & 2 & 1 \\
18 & 1 & 1 & 1 & 1 & 1 & 1 & 1 \\
19 & 1 & 1 & 1 & 4 & 1 & 4 & 1 \\
20 & 1 & 1 & 1 & 1 & 1 & 2 & 1 \\
\hline Média & 1 & 1 & 1 & 1,3 & 1,3 & 1,6 & 1 \\
\hline DP & 0,00 & 0,00 & 0,00 & 0,95 & 0,95 & 0,97 & 0,00 \\
\hline DP - desvio-padrão & & & & & &
\end{tabular}




\begin{abstract}
Apêndice AJ - Escores do grau de relaxamento muscular atribuídos pelo cirurgião aos animais do grupo midazolam propofol (GMP), nos diferentes momentos de avaliação
\end{abstract}

\begin{tabular}{cccccccc}
\hline \multirow{2}{*}{ Animal } & \multicolumn{7}{c}{ GP escores cirurgião } \\
\cline { 2 - 8 } & min & incisão & cavidade & ped 1 & ped 2 & musc & pele \\
\hline 21 & 1 & 1 & 2 & 1 & 2 & 1 & 1 \\
22 & 1 & 1 & 1 & 1 & 1 & 1 & 1 \\
23 & 1 & 1 & 1 & 1 & 1 & 1 & 1 \\
24 & 1 & 1 & 1 & 1 & 1 & 1 & 1 \\
25 & 1 & 1 & 1 & 1 & 1 & 1 & 1 \\
26 & 1 & 1 & 1 & 1 & 1 & 1 & 1 \\
27 & 1 & 1 & 1 & 1 & 1 & 1 & 1 \\
28 & 1 & 1 & 4 & 1 & 1 & 1 & 1 \\
29 & 1 & 1 & 1 & 4 & 1 & 1 & 1 \\
30 & 1 & 1 & 1 & 1 & 1 & 1 & 1 \\
\hline Média & 1 & 1 & 1,4 & 1,3 & 1,1 & 1 & 1 \\
\hline DP & 0,00 & 0,00 & 0,97 & 0,95 & 0,32 & 0,00 & 0,00 \\
\hline DP - desvio-padrão & & & & & &
\end{tabular}


Apêndice AK - Peso corpóreo e dose de propofol utilizada para intubação orotraqueal dos animais do grupo propofol (GP)

\begin{tabular}{ccc}
\hline Animal & Peso $(\mathrm{kg})$ & Dose de Propofol $(\mathrm{mg} / \mathrm{kg})$ \\
\hline 1 & 2,5 & 12,4 \\
2 & 2,3 & 12,6 \\
3 & 3,7 & 10,0 \\
4 & 2,7 & 12,6 \\
5 & 2,0 & 12,5 \\
6 & 2,8 & 10,0 \\
7 & 2,8 & 13,2 \\
8 & 3,2 & 10,0 \\
9 & 3,3 & 14,5 \\
10 & 3,1 & 10,0 \\
\hline Média & 2,8 & 11,8 \\
\hline DP & 0,50 & 1,64
\end{tabular}


Apêndice $A L$ - Peso corpóreo e dose de propofol utilizada para intubação orotraqueal dos animais do grupo propofol-midazolam (GPM)

\begin{tabular}{ccc}
\hline Animal & Peso $(\mathrm{kg})$ & Dose de Propofol $(\mathrm{mg} / \mathrm{kg})$ \\
\hline 11 & 2,9 & 10 \\
12 & 2,1 & 4,8 \\
13 & 2,5 & 7,6 \\
14 & 2,6 & 6,9 \\
15 & 2,3 & 7,4 \\
16 & 3,0 & 11,6 \\
17 & 3,2 & 6,6 \\
18 & 3,9 & 7,7 \\
19 & 4,0 & 7,5 \\
20 & 2,8 & 7,5 \\
\hline Média & 2,9 & 7,8 \\
\hline DP & 0,63 & 1,85 \\
\hline
\end{tabular}

DP - desvio-padrão 
Apêndice AM - Peso corpóreo e dose de propofol utilizada para intubação orotraqueal dos animais do grupo midazolam-propofol (GMP)

\begin{tabular}{ccc}
\hline Animal & Peso $(\mathrm{kg})$ & Dose de Propofol $(\mathrm{mg} / \mathrm{kg})$ \\
\hline 21 & 3,1 & 7,7 \\
22 & 2,6 & 8 \\
23 & 3,0 & 11 \\
24 & 2,0 & 12,5 \\
25 & 2,2 & 8,6 \\
26 & 2,8 & 10 \\
27 & 2,0 & 10 \\
28 & 3,0 & 8 \\
29 & 2,4 & 10 \\
30 & 3,5 & 5,1 \\
\hline Média & 2,7 & 9,09 \\
\hline DP & 0,51 & 2,06
\end{tabular}

